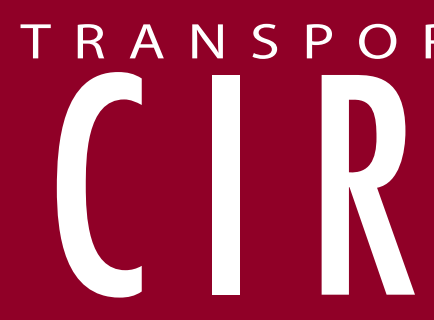

Number E-C161

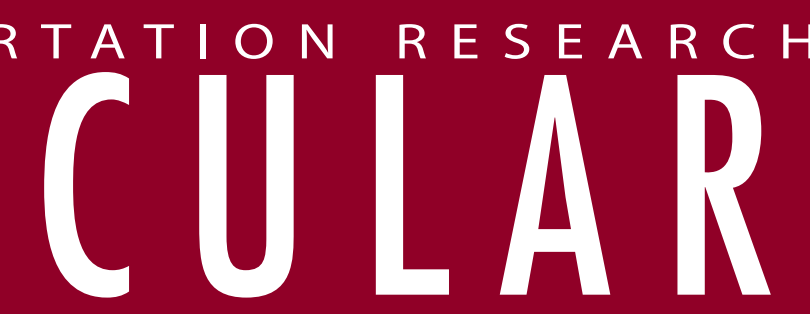

January 2012

\title{
Applications of Advanced Models to Understand Behavior and Performance of Asphalt Mixtures
}

TRANSPORTATION RESEARCH BOARD OF THE NATIONAL ACADEMIES 


\section{TRANSPORTATION RESEARCH BOARD}

2011-2012 TECHNICAL ACTIVITIES COUNCIL

Chair: Katherine F. Turnbull, Executive Associate Director, Texas Transportation Institute, Texas A\&M University, College Station

Technical Activities Director: Mark R. Norman, Transportation Research Board

Jeannie G. Beckett, Principal, Beckett Group, Gig Harbor, Washington, Marine Group Chair

Paul Carlson, Research Engineer, Texas Transportation Institute, Texas A\&M University, College Station, Operations and Maintenance Group Chair

Thomas J. Kazmierowski, Manager, Materials Engineering and Research Office, Ontario Ministry of Transportation, Toronto, Canada, Design and Construction Group Chair

Ronald R. Knipling, Principal, safetyforthelonghaul.com, Arlington, Virginia, System Users Group Chair

Mark S. Kross, Consultant, Jefferson City, Missouri, Planning and Environment Group Chair

Edward V. A. Kussy, Partner, Nossaman, Guthner, Knox, and Elliott, LLP, Washington, D.C., Legal Resources Group Chair

Peter B. Mandle, Director, LeighFisher, Inc., Burlingame, California, Aviation Group Chair

Anthony D. Perl, Professor of Political Science and Urban Studies and Director, Urban Studies Program, Simon Fraser University, Vancouver, British Columbia, Canada, Rail Group Chair

Steven Silkunas, Director of Business Development, Southeastern Pennsylvania Transportation Authority, Philadelphia, Pennsylvania, Public Transportation Group Chair

Peter F. Swan, Assistant Professor of Logistics and Operations Management, Pennsylvania State, Harrisburg, Middletown, Pennsylvania, Freight Systems Group Chair

Johanna P. Zmud, Director, Transportation, Space, and Technology Program, RAND Corporation, Arlington, Virginia, Policy and Organization Group Chair 


\title{
Applications of Advanced Models to Understand Behavior and Performance of Asphalt Mixtures
}

\author{
A Synopsis Prepared by \\ Amit Bashin \\ Eyad Masad \\ M. Emin Kutay \\ William Buttlar \\ Yong-Rak Kim \\ Mihai Marasteanu \\ Y. Richard Kim \\ Charles W. Schwartz \\ Regis L. Carvalho \\ for the
}

Characteristics of Asphalt Paving Mixtures to Meet Structural Requirements Committee

Transportation Research Board

January 2012

Transportation Research Board

500 Fifth Street, NW

Washington, D. C.

www.TRB.org 


\title{
TRANSPORTATION RESEARCH CIRCULAR E-C161
}

ISSN 0097-8515

The Transportation Research Board is one of six major divisions of the National Research Council, which serves as an independent advisor to the federal government and others on scientific and technical questions of national importance. The National Research Council is jointly administered by the National Academy of Sciences, the National Academy of Engineering, and the Institute of Medicine. The mission of the Transportation Research Board is to provide leadership in transportation innovation and progress through research and information exchange, conducted within a setting that is objective, interdisciplinary, and multimodal.

The Transportation Research Board is distributing this Circular to make the information contained herein available for use by individual practitioners in state and local transportation agencies, researchers in academic institutions, and other members of the transportation research community. The information in this circular was taken directly from the submission of the authors. This document is not a report of the National Research Council or the National Academy of Sciences.

\section{Design and Construction Group}

Thomas J. Kazmierowski, Chair

\section{Asphalt Materials Section}

Robert B. McGennis, Chair

\section{Characteristics of Asphalt Paving Mixtures to Meet Structural Requirements Committee} Jo Sias Daniel, Chair

Ala R. Abbas
Egbert Beuving
Amit Bhasin
Ramon F. Bonaquist
Ghassan R. Chehab
Shongfao Dai
Ervin L. Dukatz, Jr.
Frank Fee
Elie Y. Hajj
Kamil Elias Kaloush
Y. Richard Kim

\author{
Yong-Rak Kim \\ Muhammed Emin Kutay \\ Hyun Jong Lee \\ Eyal Levenberg \\ Eyad A. Masad \\ Leslie Ann McCarthy \\ Walaa S. Mogawer \\ Louay N. Mohammad \\ Nathan E. Morian \\ Terhi K. Pellinen \\ Michael B. Robinson
}

\author{
Reynaldo Roque* \\ Shadi Saadeh \\ A.Tom Scarpas \\ Charles W. Schwartz \\ Haroon I. Shami \\ Richard K. Steger \\ Rajarajan Subramanian \\ William R. Vavrik \\ Dean C. Weitzel \\ R. Christopher Williams \\ Habtamu Zelelew
}

*Emeritus Member

TRB Staff

Frederick D. Hejl, Engineer of Materials and Construction

Joanice L. Cole, Senior Program Associate; Michael DeCarmine, Senior Program Associate

\author{
Transportation Research Board \\ 500 Fifth Street, NW \\ Washington, D. C. \\ www.TRB.org
}




\section{Contents}

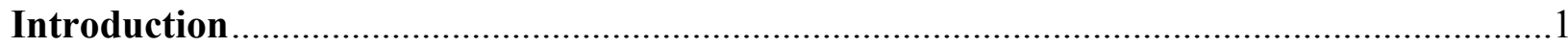

Eyad Masad

Characterization of the Internal Structure of Asphalt Mixtures .......................................2

Eyad Masad and M. Emin Kutay

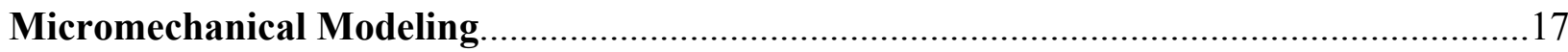

William Buttlar

Use of Fracture Tests and Models .

Yong-Rak Kim and Mihai Marasteanu

Viscoelastic Continuum Damage Model

Y. Richard Kim

Viscoplastic Modeling of Bituminous Mixtures

Charles W. Schwartz and Regis L. Carvalho 


\section{Publisher's Note}

This Circular, prepared by the authors of each section in this document, is a synopsis of current information on the applications of advanced models to understand behavior and performance of asphalt mixtures. The opinions and recommendations are those of the authors and not the standing committee sponsoring this document or the Transportation Research Board. 


\title{
Introduction
}

\author{
EYAD MASAD \\ Texas A\&M University
}

$\mathrm{T}$

he past decade has witnessed significant development in advanced, mechanistic models for asphalt mixtures. These models have the advantages of accounting for the fundamental properties of the mixture and its constituents, incorporating various loading conditions, and including environmental effects (e.g., temperature, moisture, and aging). Common to all these models is that they lend themselves to implementation in computational methods that are used to simulate and predict asphalt pavement responses (i.e., stress and strain distribution) and performance such as permanent deformation, fatigue cracking, and fracture under laboratory and field loading conditions. In addition to their prediction power, they offer useful insight on the influence of various materials, properties, and design on response and performance. This insight can be used by pavement engineers to understand factors that affect performance and develop the optimum design for prevailing loads and environmental. The power of mechanistic models over empirical ones is that the mechanistic models can be expanded to cover a wide range of conditions, while the empirical models are limited to those conditions for which they were developed.

In addition to the mechanistic models, many methods have been developed for capturing and analyzing the material microstructure (internal structure). These methods have been extremely useful to better understand the interactions of materials and their influence on overall asphalt mixture properties and phenomena such as permeability and fracture.

This E-Circular documents recent advances in the development of various classes of mechanistic (micromechanical and macro mechanical) models that have been successfully used to model the time-dependent response, permanent deformation, fracture, and fatigue of asphalt pavements. In addition, the E-Circular includes a section that documents recent advances in the characterization of the internal structure (microstructure) of asphalt mixtures, and the application of these techniques to better understand the behavior of asphalt mixtures. 


\title{
Characterization of the Internal Structure of Asphalt Mixtures
}

\author{
EyAd MASAd \\ Texas A\&M University \\ M. EMin KUTAY \\ Michigan State University
}

\begin{abstract}
$\mathrm{T}^{1}$ he internal structure of asphalt mixes refers to the directional and spatial arrangement of the mix constituents (aggregates, asphalt, and air voids) as well as the chemical and physical interactions among these constituents. The arrangement of the aggregate particles in terms of spatial distribution, directional distribution, contact points, and packing is referred to as the aggregate skeleton. This section summarizes the methods used in characterizing and quantifying the internal structure distribution in hot-mix asphalt (HMA). The implications of the internal structure analysis on the compaction, performance, and modeling of HMA are also discussed.

The internal structure distribution is the result of proportions and properties of materials as well as compaction methods used in preparing the mix. This has been long recognized in mix design methodologies through requiring certain aggregate gradations, aggregate shape, and mechanical properties, compaction methods and limits, and mix volumetrics. The design methodologies have typically relied on some measures of stability, stiffness, or strength to indicate the suitability of the internal structure distribution to sustain traffic load applications.

Recently, there has been emphasis on developing methods to quantitatively assess some aspects of the internal structure distribution $(1-5)$. These methods utilize imaging techniques to quantify the distribution of the aggregate skeleton and air voids by analyzing two-dimensional (2-D) and three-dimensional (3-D) images of the internal structure.
\end{abstract}

\section{IMAGING METHODS FOR MEASURING THE INTERNAL STRUCTURE DISTRIBUTION}

Digital image analysis has been used to quantify the internal structure distribution of HMA. It involves three major steps: image acquisition, image processing, and image analysis as illustrated in Figure 1. Two-dimensional images of the internal structure can be captured using a variety of equipment including digital cameras, microscopes, high- and medium-resolution flatbed scanners (6). X-ray computed tomography (CT) has also been used to capture the internal structure of HMA. It is a unique nondestructive tool for obtaining 3-D images of the internal structure based on differences in density between the mix constituents. The X-ray CT system consists of an Xray source and a detector with a test specimen placed in between. The source transmits X-ray radiation with certain intensity $\left(I_{\mathrm{o}}\right)$. Some portion of the X-rays penetrates through a specimen while other X-rays get absorbed or scattered. The intensities of these transmitted X-rays $(I)$ are recorded with an array of detectors placed at the other side of the specimen. The line between the $\mathrm{X}$-ray source focal spot and a single detector is called a ray, and the integral of this ray is called a ray integral. At each point within a specimen, the amount of radiation energy scattered and absorbed is a function of a constant called the linear attenuation coefficient, which is a property 


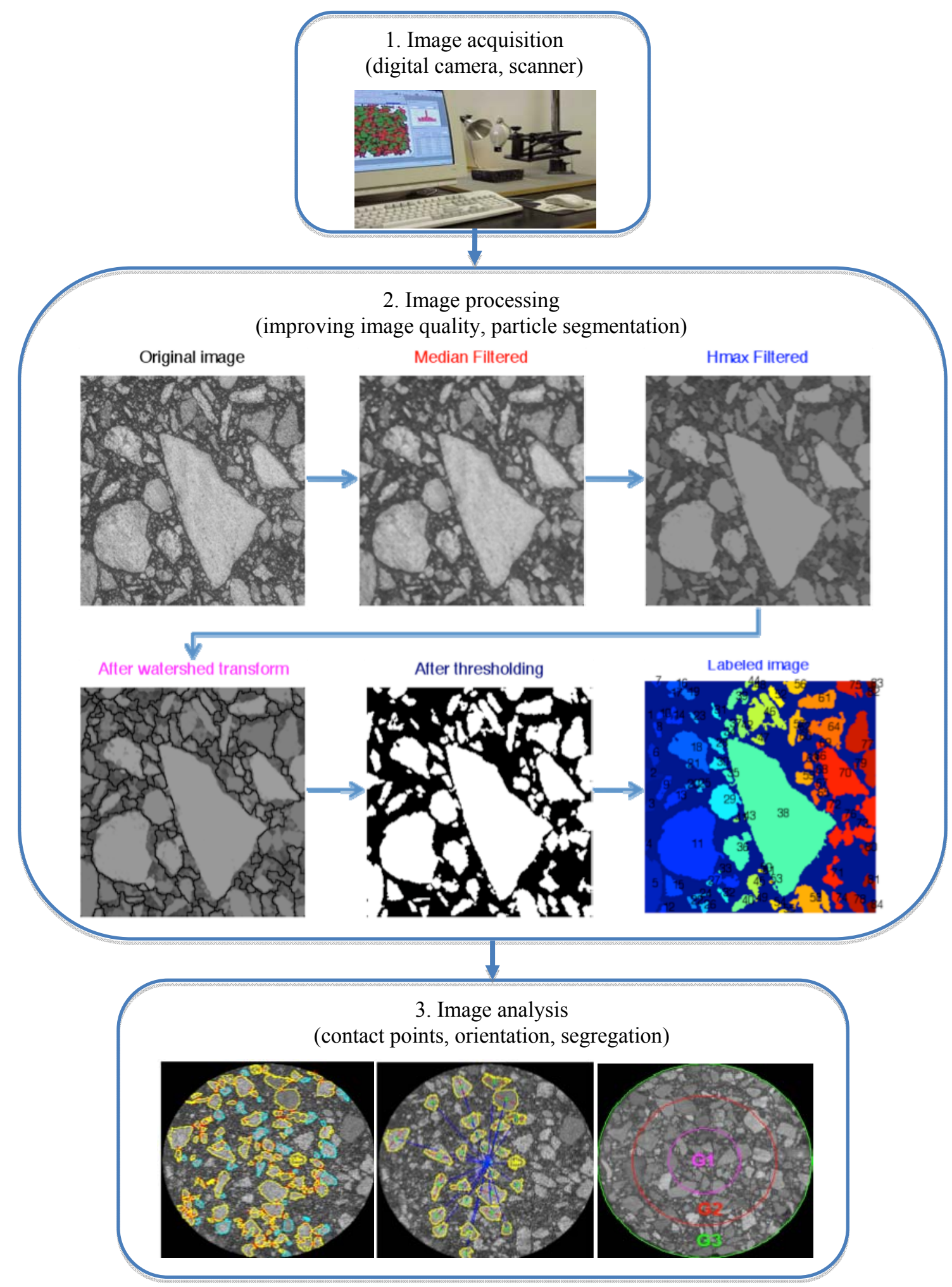

FIGURE 1 Typical steps involved in image acquisition processing and analysis. 
of the material occupying that point. The attenuation coefficient varies as a function of material density, which makes it possible to differentiate between the mix constituents. The X-rays can be applied in different geometries as described in ASTM E 1441 procedure.

\section{APPLICATIONS OF IMAGE ANALYSIS TECHNIQUES}

\section{Compaction and Mechanical Properties}

Masad et al. (2) measured aggregate orientations in specimens compacted to different numbers of gyrations and in field cores. They found that the anisotropy (preferred orientation of particles towards the horizontal direction) in gyratory specimens became more pronounced with an increase in the compaction effort (more gyrations) up to a certain point. However, further increase in the compaction effort caused a reduction in the anisotropy level and a tendency for particles to exhibit random orientation. A similar relationship between aggregate orientation and compaction effort was reported by Tashman et al. (4), where the compaction effort was controlled by using different angles of gyration, pressures, and specimen heights. As the angle was increased from $1.25^{\circ}$ to $1.5^{\circ}$, the compaction shear stresses increased, leading to an increase in the aggregate distribution anisotropy. However, the level of anisotropy decreased as the compaction angle was increased to $2^{\circ}$. Tashman et al. (4) and Saadeh et al. (7) have shown that both the compaction angle and specimen height were significant factors affecting orientation; whereas, the pressure was not.

Aggregate anisotropic distribution was found to be higher in field cores than in Superpave gyratory compacted (SGC) specimens $(4,7)$. However, improving the simulation of SGC specimens' internal structure (by changing compaction angle and specimen height) to field cores reduced the difference in mechanical properties between the laboratory and field compacted mixes. As such, image analysis techniques can be used as a tool to improve the resemblance of laboratory compaction procedures to field compaction.

Dessouky et al. (8) related the aggregate structure stability measured during compaction in the gyratory compactor to the aggregate orientation. The stability was measured using the contact energy index (CEI), which reflects the amount of shear energy needed to compact the mix. Dessouky et al. (8) measured the change in aggregate orientation between the point of maximum shear stress and the end of the compaction for mixes with limestone and uncrushed gravel aggregates. The results showed that the mixes with limestone had less change in orientation compared with the gravel mixes. In addition, they reported that an increase in the percentage of natural sand caused more change in orientation and number of contacts between the two-compaction levels. Very good correlation was found between the number of contacts and the CEI measured for limestone and gravel mixes. It was concluded that the gravel mixes and those with natural sand experienced more aggregate sliding (re-orientation) and loss of contacts during compaction compared with their counterpart limestone mixes.

These findings suggest that the aggregate structure can sustain the applied compaction loads up to a certain level. During this period, the aggregate structure develops a higher level of anisotropy. However, further increase in the compaction effort associated with high shear stresses among particles leads to sliding, rotation, and consequently, random distribution of the aggregate structure.

Comparison between the aggregate orientation in the SGC and the linear kneading compactor $(\mathrm{LKC})$ has shown that aggregate structure anisotropy was consistently larger for the SGC 
specimens compared with the LKC specimens (3). This finding indicates that different compaction methods cannot be used interchangeably in preparing mixes for mechanical testing or volumetric analysis.

Measurements of aggregate contacts have shown field cores to have more stone-to-stone contacts than gyratory specimens (4), and the contacts were higher in LKC specimens than in SGC specimens (3). Watson et al. (9) used image analysis techniques to verify the development of aggregate contacts and packing in open-graded friction course (OGFC) mixtures. It is necessary to design OGFC mixtures with stone-on-stone contacts in order to sustain the applied traffic loads and resist rutting.

Hunter et al. (10) studied the circumferential orientation of aggregates in HMA mixtures compacted using SGC, vibratory, and slab compactor. They observed more circumferential orientation in vibratory- and SGC-compacted specimens as compared to slab-compacted specimens and degree of orientation increased with increasing particle size. Hunter et al. (10) showed that particles with high aspect ratio (length/width $>2$ ) showed a higher degree of orientation.

Coenen et al. (6) performed 2-D image analyses of various HMA mixtures with different nominal maximum size of aggregate and gradations compacted using SGC, Hveem, Marshall, and German sector compactors. They also studied SGC compaction at different compaction pressures $(600 \mathrm{kPa}$ and $300 \mathrm{kPa})$ and temperatures $\left(60^{\circ} \mathrm{C}\right.$ and $\left.120^{\circ} \mathrm{C}\right)$. Images of the saw-cut faces of the HMA specimens were obtained using flatbed scanner. From the images, angles of aggregates from the horizontal axis $(\alpha)$ and the radial axis $(\theta)$ (for the cylindrical specimens) were computed (Figure $2 a$ ). Figure $2 b$ shows a typical histogram produced by dividing individual aggregate orientation ( $\alpha$ or $\theta$ ) into $10^{\circ}$ intervals. Figure $2 c$ shows the same frequency of occurrence per angle represented as line graph rather than a bar chart with the addition of a harmonic fit. A harmonic function was used as a fit for the data so that the amplitude (A) of the harmonic fit represents the predominant aggregate orientation within the image. This study revealed that the SGC had the greatest value of $A$ (7.3) for $\theta$, which implies that it has the highest tendency to orient the aggregate to a particular angle, $83^{\circ}$ from the radial arm in this case, while the Marshall had the lowest value of A or closest to uniform of the four methods, with an amplitude of 2.78 .

Coenen et al. (6) also showed that specific temperature and pressure of gyratory compaction did not significantly exaggerate or minimize aggregate orientation, though a clear difference in the number of contact points between aggregates was identified. In this study, the contact points were calculated using the surface pixels of aggregates. When the minimum distance between the surfaces of neighboring aggregates is less than a surface distance threshold (SDT) value, the aggregates were assumed to be in contact. Figure 3 shows examples of contact points calculated between aggregates, where the cross $(+)$ illustrates the location of contact. It was shown that contact points were heavily influenced by the specific gradation of the mixture. The number of contact points within the gyratory specimens directly correlates to the percent air voids in the mix, or density, which is commonly used to characterize flexible paving materials.

Kutay et al. (5) studied 3-D contact points and orientation of aggregates using X-ray CT images of HMA specimens. They showed that selected SDT value significantly affects the number of contact points. However, when different specimens with different compaction levels are compared, for a given SDT value, contact points can clearly differentiate between their densification levels. Kutay et al. (5) also showed that the maximum principal axis of the majority of aggregates lie on $x-y$ plane (i.e., perpendicular to the direction of compaction). The orientation distribution 


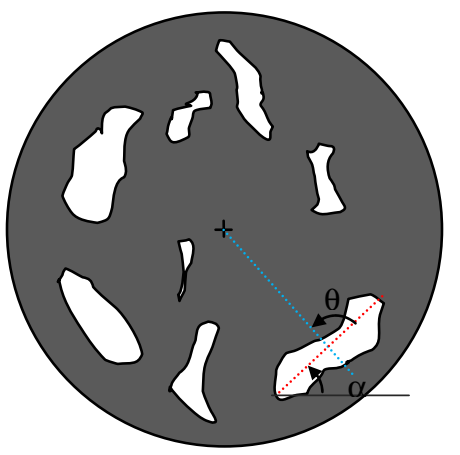

(a)

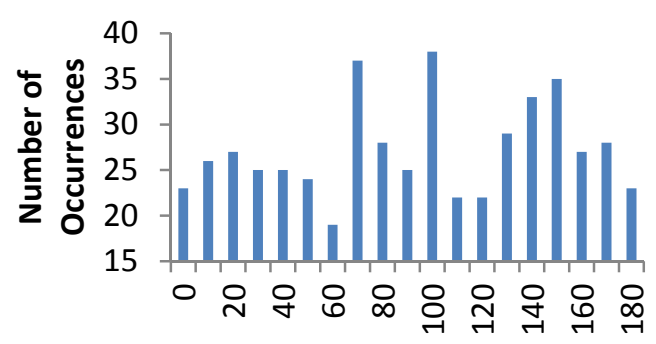

Orientation

(b)

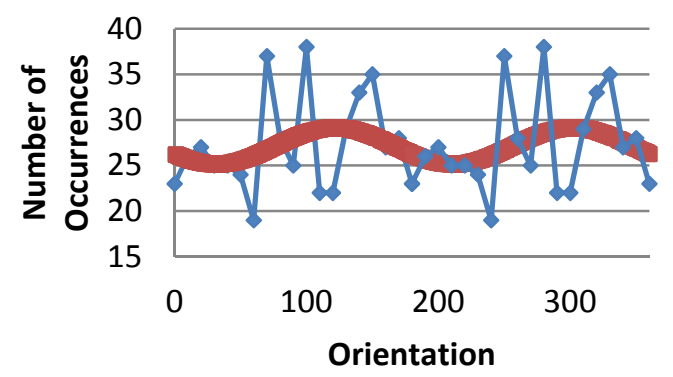

(c)

FIGURE 2 (a) Illustration of orientation angles; (b) histogram of angles $\theta$ of aggregates in an HMA specimen; and (c) conversion from histogram representation to harmonic fit [after Coenen at al. (6)].

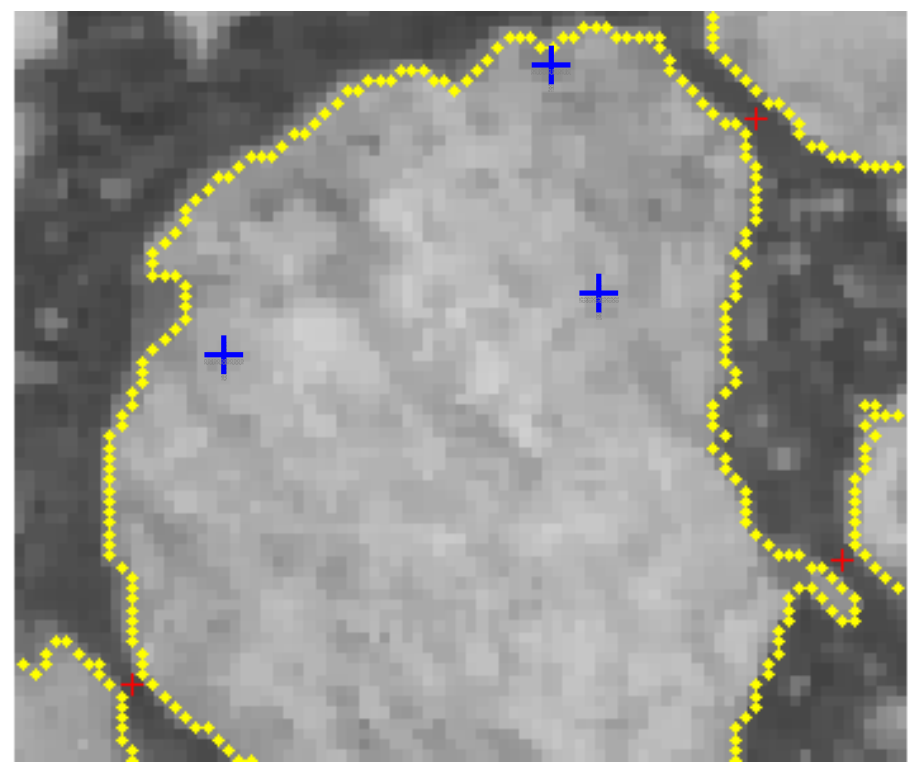

FIGURE 3 Illustration of contact points. 
of aggregates did not show significant variation as the gyration level increased from 30 to 160 . This suggests that the preferential orientation occurs early with little change as compaction increases.

One of challenges associated with processing of X-ray CT images of HMA specimens is the fact that the contrast between different phases is not always adequate. In such cases, traditional image analysis algorithms do not provide sufficient information. In order to overcome this problem, Kutay et al. (5) developed and trained an artificial neural network (ANN) model to identify the location and size of aggregates in HMA specimens. The ANN model, which was similar to face detection algorithms commonly used by computer scientists, was shown to perform very well even when poor contrast/quality X-ray CT images were analyzed.

Air void distribution was also studied using X-ray CT images. An example of air void distribution in HMA is shown in Figure 4. X-ray CT images helped to discover the nature of air void distribution in laboratory specimens and field cores. Figure 5 shows the vertical air void

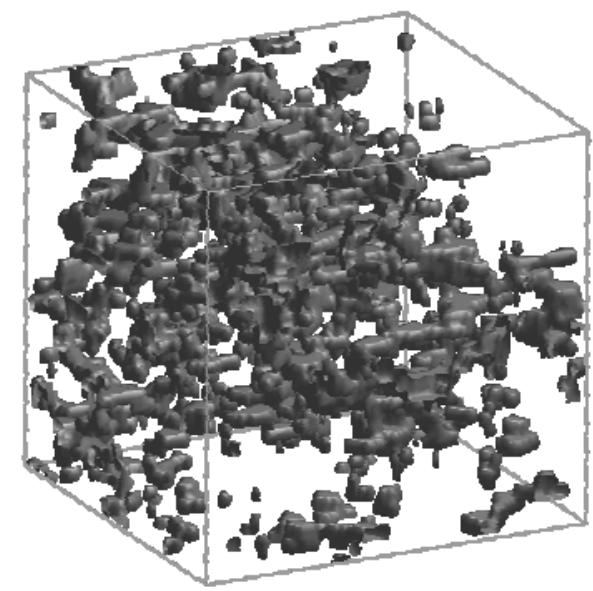

FIGURE 4 An example of 3-D distribution of air voids in HMA.

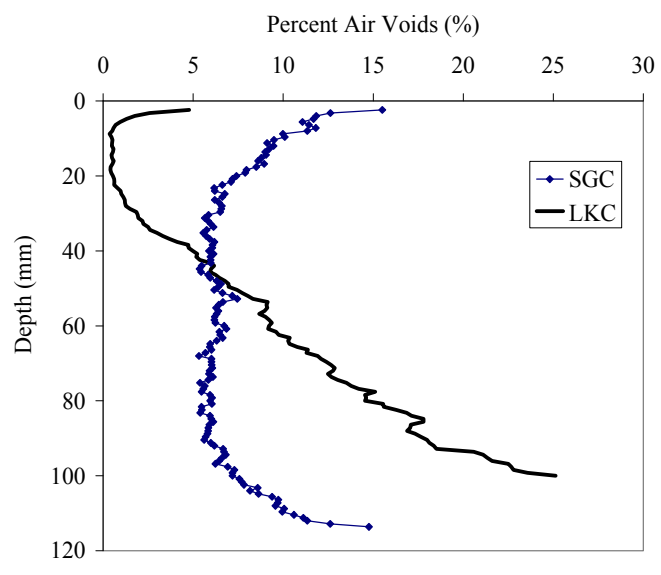

FIGURE 5 Void distribution in SGC and LKC specimens (3). 
distribution in SGC and LKC specimens. Field cores were found to have higher percent air voids toward the pavement surface. Efforts have been initiated recently in order to improve compaction methods such that more uniform distribution of air voids are achieved in laboratory specimens and field cores.

The results discussed above have direct implications on the design, compaction, and performance of HMA. It can be used to quantify the differences between the laboratory and field compacted mixes and evaluate the influence of different compaction techniques on reducing these differences. The anisotropy of the aggregate distribution in HMA influences the validity of the response and performance models. For a stress path applied in the axial direction, for example, the stiffness of an anisotropic mix in the axial direction is higher than the horizontal direction due to the larger contact areas developed normal to the applied load. Contact analysis can be used to ensure the development of stone-to-stone contact in rut-resistance mixes. The non-uniform air void distribution affects the stress and strain distribution in a test specimen, the size of the representative volume element needed for experimental characterization, and field density measurements to mention a few examples.

\section{Fluid Flow and Permeability}

Al-Omari et al. (11) used image analysis techniques to measure percent of connected air voids $(n)$, specific surface area of air voids, and air void tortousity and related these properties through the Kozeny-Carman (K-C) equation to measured permeability. Comparison between the permeability calculated using the K-C equation and laboratory measurements is shown in Figure 6. Masad et al. (12) and Kutay et al. (13) developed numerical models for the simulation of fluid flow in 3-D images of HMA. Figures 7 and 8 show simulations of fluid flow in HMA specimens. These models also provide the HMA permeability in different directions. The permeability values computed using the models were found to correlate well with experimental measurements (Figure 9). The major and minor principal directions of the permeability tensor were found to correspond to the horizontal and vertical directions, respectively. The results indicated that the non-uniform spatial distribution of air voids created more open flow paths in the horizontal directional than the vertical direction and hence was the much higher permeability in the horizontal direction.

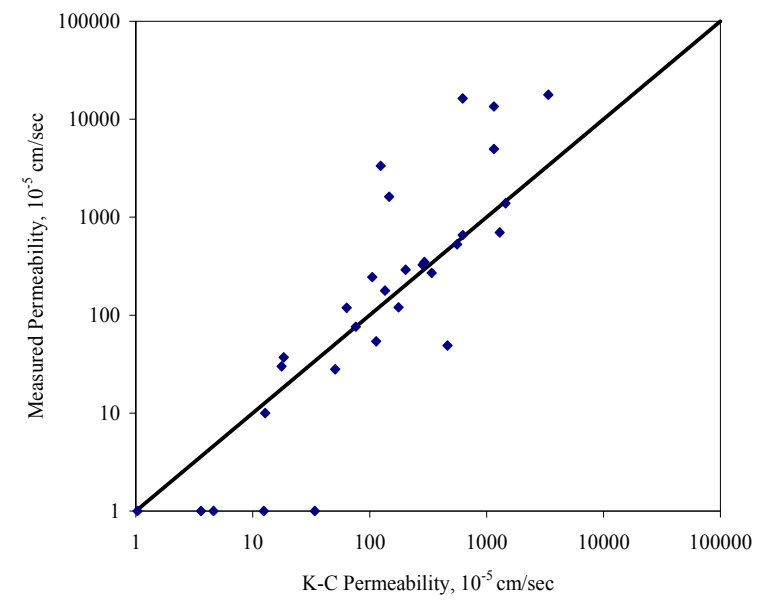

FIGURE 6 Comparison between the predicted and measured permeability values for field cores [after Al-Omary et al. (11)]. 


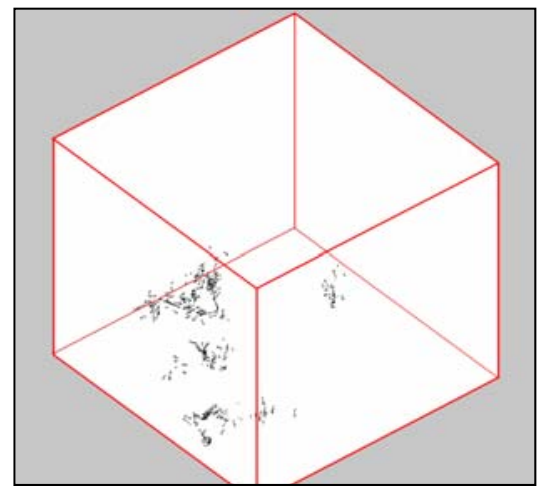

(a)

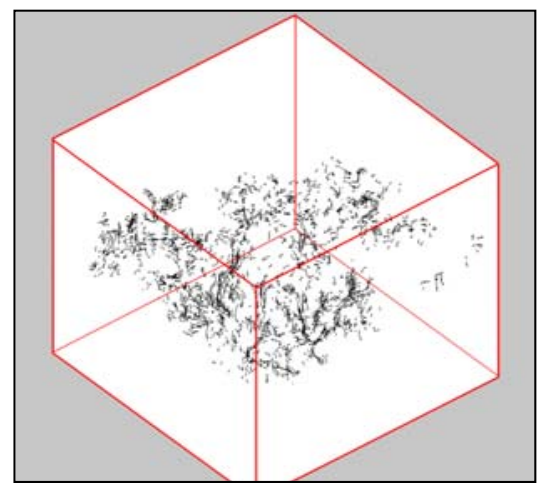

(b)

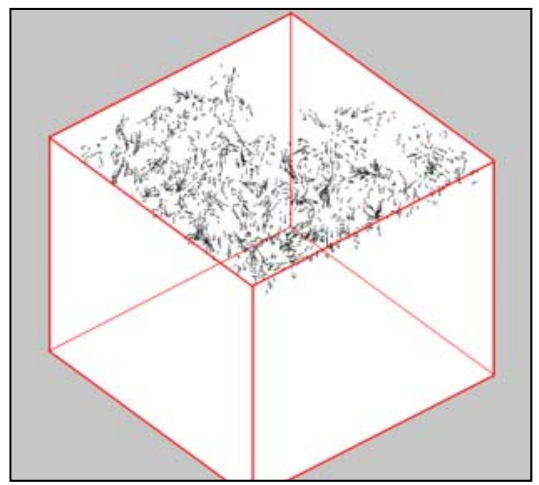

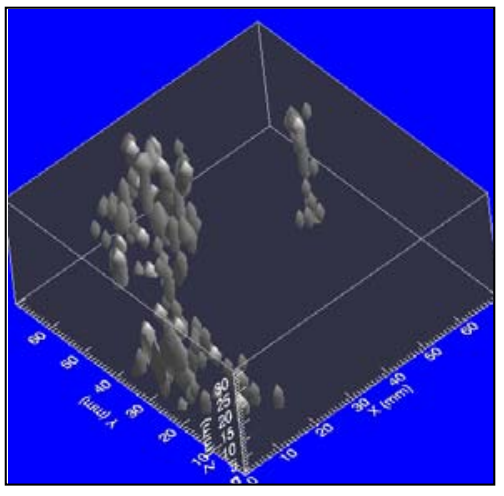
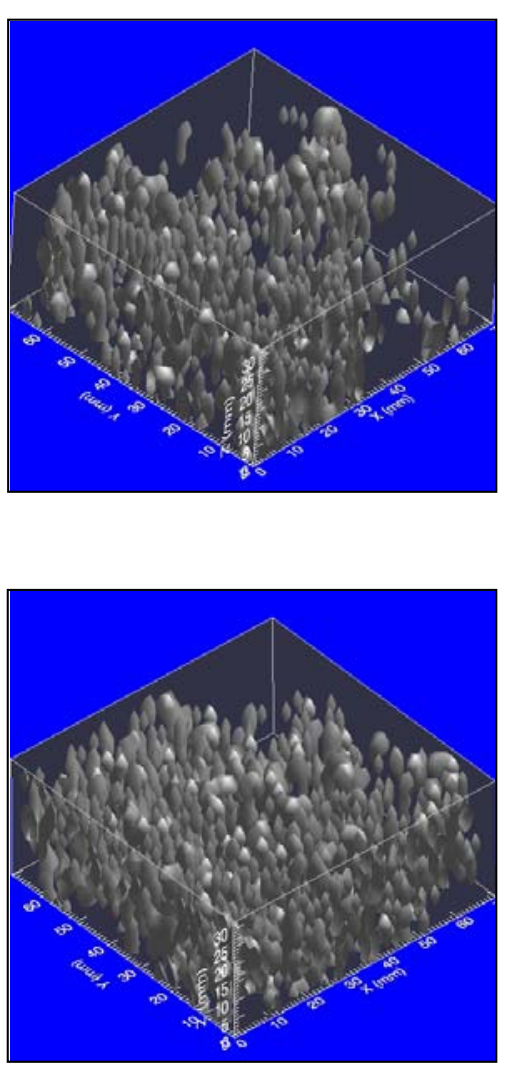

(c)

FIGURE 7 Flow patterns (left) and the corresponding air void structures (right) for the (a) top, (b) middle, and (c) bottom parts of LKC specimen [after Masad et al. (12)]. 


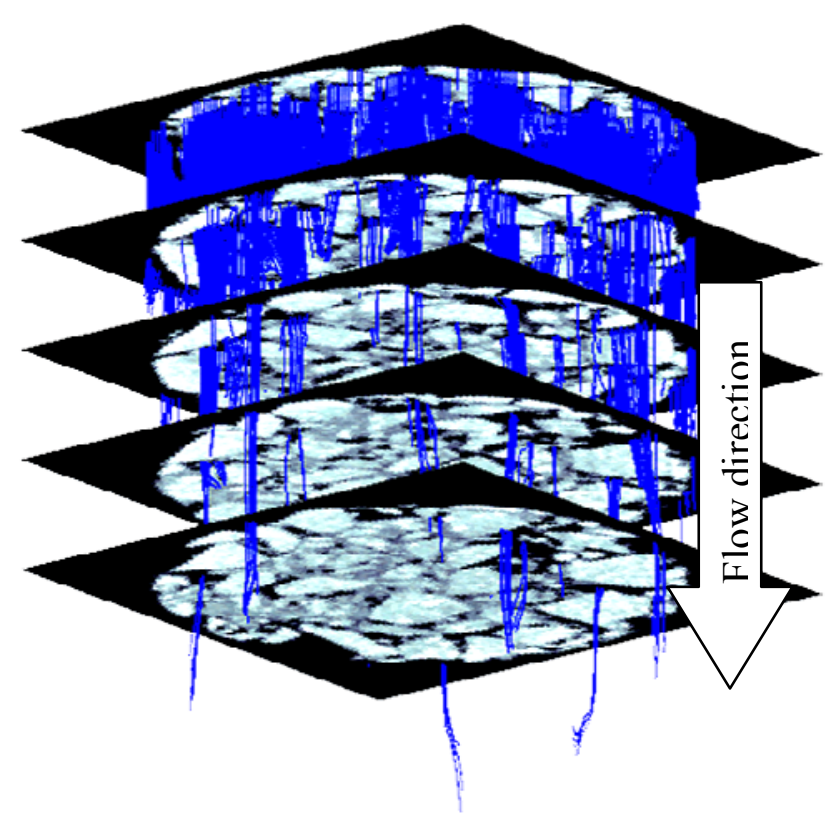

FIGURE 8 Simulation of fluid flow in 3-D image of an asphalt mix [after Kutay et al. (13)].

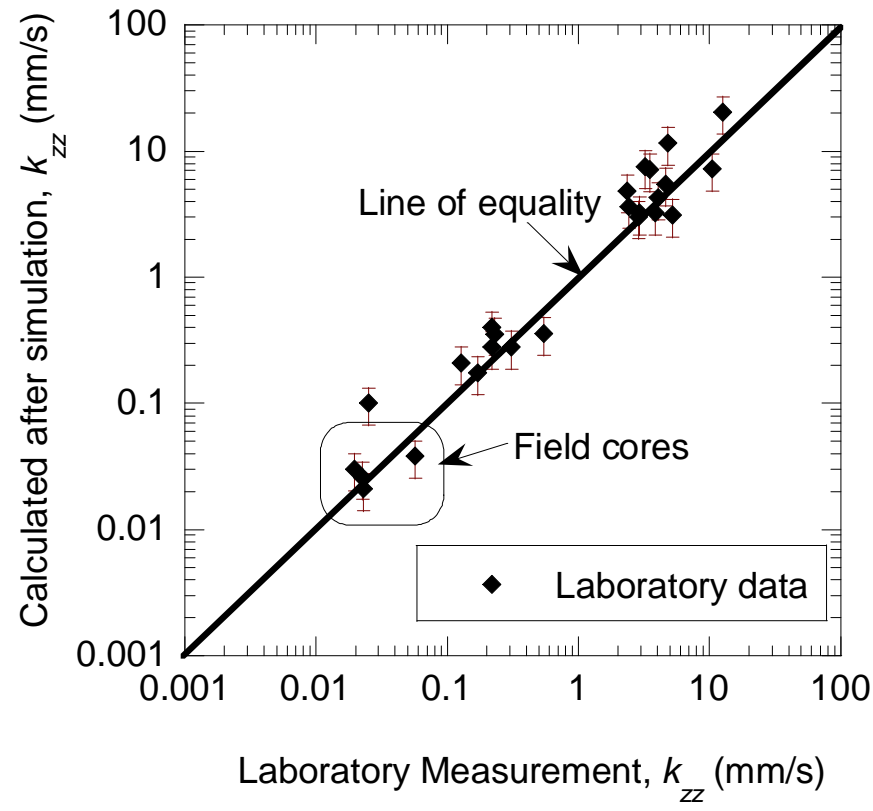

FIGURE 9 A comparison between calculated permeability and laboratory measurements [after Kutay et al. (13)].

Kutay and Aydilek (14) investigated the unsteady (dynamic) fluid flow in asphalt pavements using a 3-D fluid flow model that is based on the lattice Boltzmann method. Figure 10 shows the velocity distribution of water within pore structure for a given pulsatile water 
pressure. Kutay and Aydilek (14) also defined the dynamic permeability constant for asphalt mixtures and showed that it is a unique material property for a given frequency of dynamic water pressure. They also showed that pore pressure and velocity distribution within the pore structure exhibit quite variation as compared to a steady-state flow as shown in Figure 11. Figure 11 shows that the pressure gradient is higher at the surface under dynamic flow. As a result, significantly higher water velocities were observed in dynamic flow case. Such velocities can cause moisture-induced raveling on the surface of HMA pavements.
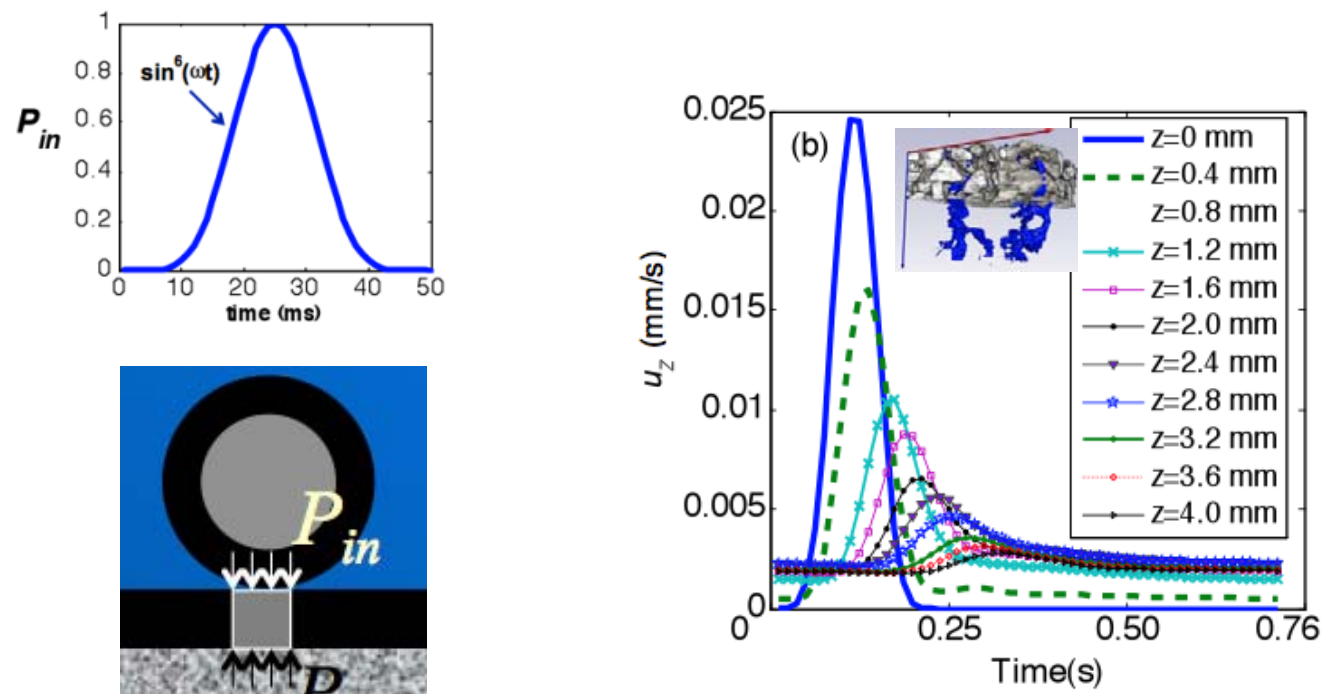

FIGURE 10 Mean water velocity in z-direction with time during entire cycle of a pulse (figure shows top $4 \mathrm{~mm}$ of specimen) [after Kutay and Aydilek (14)].

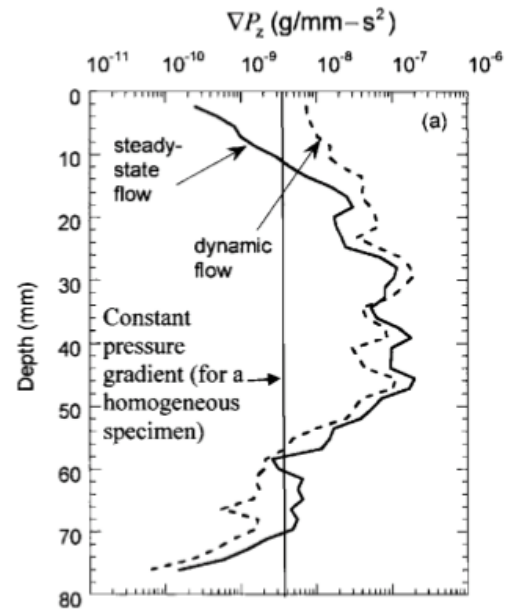

(a)

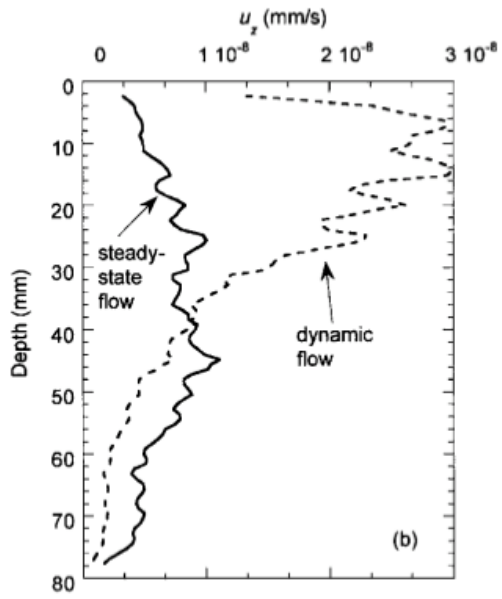

(b)

FIGURE 11 (a) Pressure gradient and $(b)$ vertical water velocity; $\left(u_{z}\right)$ versus depth relationships for an HMA specimen under steady and dynamic cases [after Kutay and Aydilek (14)]. 
Masad et al. (15) analyzed the air void distribution in different HMA specimens and related the distribution to the resistance to moisture damage. The results showed that there is a range of "pessimum" air void sizes and permeability values at which the mix has the least resistance to moisture damage. Researchers suggested that small air void sizes associated with low permeability reduce infiltration of water within the mix, while large air voids make it easier for the water to drain out of the mix. Hence, acceptable resistance to moisture damage occurs at these two levels of air void sizes. At the pessimum air void sizes, water permeates the mix and it is difficult for water to drain out of the mix, leading to more moisture damage. This concept can be used to design mixes outside the pessimum range in order to improve the resistance to moisture damage.

\section{Modeling Mix Response}

This circular includes a section on micromechanical modeling of asphalt mixes. A critical factor that determines the validity of these models is the realistic representation of the internal structure distribution. Image analysis techniques have been used for this purpose in both micromechanical finite element and discrete element models. Figure 12 shows an example of an image of the internal structure in which the asphalt and aggregate phases are identified. In a finite element model, material properties are assigned to each of these phases. In a discrete element model, properties are assigned for the different contact types (aggregate-aggregate, asphalt-asphalt, and aggregate-asphalt) that are present in the model as shown in Figure 13. Image analysis techniques coupled with micromechanical models have been used to study strain distribution in the mix and its influence on the nonlinear response (16-18), analyze micro fracture (19-22),

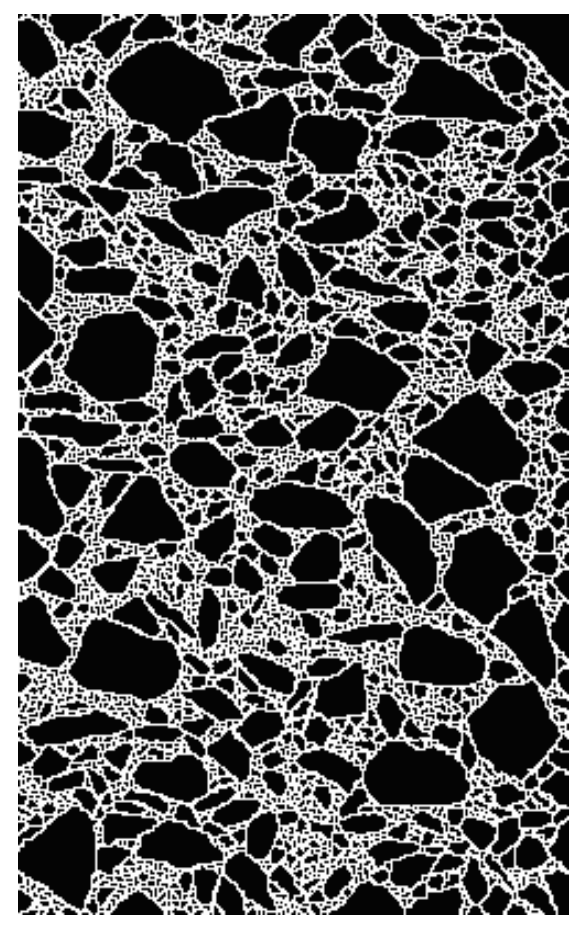

FIGURE 12 Image of HMA internal structure digitized to aggregate and asphalt phases. 


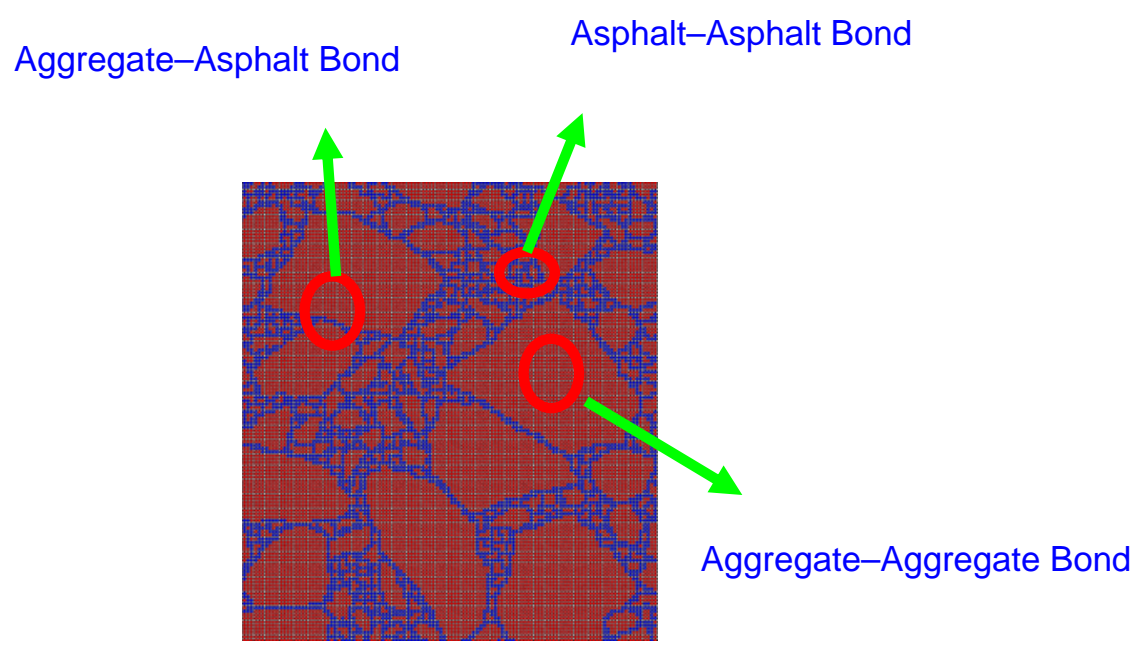

FIGURE 13 Types of bonds in DEM.

analyze stress localization in the mix and its influence on performance $(23,24)$, and study the deformational behavior of asphalt mixtures under conditions simulating those used in different testing methods in the laboratory $(25,26)$. Image analysis techniques have also been used to obtain properties of the internal structure distribution for continuum models. Tashman et al. (27) developed a continuum performance model for HMA, which includes parameters describing the directional distribution of aggregate particles, air void distribution, and damage. The results showed that better predictions of performance are achieved by including internal structure parameters in these models.

\section{LIMITATIONS AND FUTURE DEVELOPMENTS}

Image processing and segmentation techniques are needed to identify the different phases of the internal structure. However, the complexity of the internal structure and the different scales involved makes it very difficult to adopt a set of processing techniques that are applicable for all types of HMA mixtures. Therefore, users have to adopt processing techniques mainly based on visual inspection of the internal structure and realistic representation of the different phases in this structure. This subjectivity is considered a limitation that hinders unifying the methods for processing the HMA internal structure. One method to improve the objectivity of image analysis methods is that the image processing filter parameters and thresholds can be selected such that known properties of the specimens, such as gradation and relative percentage of aggregates, can be matched from the image.

Another limitation is caused by the artifacts that can be produced in X-ray CT images. Artifacts refer to the production of certain features in an image that do not actually exist in the specimen, and they are mainly the result of the scanning technique. Also, density resolution, spatial resolution, and noise are interrelated in X-ray CT and optimizing one of them can adversely influence the other two. One has to decide on the acceptable resolution (density and spatial) for a given application and select the specimen size and X-ray CT scanning factors accordingly. 


\section{SUMMARY OF FINDINGS}

The internal structure distribution has long been recognized as a critical factor influencing the performance of HMA. This has been reflected in design methodologies through specifying requirements on the volumetrics of asphalt mixes. Recently, there has been emphasis on the development of methods to quantify the internal structure distribution.

Developments of computer technology, image processing and analysis techniques, and nondestructive 3-D imaging have led to the developments of methods that can directly quantify the internal structure distribution. These methods have been applied recently in studying the differences among different laboratory compaction methods, improving the simulation of laboratory compaction to field compaction, and predicting the permeability of HMA mixtures.

These advances in imaging techniques for measuring the internal structure are expected to impact modeling, design, construction, and forensic evaluation of asphalt pavements. In modeling, they offer the tools to develop realistic representations of the internal structure in numerical models of HMA. The design of HMA can benefit from these methods through ensuring the development of optimum and homogeneous aggregate contacts and orientation, air void size distribution, and asphalt film thickness distribution. The optimum values of these elements can be determined through analytical and experimental studies that link the different possible values to performance. Mechanical testing variability is expected to be reduced due to the use of specimens with relatively homogenous internal structure. In construction, different field compaction practices can be related to the internal structure distribution in order to develop compaction techniques that are able to achieve the optimum distributions and performance. Imaging techniques can also be used in forensic evaluation of asphalt pavements such as segregation throughout the thickness of the asphalt mat, and the lack of proper contacts due to construction or mix design. They can also be used to verify certain concepts such as the development of the necessary levels of aggregate contacts and packing in asphalt mixes.

\section{REFERENCES}

1. Yue, Z. Q., W. Bekking, and I. Morin. Application of Digital Image Processing to Quantitative Study of Asphalt Concrete Microstructure. In Transportation Research Record 1492, TRB, National Research Council, Washington, D.C., 1995, pp. 53-60.

2. Masad, E., B. Muhunthan, N. Shashidhar, and T. Harman. Internal Structure Characterization of Asphalt Concrete Using Image Analysis. Journal of Computing in Civil Engineering (Special Issue on Image Processing), Vol. 13, No. 2, 1999a, pp. 88-95.

3. Masad, E. A., B. Muhunthan, N. Shashidhar, and T. Harman. Quantifying Laboratory Compaction Effects on the Internal Structure of Asphalt Concrete. In Transportation Research Record: Journal of the Transportation Research Board, No. 1681, TRB, National Research Council, Washington, D.C., 1999b, pp. 179-184.

4. Tashman, L., E. Masad, B. Peterson, and Saleh. Internal Structure Analysis of Asphalt Mixes to Improve the Simulation of Superpave Gyratory Compaction to Field Conditions. Journal of the Association of Asphalt Paving Technologists, Vol. 70, 2001, pp. 605-645.

5. Kutay, M. E., E. Arambula, N. H. Gibson, and J. Youtcheff. Three-Dimensional Image Processing Methods to Identify and Characterize Aggregates in Compacted Asphalt Mixtures. International Journal of Pavement Engineering, 2010. Available at http://www.informaworld.com/10.1080/10298431003749725. 
6. Coenen, A. R., M. E. Kutay, H. U. Bahia, and E. Mahmoud. Identification and Verification of Compaction Characteristics of Laboratory Asphalt Concrete Mixtures Using 2-Dimensional Imaging Analysis. International Journal of Road Materials and Pavement Design, 2010.

7. Saadeh, S., L. Tashman, E. Masad, and W. Mogawer. Spatial and Directional Distributions of Aggregates in Asphalt Mixes. Journal of Testing and Evaluation, Vol. 30, No. 6, 2002, pp. 483-491.

8. Dessouky, S., E. Masad, and F. Bayomy. Evaluation of Asphalt Mix Stability Using Compaction Properties and Aggregate Structure Analysis. International Journal of Pavement Engineering, Vol. 4, No. 2, 2003, pp. 87-103.

9. Watson, D., E. Masad, K. A. Moore, K. Williams, and L. A. Cooley. Verification of VCA Testing to Determine Stone-On-Stone Contact of HMA Mixtures. In Transportation Research Record: Journal of the Transportation Research Board, No. 1891, Transportation Research Board of the National Academies, Washington, D.C., 2004, pp. 182-190.

10. Hunter, A. E., G. D. Airey, and A. C. Collop. Aggregate Orientation and Segregation in Laboratory Compacted Asphalt Samples. In Transportation Research Record: Journal of the Transportation Research Board, No. 1891, Transportation Research Board of the National Academies, Washington, D.C., 2004, pp. 8-15.

11. Al-Omari, A., L. Tashman, E. Masad, A. Cooley, and T. Harman. Proposed Methodology for Predicting HMA Permeability. Journal of the Association of Asphalt Paving Technologists, Vol. 71, 2002, pp. 30-58.

12. Masad, E., A. Al-Omari, and H. C. Chen. Computations of Permeability Tensor Coefficients and Anisotropy of Hot Mix Asphalt Based on Microstructure Simulation of Fluid Flow. Journal of Engineering Mechanics, 2006a.

13. Kutay, M. E., A. H. Aydilek, E. Masad, and T. Harman. Computational and Experimental Evaluation of Hydraulic Conductivity Anisotropy in Hot Mix Asphalt. International Journal of Pavement Engineering, Vol. 8, No. 1, 2007, pp. 29-43.

14. Kutay, M. E., and A. H. Aydilek. Dynamic Effects on Moisture Transport in Asphalt Concrete. ASCE Journal of Transportation Engineering, Vol. 133, No. 7, 2007, pp. 406-414.

15. Masad, E., A. Castelblanco, and B. Birgisson. HMA Moisture Damage as a Function of Air Void Size Distribution, Pore Pressure and Bond Energy. Journal of Testing and Evaluation, Vol. 34, No. 1, 2006b, pp. 15-23.

16. Kose, S., M. Guler, H. Bahia, and E. Masad. Distribution of Strains within Hot-Mix Asphalt Binders. In Transportation Research Record: Journal of the Transportation Research Board, No. 1728, TRB, National Research Council, Washington, D.C., 2000, pp. 21-27.

17. Papagiannakis, T., A. Abbas, and E. Masad. Micromechanical Analysis of the Viscoelastic Properties of Asphalt Concretes. In Transportation Research Record: Journal of the Transportation Research Board, No. 1789, Transportation Research Board of the National Academies, Washington, D.C., 2002, pp. 113-120.

18. Abbas, A., T. Papagiannakis, and E. Masad. Linear and Non-Linear Viscoelastic Analysis of the Microstructure of Asphalt Concretes. Journal of Materials in Civil Engineering, Vol. 16, No. 2, 2004, pp. 133-139.

19. Guddati, M. N., Z. Feng, and R. Kim. Toward a Micromechanics-Based Procedure to Characterize Fatigue Performance of Asphalt Concrete. In Transportation Research Record 1789, TRB, National Research Council, Washington, D.C., 2002, pp. 121-128.

20. Sadd, M. H., Q. Dai, V. Parameswaran, and A. Shukla. Simulation of Asphalt Materials Using Finite Element Micromechanical Model with Damage Mechanics. In Transportation Research Record: Journal of the Transportation Research Board, No. 1832, Transportation Research Board of the National Academies, Washington, D.C., 2003, pp. 86-95.

21. Buttlar, W. G., and Z. You. Discrete Element Modeling of Asphalt Concrete: A Micro-Fabric Approach. In Transportation Research Record: Journal of the Transportation Research Board, No. 1757, TRB, National Research Council, Washington, D.C., 2001, pp. 111-118. 
22. Kim, Y. R., D. Allen, and D. N. Little. Damage-Induced Modeling of Asphalt Mixtures through Computational Micromechanics and Cohesive Zone Fracture. Journal of Materials in Civil Engineering, Vol. 17, No. 5, 2005, pp. 477-484.

23. Wang, L., D. Frost, and N. Shashidhar. Microstructure Study of Westrack Mixes From X-Ray Tomography Images. In Transportation Research Record: Journal of the Transportation Research Board, No. 1767, Transportation Research Board of the National Academies, Washington, D.C., 2001, pp. 85-94.

24. Wang, L. B., L. A. Myers, L. N. Mohammad, and Y. R. Fu. A Micromechanics Study on Top-Down Cracking. In Transportation Research Record: Journal of the Transportation Research Board, No. 1853, Transportation Research Board of the National Academies, Washington, D.C., 2003, pp. 121133.

25. Abbas, A., E. Masad, T. Papagiannakis, and T. Harman. Micromechanical Modeling of the Viscoelastic Behavior of Asphalt Mixtures Using the Discrete Element Method. International Journal of Geomechanics, Vol. 7, No. 2, 2006, pp. 131-139.

26. You, Z., and W. G. Buttlar. Micromechanical Modeling Approach to Predict Compressive Dynamic Moduli of Asphalt Mixture Using the Distinct Element Method. In Transportation Research Record: Journal of the Transportation Research Board, No. 1970, , Transportation Research Board of the National Academies, Washington, D.C., 2006, pp. 73-83.

27. Tashman, L., E. Masad, H. Zbib, D. Little, and K. Kaloush. Microstructural Viscoplastic Continuum Model for Asphalt Concrete. Journal of Engineering Mechanics, Vol. 131, No. 1, 2005, pp. 48-57. 


\title{
Micromechanical Modeling
}

\author{
WILLIAM BUTTLAR \\ University of Illinois
}

\begin{abstract}
Composite materials are used extensively in engineered structures. Similar or dissimilar materials can be combined for economy and/or to produce a material with superior properties as compared to any of its component materials. Some well-known composite infrastructure materials are: portland cement concrete (PCC), steel-reinforced concrete, fiberreinforced concrete, and asphalt concrete. In the case of asphalt concrete, the aggregates provide stiffness and economy, while the asphalt binder stabilizes the aggregate particles producing even higher stiffness and shear strength (as compared to unbound pavement layers), reduces permeability, reduces noise, and improves ride quality.
\end{abstract}

\section{MICROMECHANICAL MODELS: WHAT ARE THEY?}

Along with their advantages, composites have some complexities associated with them. For instance, when there is a great discrepancy between one or more physical properties of the constituents, overall qualities might be difficult to estimate. In the case of aggregate stiffness versus binder stiffness, the overall stiffness of the composite is not only difficult to estimate, but also sensitive to the geometry or morphology of the material microstructure. For example, the stiffness of mastic with a moderate volume concentration of filler particles will be closer to the binder stiffness than the stiffness of the filler particles (1). On the other hand, an asphalt concrete mixture with a slightly higher volume concentration of aggregate particles as compared to the mastic, such that many of the aggregate particles are in contact with one another, will have an overall stiffness that is greatly dependent upon the aggregate stiffness (2).

This type of complexity poses a challenge to pavement designers, since stiffness of the asphalt mixture is a critical input to pavement design, but most practical design schemes cannot logistically include physical testing of proposed mixtures as part of the design process

(contractor, equipment, and material source are not known a priori). Empirical models have been developed, such as the Witczak (3) and Hirsch (4) models, which provide a means to estimate asphalt mixture properties such as dynamic modulus as a function of binder properties and mixture volumetrics (Figure 1). However, because of the empirical nature of these models, they have limited prediction accuracy and may lead to large errors when applied outside of their calibration ranges (when they are extrapolated); the occurrence of which is often not obvious to the user. Furthermore, they provide only an incomplete picture of the mixture, often ignoring important parameters such as Poisson's ratio, phase angle, etc., which limit their use in more mechanistic pavement models.

Finally, one must be extremely careful in using empirical models to perform sensitivity analyses, with the goal of drawing insight toward the effect of certain mixture variables on mixture properties. This is due to the fact that these models rely heavily on the selection of mixture variables based upon experience, followed by non-linear regression to determine regression coefficients to be applied to these variables. Since multiple weight factors are determined simultaneously using a least squared error statistical approach, non-intuitive results 
can be obtained since the empirical parameters are driven by the goal of model fitting rather than physics.

Micromechanics models have been developed over the past 30 years that allow properties of composite materials to be computed, taking into account the inherent heterogeneous nature of these materials and using sound principles of the mechanics of materials (Figure 2). The models range from very simple analytical expressions, where limited morphological information is taken into account (less prediction accuracy/more calibration required) to more complicated analytical expressions or numerical methods or simulations, where detailed morphological information is considered (more prediction accuracy, less or no calibration required, more computationally expensive and time consuming).

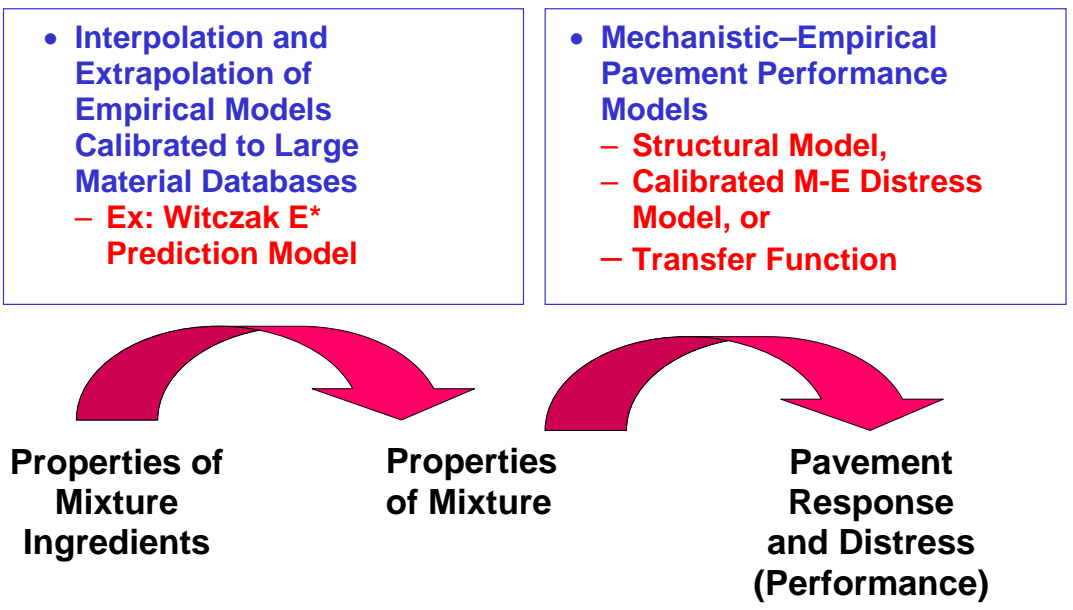

FIGURE 1 Current approach to pavement design in the Mechanistic-Empirical Pavement Design Guide.

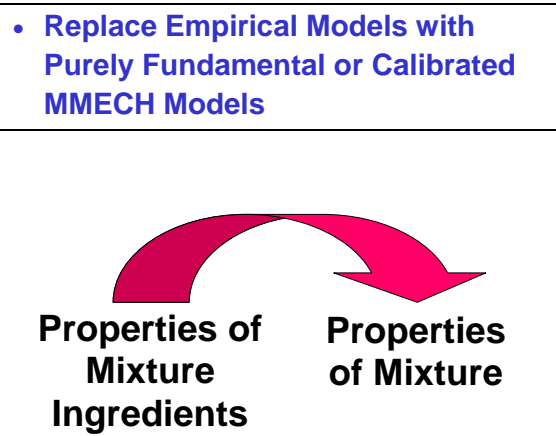

\author{
Fundamental or \\ Calibrated MMECH \\ Models Potentially: \\ - Reduce or Eliminate Size \\ of Calibration Set \\ - Provide Rational \\ Interpolation and \\ Extrapolation
}

FIGURE 2 Use of micromechanics models to replace empirical models. 
Figure 3 demonstrates how micromechanical simulation can be used in conjunction with more traditional homogeneous, layered pavement analysis to create a multiscale approach to pavement and material design. Although the employment of the micromechanical simulations may be difficult for mix design today, these models have already begun to yield benefits in the field of asphalt technology and, moreover, provide a new tool that may help mix designers and research scientists to explore fundamentally new materials, evaluate existing and new material tests, and develop new mix design procedures. This section provides a glimpse into how micromechanics models work, how they have been applied to date, what results have been obtained, and what future applications are envisioned.
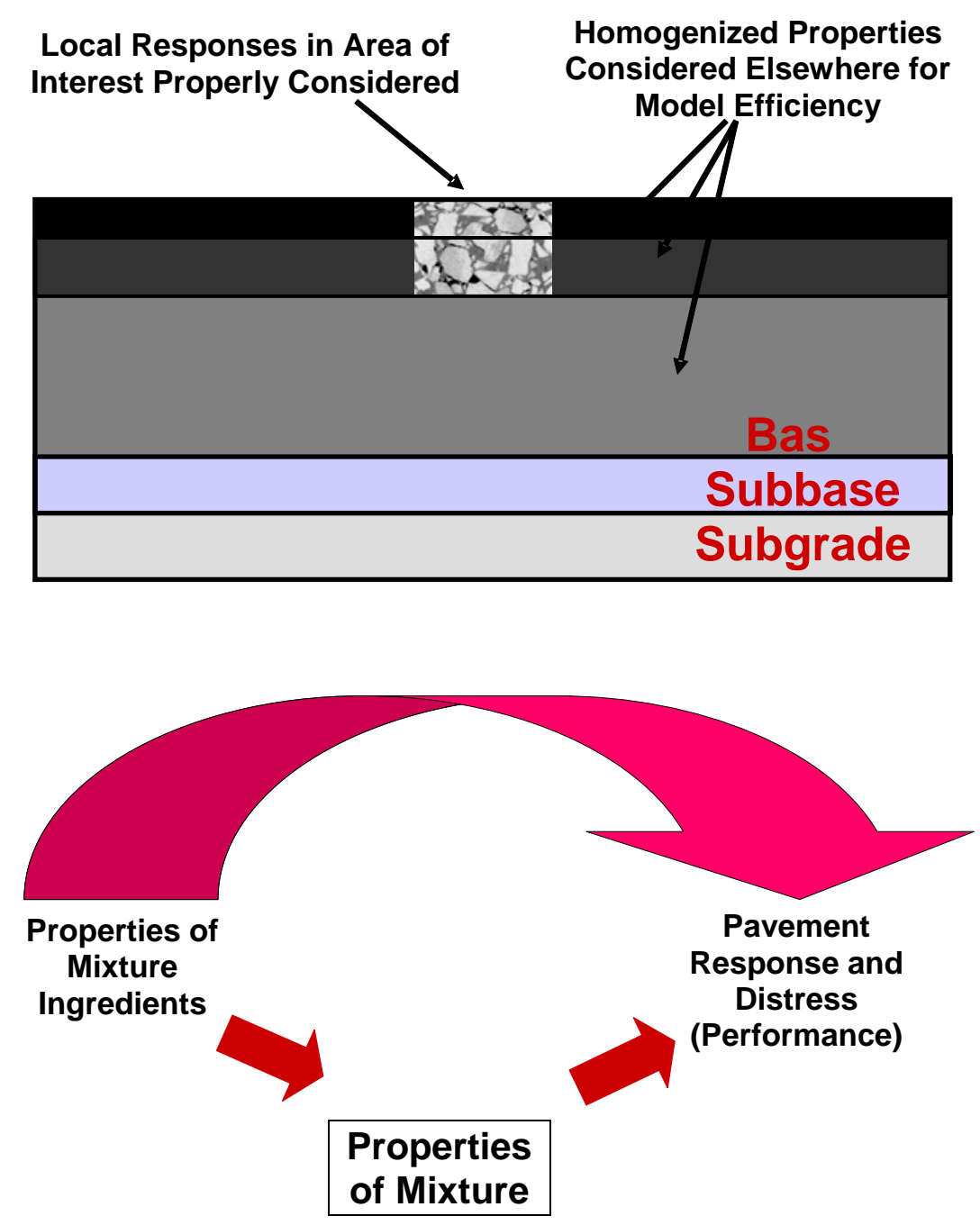

FIGURE 3 Use of micromechanical simulation models as a mechanistic pavement design methodology. 


\section{MICROMECHANICAL MODELS: HOW DO THEY WORK?}

There are a number of different types of micromechanics models that have been developed, which from the viewpoint of asphalt concrete applications, depending upon the nature of interactions of the particles (particle phase), can be broadly categorized as shown in the following table (Table 1).

Models in the first two categories listed in the table have been developed by the mechanics community, starting with the fundamental work of Eshelby (5) and Mura (6) to explore a wide range of composite materials, including solid rocket fuel propellant, fiberreinforced ceramics, and a number of other bi-material and composite material systems (7-11). In order to apply these models to asphalt concrete, one must normally reformulate the solutions to handle the viscoelasticity of the matrix material, namely, the asphalt binder $(12,13)$, as the most of the models reported in the literature were developed for elastic materials.

A common simplifying assumption is to take the binder properties at a fixed temperature and loading frequency (or loading time) along with the aggregate properties, input these values into the models, and compute the mixture properties at the same loading time and temperature $(2$, 14-16). By repeating this process, a mixture master curve can be obtained from a binder master curve. However, the results obtained will differ from the true viscoelastic solution, and furthermore, the phase angle of the composite will be retrievable only from the viscoelastic formulation. That notwithstanding, with some care and experimental validation, the aforementioned approach can be employed to obtain reasonable first-order estimates of composite material properties.

Figure 4 shows a typical result for a noninteracting particle model, in this case the selfconsistent scheme model, when reformulated into a viscoelastic solution and used to predict asphalt mastic stiffness. As can be seen, the model does a reasonable job of predicting the complex modulus and phase angle of the mastic material, based upon properties of the binder and assumed properties of the filler (12). Luo and Lytton (17) also reported on an inverse analysis scheme with the self-consistent scheme (SCS) micromechanics model to back-estimate aggregate properties when measured binder and mixture properties are available. This is a useful

TABLE 1 Different Types of Micromechanics Models

\begin{tabular}{|l|l|l|}
\hline Model Category & Nature of Model & Examples \\
\hline $\begin{array}{l}\text { Noninteracting particles, } \\
\text { arbitrary geometry }\end{array}$ & $\begin{array}{l}\text { Analytical (closed form } \\
\text { mathematical model), resulting } \\
\text { in upper and lower bounds on } \\
\text { material properties }\end{array}$ & Arbitrary phase geometry model \\
\hline $\begin{array}{l}\text { Noninteracting particles, } \\
\text { geometry specified }\end{array}$ & $\begin{array}{l}\text { Analytical (closed form } \\
\text { mathematical model), resulting } \\
\text { in upper and lower bounds on } \\
\text { material properties }\end{array}$ & $\begin{array}{l}\text { Composite spheres model, self- } \\
\text { consistent scheme, generalized } \\
\text { self-consistent scheme, } \\
\text { differential scheme }\end{array}$ \\
\hline Interacting particles & $\begin{array}{l}\text { Generally involves numerical } \\
\text { simulations }\end{array}$ & $\begin{array}{l}\text { Discrete element and finite } \\
\text { element simulations }\end{array}$ \\
\hline
\end{tabular}



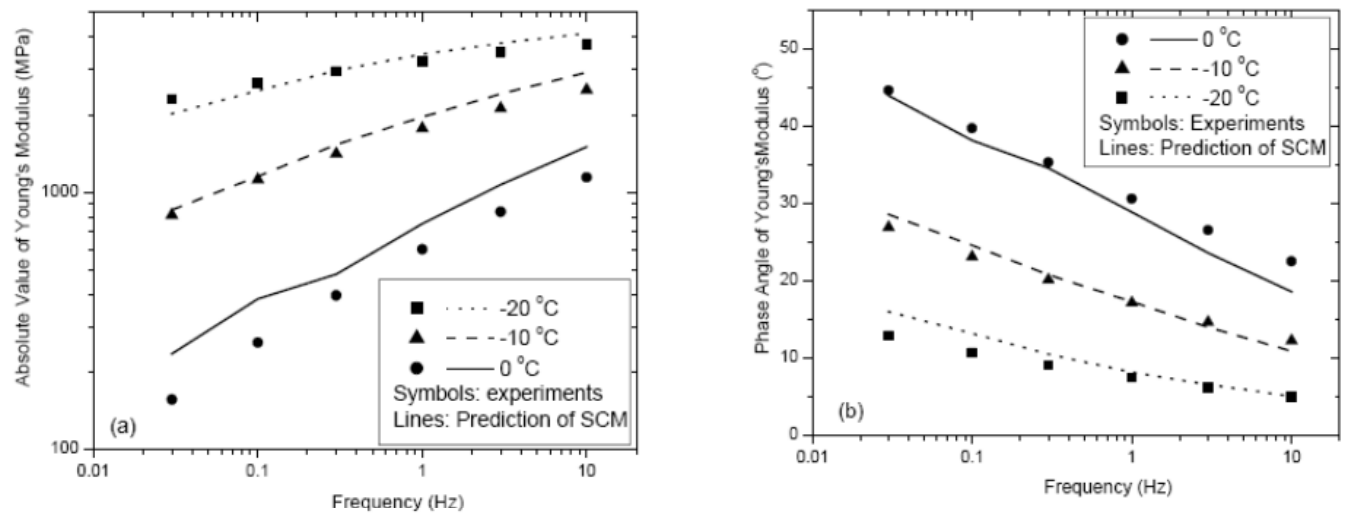

\section{FIGURE 4 Results of self consistent scheme micromechanical model prediction for asphalt mastic [from Yin et al. (12)].}

approach, since aggregate properties such as modulus and Poisson's ratio are not routinely measured but, once obtained, can be used in numerical simulation trials to develop mixtures with desired properties. However, the SCS and similar models would be expected to underpredict the stiffness of typical asphalt concrete mixtures, as aggregate interlock is not directly captured in these approaches. This has also been demonstrated by Kim (18) and Kim and Buttlar (13), where an extensive experimental database was generated to study the role of aggregates in the stiffening of asphalt mixtures, by testing and modeling asphalt mastics and mixtures across a broad range of aggregate volume concentrations. The authors showed that while a newly developed viscoelastic differential scheme micromechanics model could successfully predict mastic stiffness without the need for model calibration, the scheme tends to slightly underpredict the stiffness of asphalt concrete mixtures.

Some authors have introduced phenomenological calibration terms in order to extend the noninteracting particle models to be able to predict asphalt concrete properties $(1,19)$. However, since these models must be used with caution when evaluating materials outside their calibration set, there is still a need for more sophisticated micromechanics models to predict asphalt concrete properties in a fundamental way.

In order to overcome the limitations of the noninteracting particle models, some researchers have employed numerical simulations, using either computer-generated microstructures or actual material microstructure representations as obtained through various imaging techniques, as inputs to the models. The section on Characterization of the Internal Structure of Asphalt Mixtures details these powerful characterization techniques. The two most common micromechanical simulation techniques are the discrete element method and the finite element method. For brevity, examples herein are limited to those relating to the discrete element technique. Micromechanical simulations assuming heterogeneous hot-mix asphalt microstructure based upon the finite element technique have been reported by Masad et al. (20).

In the discrete element modeling method, complex structures or material systems can be represented by an assembly of small bonded or unbonded particles $(14,21,22)$. For a composite material, the stiffness of particles and strength of bond between particles vary for the individual constituents and interfaces between them. These models can be used for small strain simulations 
to estimate composite material stiffness or in large strain simulations to study material damage and even fracture.

Figure 5 provides an example of how a two-dimensional (2-D) discrete element model (DEM) was used to study how load is transmitted through aggregates and mastic in asphalt concrete (2). In this simulation, the aggregates Figure $5 a$ were dilated to produce the image in Figure $5 b$, to study how aggregate contact and aggregate volume concentration effects force transmission through the mix. Clearly, the mixture on the right has a larger number of aggregates in contact, leading to a stiffer mix, with aggregates experiences higher average stress levels. Figure 6 compares the three categories of micromechanics models presented in Table 1. Clearly the ability to predict asphalt concrete mixture stiffness is improved as model complexity increases. In other words, the simulation model result, where aggregate morphology is more accurately modeled, is superior to the non-interacting particle models with specified geometry. The noninteracting, arbitrary phase geometry model produces the least accurate result, and furthermore, produces bounds around the possible solution as opposed to a deterministic result. Discrete element simulations are most advantageous for problems with very large strain, damage, and especially fracture. It can also be used for other nonlinear models, such as those involving such as microcracking or those with a high degree of contacting interfaces, such as
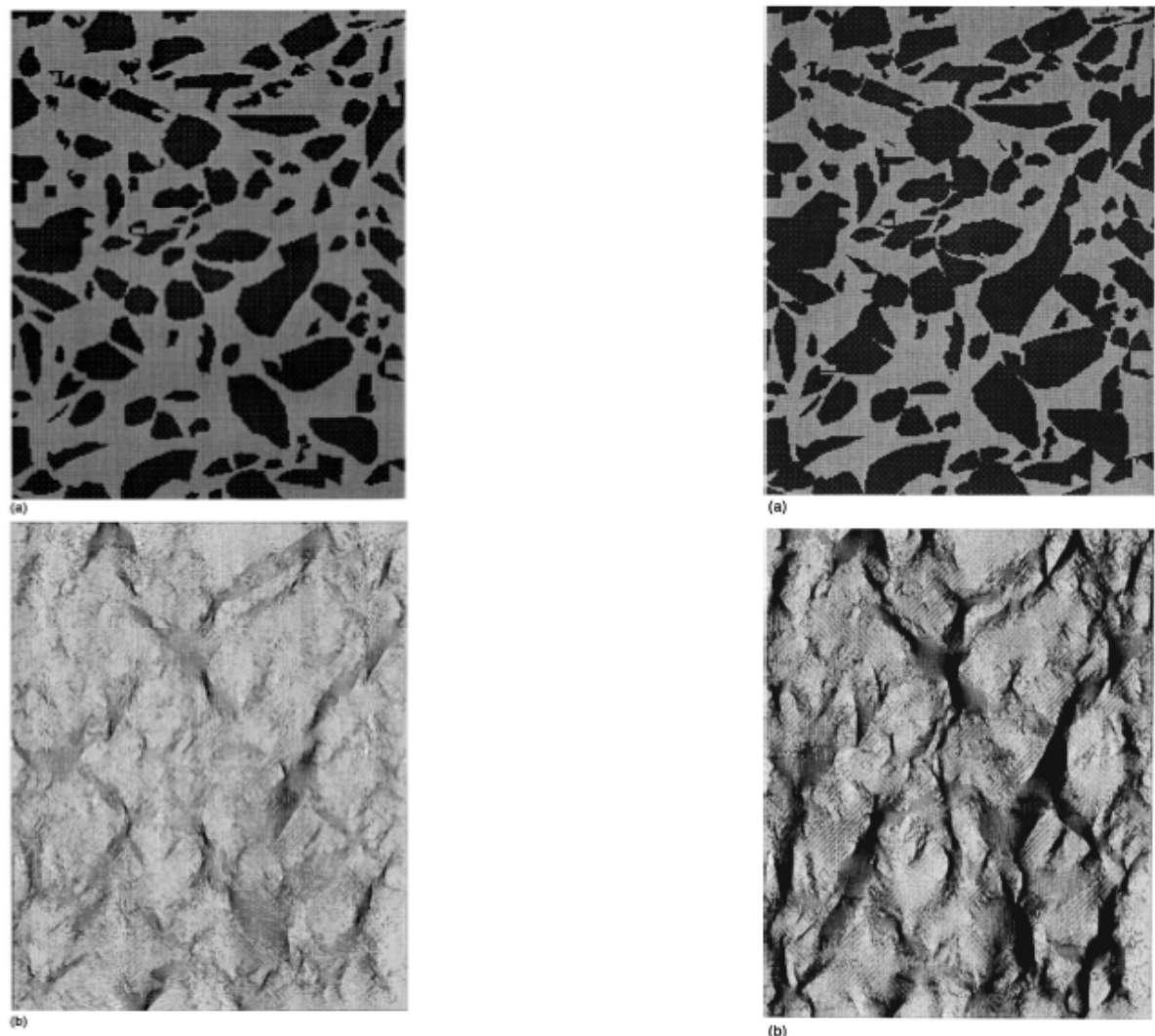

FIGURE 5 DEM simulation of uniaxial compression test on asphalt concrete [from You and Buttlar (2)]. 


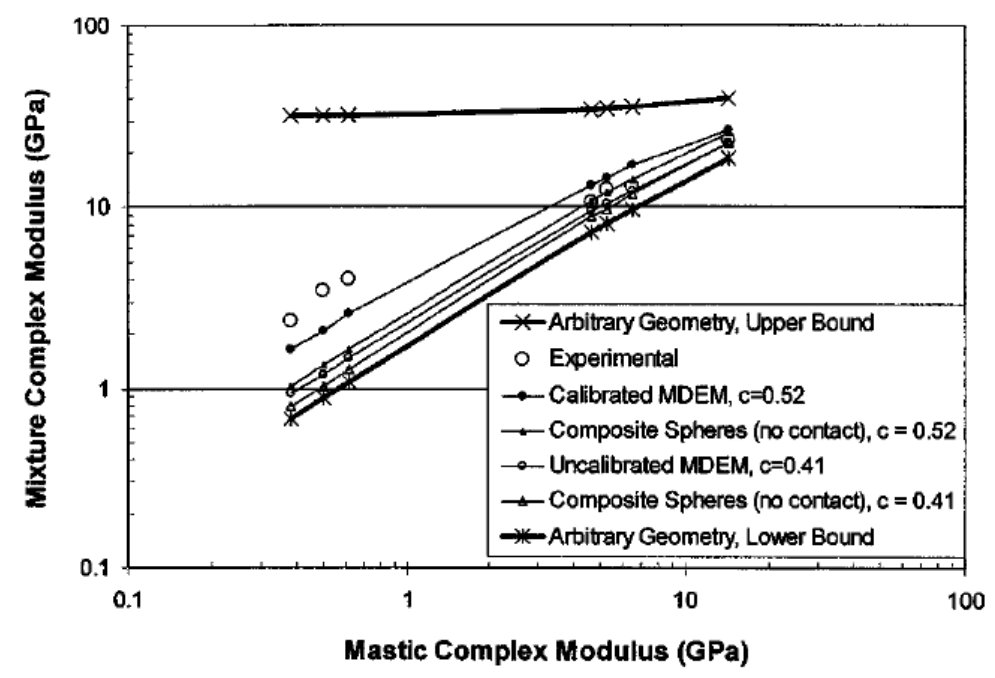

\section{FIGURE 6 Comparison of various micromechanical model predictions versus laboratory data [from You and Buttlar (2)].}

frictional sliding along pavement layer interfaces and along crack faces. The first such simulation reported in the literature was based upon research conducted at the University of Waterloo, as reported by Rothenburg et al. (23). As shown in Figure 7, a 2-D polygonal DEM was used to simulate damage and fracture developing in an asphalt mixture subjected to very high loads in a uniaxial compression test. The continual application of compressive force led to the well-known barreling effect observed in laboratory experiments. The main limitation of the model was the inability to account for the fracturing of aggregates. In Figure 8, clusters of disk-shaped discrete elements were used to fabricate an asphalt concrete indirect tensile test specimen (14). In this modeling approach, each aggregate consisted of a cluster of small, bonded discrete element particles, which allowed fracturing though aggregates.
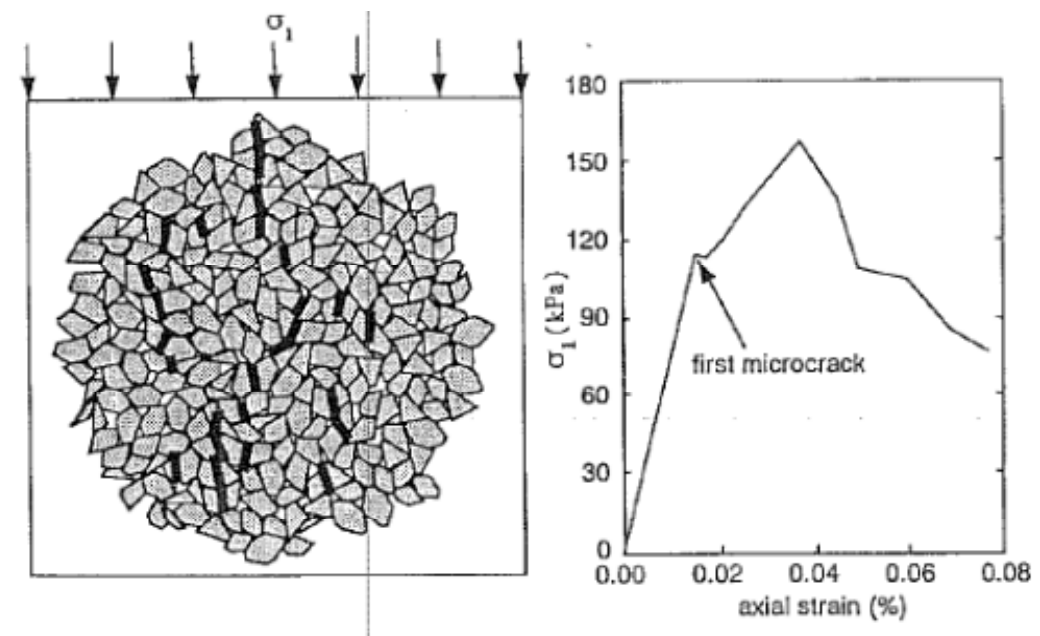

FIGURE 7 DEM simulation of uniaxial compressive behavior of asphalt concrete [from Rothenburg et al. (23)]. 


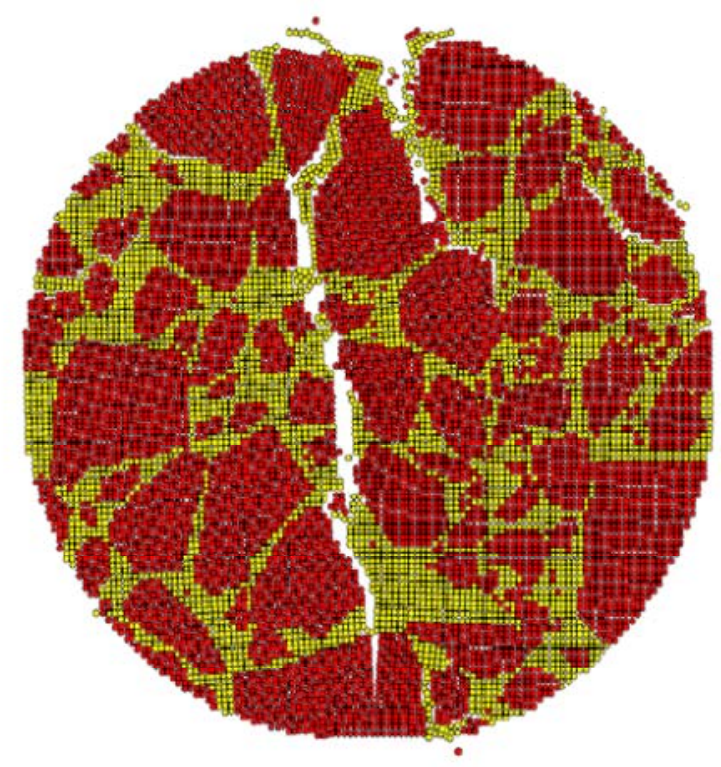

FIGURE 8 DEM simulation of indirect tensile test [from Buttlar and You (14)].

Figures 9 and 10 illustrate how the discrete element modeling technique was used to study fracturing processes in the ASTM D7313-07b disk-shaped compact tension test $(24,25)$. By considering material heterogeneity, model predictions were found to be more realistic than those obtained in previous attempts at modeling with a homogeneous material model.

Furthermore, the model provided valuable insight toward complex fracturing mechanisms, such as crack branching, crack sliding, and microcracking.

Another commonly used micromechanical scheme that has been widely adopted for simulation of damage and cracking in asphalt and PCC materials is the lattice model. This type of models utilizes periodic structure with repeated elemental units. Within this type periodic structure a random truss mesh of beam type elements are constructed. The beam elements provide the local response of material at a small scale. It is common practice to utilize lattice models within numerical simulation systems such as, finite element method. Bolander et al. (26) demonstrated use of lattice model for analysis of size effects in fracture process of PCC. Guddati et al. (27) utilized micromechanical lattice modeling approach to study fatigue damage and cracking in asphalt mixtures. Kutay et al. (28) used Boltzmann method within the lattice modeling framework for simulation of viscous flow through porous media, such as flow of water through asphalt concrete.

This section has exclusively dealt with the application of micromechanical analysis techniques to study composite materials. This is obviously an important topic, considering that asphalt mixtures and flexible and composite pavement systems are substantially comprised of highly heterogeneous material systems. However, in the mechanics community, the term micromechanics is not strictly limited to the study of materials with heterogeneity. For instance, 

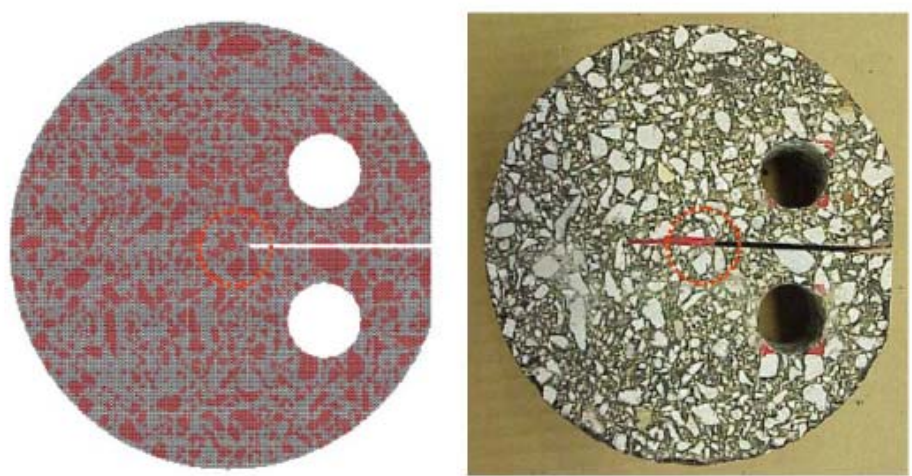

(a) DEM specimen representation (left) and laboratory specimen (right)

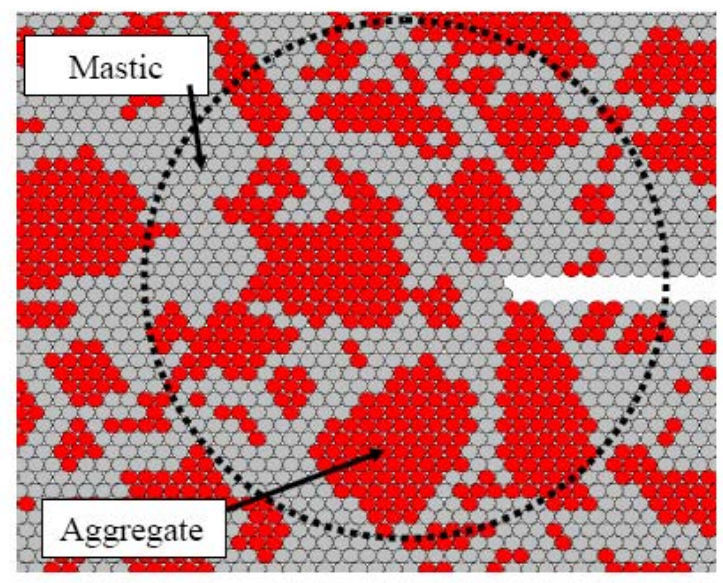

(b) Model configuration around crack tip

FIGURE 9 Simulation of ASTM D7313-07b DC(T) fracture energy test using DEM.

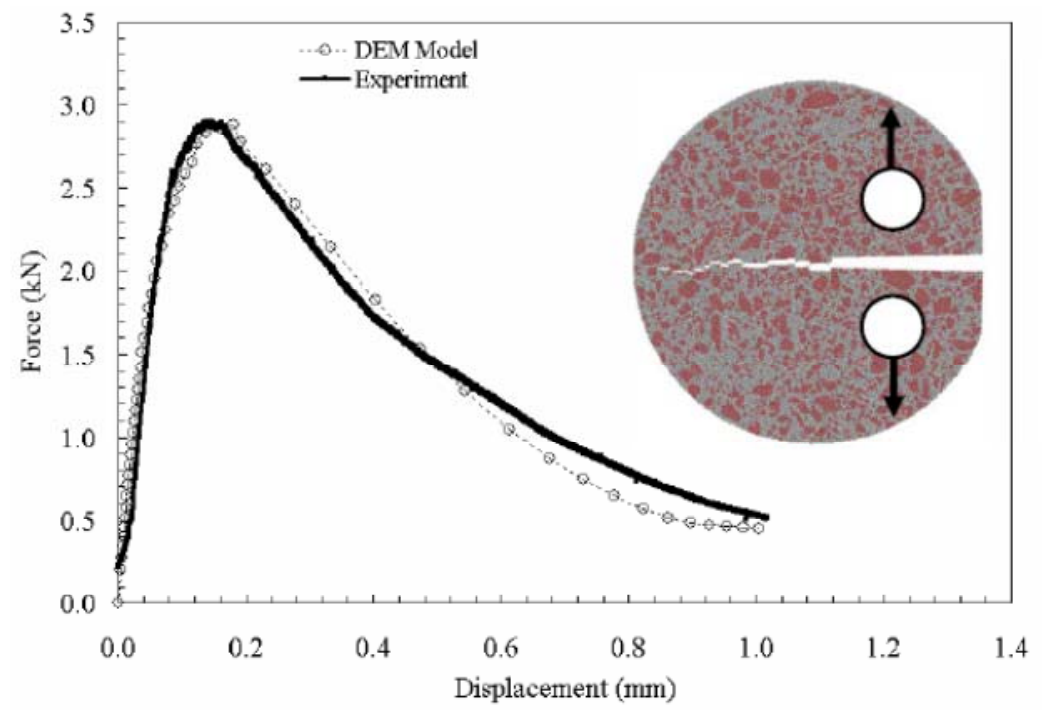

FIGURE 10 Numerical simulation results of DEM fracture simulation of DC(T). 
the use of numerical models such as the finite element method to study crack initiation and propagation can be considered as micromechanical modeling, even when a homogeneous material system is considered. Examples of micromechanical analysis of fracture in pavement systems with homogeneous material assumptions have been reported by Song et al. (29), Song et al. (30), and Soares et al. (31). Such works in the realm of pavement engineering are more appropriately categorized within the context of fracture or fatigue studies and have not been summarized herein. Still, it is clear that the field micromechanics provides powerful tools and insight toward the complex behavior exhibited by modern pavement systems and a means to enhance the durability, economy, and sustainable design and utilization of these systems.

\section{SUMMARY}

Micromechanics have been shown to provide an attractive alternative over purely empirical models for use in predicting key physical properties of composite materials, such as the dynamic modulus of asphalt concrete. Although there are certainly trade-offs (computational expense with model complexity and accuracy), advances in personal computer processing speed have brought even the most complex 2-D simulations into the realm of possibility for routine design. However, there is a limit to the accuracy that can be obtained with 2-D models (not all contacts between aggregates can be seen in a 2-D model, nor can the air voids be properly portrayed), and thus, ultimately 3-D models will be needed in order to obtain the best possible results.

That limitation notwithstanding, analytical models and 2-D simulation models with a modest degree of calibration can be employed in a practical way today. Work on 3-D modeling is progressing at a rapid pace, is research ready now, and will be available to the practitioner in the next 5 to 10 years. Moreover, micromechanical models provide researchers with something that empirical models simply cannot deliver: insight. New insight in stiffening mechanisms, damage mechanisms, and fracture mechanisms provide a tool that can allow material formulators and designers to see inside the material, creating possibilities for completely new material systems to be explored. The models presented herein can also be applied in the emerging fields of multiscale modeling and nanotechnology.

\section{REFERENCES}

1. Buttlar, W. G., D. Bozkurt, G. G. Al-Khateeb, and A. S. Waldhoff. Understanding Asphalt Mastic Behavior Through Micromechanics. In Transportation Research Record 1681, TRB, National Research Council, Washington, D. C., 1999, pp. 157-169.

2. You, Z., and W. G. Buttlar. Discrete Element Modeling to Predict the Modulus of Asphalt Concrete Mixtures. Journal of Materials in Civil Engineering, Vol. 17, 2004, pp. 140-146.

3. Bari, J., and M. W. Witczak. New Predictive Models for Viscosity and Complex Shear Modulus of Asphalt Binders: For Use with Mechanistic-Empirical Pavement Design Guide. In Transportation Research Record: Journal of the Transportation Research Board, No. 2001, Transportation Research Board of the National Academies, Washington, D.C., 2007, pp. 9-19.

4. Christensen, D. W., T. Pellinen, and R. F. Bonnaquist. Hirsch Model for Estimating the Modulus of Asphalt Concrete. Journal of the Association of Asphalt Paving Technologists, Vol. 72, 2003, pp. 97 121.

5. Eshelby J. D. The Determination of the Elastic Field of an Ellipsoidal Inclusion, and Related Problems. Proc., Royal Society A, Vol. 241, 1957, pp. 376-396. 
6. Mura T. Micromechanics of Defects in Solids (2nd ed.). Kluwer Academic Publishers, Dordrecht, 1987.

7. Christensen R. M., and K. H. Lo. Solutions for Effective Shear Properties in Three Phase Sphere and Cylinder Models. Journal of the Mechanics and Physics of Solids, Vol. 27, 1979, pp. 315-330.

8. Hashin, Z., and S. Shtrikman. A Variational Approach to the Theory of the Elastic Behavior of Multiphase Materials. Journal of the Mechanics and Physics of Solids, Vol. 11, 1963, pp. 127-140.

9. Hashin, Z. Viscoelastic Behavior of Heterogeneous Media. Journal of Applied Mechanics, Vol. 32, 1965, pp. 630-636.

10. Hill, R. A Self-Consistent Mechanics of Composite Materials. Journal of the Mechanics and Physics of Solids, Vol. 13, 1965, pp. 213-222.

11. Mori, T., and K. Tanaka. Average Stress in Matrix and Average Elastic Energy of Materials with Misfitting Inclusions. Acta Metallurgica, Vol. 21, 1973, pp. 571-574.

12. Yin, H. M., W. G. Buttlar, G. H. Paulino, and H. Di Benedetto. Assessment of Existing Micromechanical Models for Asphalt Mastics Considering Viscoelastic Effects. International Journal of Road Materials and Pavement Design, Vol. 9, No. 1, 2008, pp. 31-57.

13. Kim, H., and W. G. Buttlar. Stiffening Mechanisms of Asphalt-Aggregate Mixtures: from Binder to Mixture. In Transportation Research Record: Journal of the Transportation Research Board, No. 2181, Transportation Research Board of the National Academies, Washington, D.C., 2010, pp. 96 108.

14. Buttlar, W. G., and Z. You. Discrete Element Modeling of Asphalt Concrete: A Microfabric Approach. In Transportation Research Record: Journal of the Transportation Research Board, No. 1757, Transportation Research Board of the National Academies, Washington, D.C., 2001, pp. 111118.

15. Shu, X., and B. Huang. Dynamic Modulus Prediction of HMA Mixtures Based on the Viscoelastic Micromechanical Model. Journal of Materials in Civil Engineering, Vol. 20, No. 8, 2008, pp. 530538.

16. Shu, X., and B. Huang. Micromechanics-based Dynamic Modulus Prediction of Polymeric Asphalt Concrete Mixtures. Composites Part B: Engineering, Vol. 39, No. 4, 2008, pp. 704-713.

17. Luo, R., and R. L. Lytton. Self-Consistent Micromechanics Models of an Asphalt Mixture. Presented at 88th Annual Meeting of the Transportation Research Board, Washington, D.C., 2009.

18. Kim, M. Development of Differential Scheme Micromechanics Modeling Framework for Predictions of Hot-Mix Asphalt (HMA) Complex Modulus and Experimental Validations. Doctoral dissertation. University of Illinois at Urbana-Champaign, Urbana, 2009.

19. Shashidhar, N., and A. Shenoy. On Using Micromechanical Models to Describe Dynamic Mechanical Behavior of Asphalt Mastics. Mechanics of Materials, Vol. 34, 2002, pp. 657-669.

20. Masad, E., N. Somadevan, H. U. Bahia, and S. Kose. Modeling and Experimental Measurements of Strain Distribution in Asphalt Mixes. Journal of Transportation Engineering, Vol. 127, No. 6, 2001, pp. 477-485.

21. Cundall, P. A., and O. D. L. Strack. A Discrete Numerical Model for Granular Assemblies. Géotechnique, Vol. 29, 1979, pp. 47-65.

22. Chang K. G., and J. N. Meegoda. Micromechanical Simulation of Hot-Mix Asphalt. Journal of Engineering Mechanics, Vol. 123, No. 5, 2007, pp. 495-503.

23. Rothenburg, L., A. Bogobowicz, and R. Haas. Micromechanical Modeling of Asphalt Concrete in Connection with Pavement Rutting Problems. Proc., 7th International Conference on Asphalt Pavements, Vol. 1, 1992, pp. 230-245.

24. Kim, H., M. P. Wagoner, and W. G. Buttlar. Simulation of Fracture Behavior in Asphalt Concrete Using a Heterogeneous Cohesive Zone Discrete Element Model. ASCE Journal of Materials in Civil Engineering, Vol. 20, No. 8, 2008, pp. 1-12.

25. Kim, H., and W.G. Buttlar, "Discrete Fracture Modeling of Asphalt Concrete," International Journal of Solids and Structures, Vol. 46, pp. 2593-2604, 2009. 
26. Bolander J. E., H. Hikosaka, and W.-J. He. Fracture in Concrete Specimens of Differing Scale. Engineering Computations, Vol. 15, No. 8, 1998, pp. 1094-1116.

27. Guddati, M. N., Z. Feng, and Y. R. Kim. Toward a Micromechanics-Based Procedure to Characterize Fatigue Performance of Asphalt Concrete. In Transportation Research Record: Journal of the Transportation Research Board, No. 1789, Transportation Research Board of the National Academies, Washington D.C., 2002, pp. 121-128.

28. Kutay, M. E., A. H. Aydliek, and E. Masad. Laboratory Validation of Lattice Boltzmann Method for Modeling Pore-scale Flow in Granular Materials. Computers and Geotechnics, Vol. 33, No. 8, 2006, pp. 381-95.

29. Song, S. H., G. H. Paulino, and W. G. Buttlar. Simulation of Crack Propagation in Asphalt Pavements Using an Intrinsic Cohesive Zone Model. Journal of Engineering Mechanics, Vol. 132, No. 11, 2006, pp. 1215-1223.

30. Song, S. H., G. H. Paulino, and W. G. Buttlar. A Bilinear Cohesive Zone Model Tailored for Fracture of Asphalt Concrete Considering Viscoelastic Bulk Material. Engineering Fracture Mechanics, Vol. 73, No. 18, 2006, pp. 2829-2848.

31. Soares, J. B., F. A. Colares de Freitas, and D. H. Allen. Considering Material Heterogeneity in Crack Modeling of Asphalt Mixtures. In Transportation Research Record: Journal of the Transportation Research Board, No.1832, Transportation Research Board of the National Academies, Washington D.C., 2003, pp. 113-120. 


\title{
Use of Fracture Tests and Models
}

\author{
YONG-RAK KIM \\ University of Nebraska \\ Mihai Marasteanu \\ University of Minnesota
}

$\mathrm{V}$

arious asphalt pavement distresses are related to fracture, including fatigue cracking (both

top down and bottom up), thermal (transverse) cracking, and reflective cracking of the asphalt layer. The fracture resistance of asphalt materials significantly influences the service life of asphalt pavements and consequently the maintenance and management of the pavement network.

Fatigue damage is normally defined as incremental damage that occurs gradually in the pavement due to stresses induced by traffic loading. Normally, highway engineers consider fatigue damage to be the result of cracking. Fatigue damage is the result of the growth of small cracks and voids that form larger cracks. The cracking mechanism can be divided into two stages: initiation of cracks of sufficient length that grow under repeated loading and propagation of these cracks due to repeated loading. When a sufficient number of cracks develop within a wheelpath, severe distress results, and pavements quickly lose serviceability. However, fatigue may also manifest as permanent deformation or rutting in the wheelpath. Such permanent deformation is traditionally considered to be due to plastic flow but can also be the result of weakening of the mixture due to a concentration of small cracks caused by a fatigue process.

Good understanding of the fracture process is an essential requirement for asphalt pavements built in the northern part of the United States and in Canada for which the predominant failure mode is cracking due to high thermal stresses that develop at low temperatures.

Currently, there is no solid experimental method and analysis approach used to investigate the thermal fracture resistance of asphalt materials and the fracture performance of asphalt pavements. Improving the fracture resistance of the asphalt materials used in pavements and understanding the role played by the individual components of the pavement system in the fracture mechanism become a very important priority in the effort to reduce and eventually eliminate the occurrence of thermal cracks in asphalt pavements. This will maximize the service life of both new and rehabilitated pavements and significantly reduce the high costs of repairing low-temperature cracks.

The current Superpave specifications and the newly proposed pavement design guide, the Mechanistic-Empirical Pavement Design Guide (MEPDG) (1) are based on the linear viscoelastic dynamic modulus for the prediction of fatigue cracking damage. However, this approach cannot provide the tools to predict the temporally and spatially varying nonlinear evolution of cracks. The guide is not based on fundamental properties related to the fracture process. For example, the design guide uses the same approach to model both types of fatigue cracking (top down and bottom up) but with different locations for determining the critical stresses and different calibration coefficients. The simplicity of the fatigue model is attractive for pavement design; however, the basic assumption which implies the same governing mechanisms for both top-down and bottom-up fatigue cracking, is not considered accurate, as the mechanism 
of bottom-up cracking is bending, while top-down cracking is highly influenced by tirepavement stress distribution and surface aging. In addition, the fracture properties of the mixture are not included in the design models for predicting fracture events: cracking.

For the prediction and characterization of low-temperature cracking behavior, the current Superpave specifications and the MEPDG are based on the creep and strength data for both asphalt binders and asphalt mixtures. For asphalt binders, two laboratory instruments were developed during the SHRP to investigate the low-temperature behavior of asphalt binders: the bending beam rheometer and the direct tension tester (DTT). For asphalt mixtures, one laboratory testing device was developed: the indirect tension (IDT) tester. In this test, a cylindrical specimen is loaded in compression along the diameter. This is similar to the splitting tension test used to determine the tensile strength of rocks and concrete. A critical temperature can be determined at the intersection between the tensile strength-temperature curve and the thermal stress-temperature curve. This approach is used in the thermal cracking (TC) model, which has been implemented in the MEPDG (1). The TC model is viewed as a state-of-the-art tool for performance-based TC prediction, since this model is based on the theory of viscoelasticity, which mechanically predicts thermal stress as a function of time and depth in the pavements based on pavement temperatures, which are computed using air temperatures. However, several limitations in the TC model have been arguably issued such as the use of the simple, phenomenological Paris' law (2) to estimate crack growth rate, using test results obtained from the Superpave IDT test, which does not accurately identify fracture properties. In addition, the TC model does not consider crack developments related to vehicle loading; thus, this model cannot fully reflect fracture processes in the mixtures and pavements subject to traffic loading and low-temperature conditions.

One of the most powerful tools for studying the fracture-related process and damage evolution of engineering materials is fracture mechanics. Fracture mechanics is the study of the response and failure of structures as a consequence of crack initiation and propagation. Fracture mechanics approaches directly deal with discrete internal boundaries (cracks), and damage evolution is characterized by employing certain fracture criteria governing the prediction of internal boundaries.

Since Majidzadeh et al. (3) introduced fracture mechanics concepts to the field of pavements, the fracture mechanics approach has been widely used in characterizing and predicting pavement cracking (fatigue, low temperature, and reflection cracking) analysis, while most attempts have been research-oriented due to practical complexities. Different from continuum damage mechanics approaches, which typically hypothesize that phenomenologically determined internal state variables can be used to represent the overall locally averaged amount of damage in the sample, the fracture mechanics approach can account for the initiation of microcracks, their coalescence to macrocracks followed by complete failure of the structures. Therefore, the fracture mechanics approach reflects detailed damage evolution characteristics that are based on the underlying physics of the damage.

Over the past several decades, two primary attempts have been made by various researchers for the use of fracture mechanics approaches in the asphaltic materials and pavements. One of the primary efforts has been pursued to estimate fracture properties of the materials so that the properties can be used to predict fracture-related damage evolution in the mixtures and structures. For a more appropriate estimation, researchers have sometimes modified pre-existing fracture test methods or even newly designed their own testing protocols, since preexisting fracture test methods could not properly capture fracture processes of highly nonlinear, 
inelastic, and heterogeneous materials such as asphaltic materials. Another challenge that researchers have faced is the development of fracture models that are tailored for a more accurate estimation of fracture mechanisms and a better performance prediction of damage and failure in the asphalt mixtures and pavement structures. Traditional linear elastic fracture studies based on stress intensity factors or strain energy release rates are not valid when the crack tip is subjected to certain levels of plastic yielding, which are frequently observed from asphalt mixtures. Furthermore, the traditional linear elastic fracture mechanics (LEFM) approaches assume the existence of infinitely sharp crack tips leading to stress singularities preceding the crack tips. However, in actual materials (rather than in the conceptual situations), neither the sharpness of the crack nor the stress singularity of the crack tip is often observed; therefore, there is a clear need for more appropriate fracture characterization techniques and prediction models.

To that end, the following sections introduce some of the attempts (obviously not all) made by researchers to advance testing methods that characterize the fracture properties of asphalt materials and fracture mechanics-based models that predict mixture-structural failure due to fracture in a summarized form. The following sections provide meaningful answers to questions such as "How do the fracture mechanics approaches work?" and "How are the fracture mechanics models applied to practical problems?" In addition, the limitations and advantages of the currently available fracture mechanics approaches (testing methods and models) that have been developed by researchers are included in the discussion.

\section{FRACTURE MECHANICS-BASED TESTS ON ASPHALT BINDERS}

Two factors have been considered in the determination of the specimen geometry used in fracture tests on asphalt binders: $(a)$ convenient specimen preparation and $(b)$ compatibility with the current equipment used in the Superpave specifications. Asphalt binder specimens are usually cast in molds and require little preparation before testing, which provides some flexibility in choosing the geometry of the test specimen. Two geometries have often been assessed by researchers. They are $(a)$ single edge notched beam [SE(B)] test and $(b)$ double edge notched tension (DENT) test, as presented in Figure 1.

The SE(B) method closely follows the ASTM E399 procedure (4). A crack starter notch is machined at the middle point of the span from the bottom side of the beam. The beam is symmetrically supported by two rollers and a line load is applied at the top side of the beam. The $\mathrm{SE}(\mathrm{B})$ test is the most documented method for determining fracture properties based on LEFM conditions. With the LEFM condition, the opening-mode stress intensity factor $\left(K_{I}\right)$ is used to characterize the stress field in the vicinity of the crack tip. The critical stress intensity factor $\left(K_{I C}\right)$ corresponding to the initiation of a crack is defined as the measure of fracture toughness.

Lee and Hesp (5) and Lee et al. (6) were among the first to use SE(B) geometry to measure the fracture properties of asphalt binders. A notched asphalt binder beam was cast in a silicone mold and conditioned at $-20^{\circ} \mathrm{C}$ for at least $12 \mathrm{~h}$ before testing. The specimen was 25 $\mathrm{mm}$ wide by $12.5 \mathrm{~mm}$ thick by $175 \mathrm{~mm}$ long, and the span of the beam was $100 \mathrm{~mm}$. The experiment was controlled by the displacement of the crosshead at a speed of $0.01 \mathrm{~mm} / \mathrm{s}$. Based on test results from various binders, the researchers observed that the addition of the modifier increased the fracture toughness of the asphalt binder. To estimate the fracture energy, beam specimens with different initial notch lengths $(\mathrm{a}=12.5 \mathrm{~mm}, 15.5 \mathrm{~mm}$, and $18.2 \mathrm{~mm})$ were tested, and the graphical method by Dongre et al. (7) was used to calculate the fracture energy. 


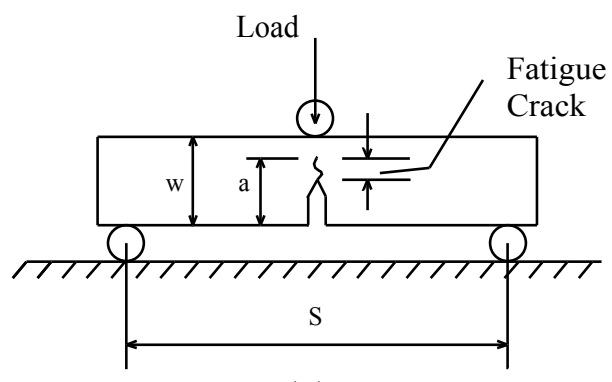

(a)

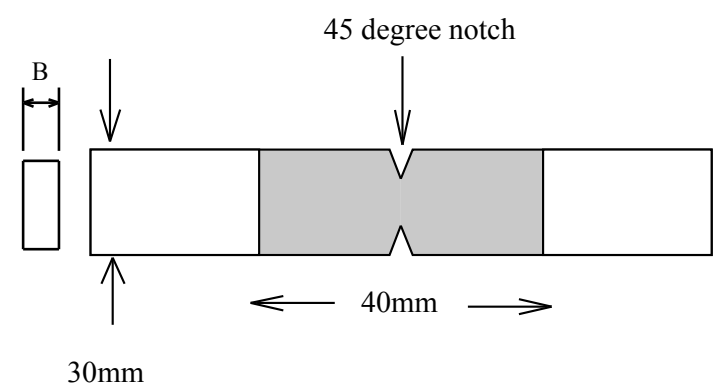

(b)

FIGURE 1 Two primary test methods used to assess asphalt binder fracture properties: (a) SE(B) test and (b) DENT test.

Anderson et al. (8) used the SE(B) test to measure the fracture toughness of 14 types of asphalt binders and checked the effectiveness of the characterization of low-temperature cracking resistance with different binder grading methods. The researchers also found that fracture toughness $\left(K_{I C}\right)$ discriminated the asphalt binders much better compared to the Superpave performance grade (PG) criteria. Olard and Di Benedetto (9) studied the temperature and loading rate effects on asphalt binder fracture toughness and fracture energy measured on $\mathrm{SE}(\mathrm{B})$ specimens. The researchers tested binders at different loading rates with varying temperatures ranging from $-23^{\circ} \mathrm{C}$ to $-4^{\circ} \mathrm{C}$. The results indicated that the fracture toughness was less dependent on temperature and loading rate than the fracture energy. The data showed the probable existence of a lower bound for the fracture energy of asphalt binders, which was reached in the glassy and brittle state of the asphalt binders. The existence of an asymptotic value for the fracture energy of asphalt mixtures was also reported by Li and Marasteanu (10).

One of the first attempts to use the DENT test for asphalt binders is described in a study by Andriescu et al. (11). As Figure $1 b$ presents the specimen dimensions, a 45-degree notch angle was used to facilitate making initial notches at both sides of the tension bar. Five different notch lengths were tested at $20^{\circ} \mathrm{C}$, and the fracture energy of the asphalt binders was measured to predict the fatigue cracking in asphalt mixtures. The essential work of fracture method (12) was used to estimate the fracture resistance of asphalt binders by dividing the strain energy into the essential work of fracture and the plastic work of fracture. Later, Roy and Hesp (13) used the DENT and DTT geometries to compare thermal stress restrained in the specimen due to the reduction of temperatures at a rate of $10^{\circ} \mathrm{C}$ per hour until the specimens failed. Large differences were found between the failure temperatures of the notched (DENT) and the unnotched (DTT) specimen for the same type of asphalt binder. More recently, Zofka and Marasteanu (14), using an approach developed by Gauthier and Anderson (15), also compared DENT to DTT with nine different asphalt binders. Test results showed that DENT produces better repeatability than DTT and can be used to estimate critical cracking temperatures of asphalt binders.

\section{FRACTURE MECHANICS-BASED TESTS ON ASPHALT MIXTURES}

To characterize the fracture properties of asphalt mixtures, three geometries have typically been pursued by researchers. They are: (a) SE(B) specimen; (b) disc-shaped compact tension [DC(T)] specimen; and (c) semi-circular bending (SCB) specimen, as presented in Figure 2. 


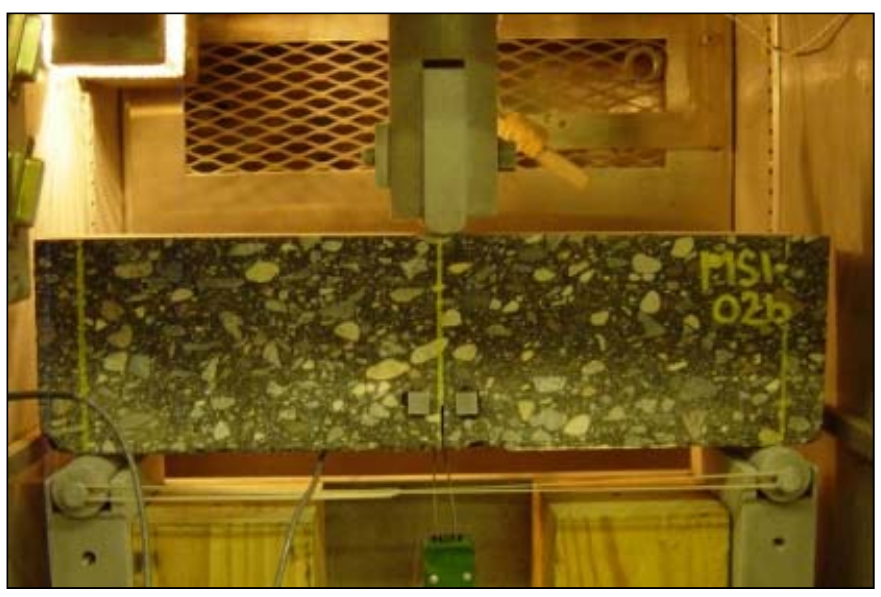

(a)

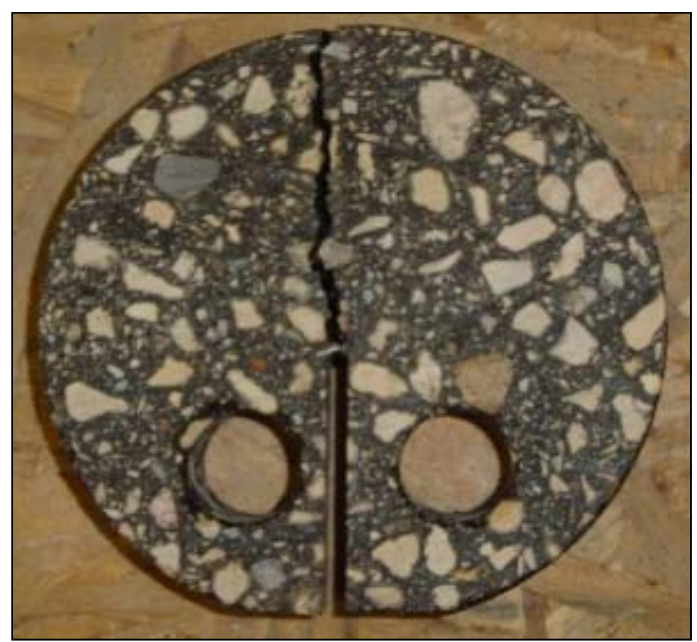

(b)

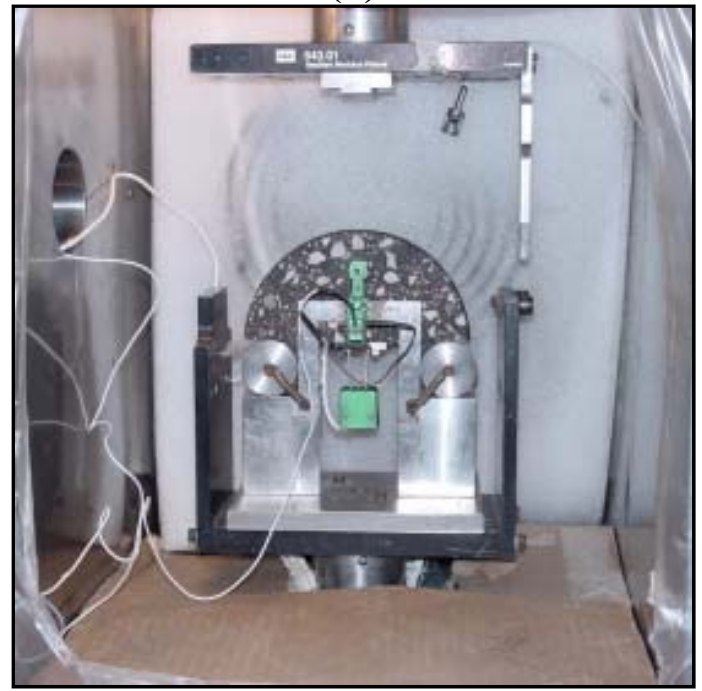

(c)

FIGURE 2 Typical test methods used to assess asphalt mixture fracture properties: (a) SE(B) test; (b) DC(T) test; and (c) SCB test. 
Even before the adoption of ASTM E399 in 1970, Majidzadeh et al. (3) used the SE(B) specimens to predict the fatigue life of paving mixtures in terms of material constants, geometry, boundary conditions, and the state of stress. They described fatigue failure by three processes: damage initiation, crack growth, and final failure. Many studies (16-18) after SHRP used the $\mathrm{SE}(\mathrm{B})$ specimens to investigate the material-specific, temperature-dependent fracture toughness of asphalt concrete based on the LEFM concept. Roy and Hesp (13) monitored the crack mouth opening displacement (CMOD) and the crack tip opening displacement to account for inelastic deformation, which can allow one to characterize fracture behavior based on elastic-plastic fracture mechanics. More recently, Wagoner et al. (19) concluded in their studies that SE(B) testing is probably the most promising fracture test based on test control, crack front development, test repeatability, test temperature, and mixed mode fracture.

The compact tension test is a part of ASTM E399 (4) and recommended as an alternative to the $\mathrm{SE}(\mathrm{B})$ test. Although the compact tension test can be performed with both rectangular and disc-shaped compact specimens, the DC(T) specimen has typically been used in the characterization of asphalt concrete fracture properties, because the specimen can be easily prepared by compacting asphalt mixtures with a Superpave gyratory compactor. Significant work has been conducted by researchers at the University of Illinois at Urbana-Champaign on the development of the DC(T) fracture testing protocol. Wagoner et al. (19-21) modified the original ASTM DC(T) geometry, which is usually for metallic materials, by moving the location of the loading holes to reduce failure at the loading holes. The researchers also set the thickness of the specimens to $50 \mathrm{~mm}$ and the notch length to $19 \mathrm{~mm}$ to maximize the ligament area. At different testing temperatures $\left(-20,-10\right.$, and $\left.0^{\circ} \mathrm{C}\right)$ and loading rates, the fracture energy was simply computed by the area under the load-CMOD curve normalized by the area of the fracture surface. The researchers found that as the temperature increased, the fracture energy increased, and as the loading rate increased, the fracture energy decreased. The DC(T) test is now specified as ASTM D7313-07a (22).

One simpler alternative to the SE(B) and the DC(T) is the SCB test. The SCB specimen has since been used by many researchers $(23-29)$ to obtain the fracture toughness, fracture energy, and stress-softening curves of asphaltic materials. The SCB is advantageous due to its relatively simple testing configuration, more economical aspects in specimen fabrication (two testing specimens are produced from one cylinder sample), and repeatable testing results. Another benefit of SCB testing is that it can be used to determine not only mode I fracture toughness but also mixed mode (I and II) fracture toughness by adjusting the angle of the notch (30). According to studies (27-29), the SCB test can identify fracture characteristics in a sensitive manner depending on the testing temperatures, materials used in the mixtures, and loading conditions (e.g., rates). Li (29) used acoustic emission (AE) techniques incorporated with SCB fracture testing to obtain relevant information about the fracture process in asphalt mixtures. AE is regarded as a useful tool for obtaining information about the microscopic damage during fracture and allows for a better understanding of the relationship between the microstructural events and the macroscopic performance. Significant work conducted by researchers at the University of Minnesota has resulted in an AASHTO-designated SCB facture testing protocol (31). The test method is based on the LEFM to determine mode I fracture toughness $\left(K_{I C}\right)$ and stiffness of asphalt concrete mixtures at low temperatures. The test method applies to test specimens (150 $\pm 9 \mathrm{~mm}$ in diameter and $25 \pm 5 \mathrm{~mm}$ thick) having a maximum aggregate size of $19 \mathrm{~mm}$ or less. 
While the SCB test geometry has presented advantageous aspects compared to other geometries, some drawbacks have been reported by researchers. Wagoner et al. (20) indicated that the $150-\mathrm{mm}$ diameter of a SCB specimen could lead to a relatively short (or insufficient) fracture ligament, which should be as large as possible to produce a reliable fracture property. In addition, the crack propagation with the SCB geometry creates an arching effect with high compressive stress, which further reduces the effective ligament, creating potentially invalid testing results.

In addition to the three typical testing geometries for the fracture characterization of asphaltic mixtures, researchers at the University of Florida have attempted different testing configurations. Roque et al. (32) modified the IDT testing specimen by drilling an $8 \mathrm{~mm}$ diameter hole in the center of the specimen, as shown in Figure 3. Their research focused on obtaining suitable crack growth rate parameters to describe the fatigue cracking of asphalt mixtures under traffic loading at intermediate temperatures. The stress intensity factor $\left(K_{I}\right)$ captured at different loading cycles was used to predict the crack growth with Paris' law (2). Roque et al. (33) also incorporated the dissipated creep strain energy limit and fracture energy limit with the testing to account for the inelastic deformation of asphalt mixtures. Later, Koh et al. (34) proposed an alternative type of test, the dog-bone direct tension (DBDT) test that is presented in Figure 3, to determine the asphalt mixture fracture-damage properties. Koh et al. (34) claimed in their study that the DBDT test method can reduce the disadvantages of IDT and uniaxial tensile tests, since this test method provides the failure plane a priori. It allows direct tension testing of gyratory compacted specimens or field cores by simply coring opposing sides from slices or disks obtained from cylindrical laboratory samples or field cores.

\section{USE OF FRACTURE MODELS FOR ASPHALT MATERIALS AND PAVEMENT STRUCTURES}

The most frequent application of the fracture mechanics approach to the modeling of crack propagation in asphaltic mixtures and pavement structures has been based on the well-known Paris' law (2). Paris' law has successfully been applied to HMA by many researchers, for the analysis of experimental tests [such as the SE(B) and the SCB tests introduced earlier] and

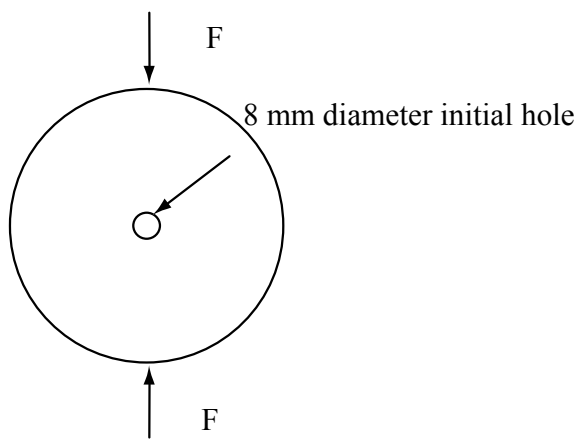

(a)

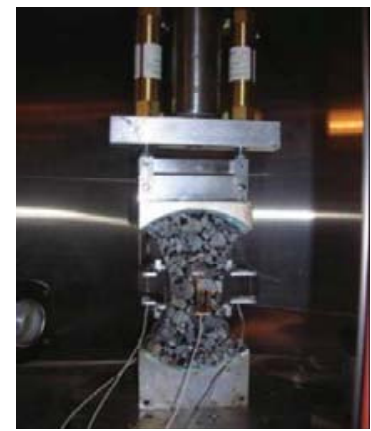

(b)

FIGURE 3 Two other testing configurations proposed at the University of Florida: (a) IDT with a hole and (b) DBDT test. 
prediction of fatigue cracking, reflective cracking, and low-temperature cracking. The rate of crack propagation is determined from the amplitude of the stress intensity factor at each cycle. In the case of fatigue cracking, the amplitude of the stress intensity factor at each cycle is related to mechanical loading, while the change in temperature during 1 day is taken as one loading cycle for the modeling of thermal cracking (e.g., the TC model). The number of cycles required to propagate a crack from an initial length to a final length is simply calculated by a numerical integration.

If the material is linear elastic such as asphaltic materials subject to very low temperature conditions, the conditions at the crack tip are uniquely defined by the stress intensity factor $(K)$, since the size of the fracture process zone is small enough. However, under certain conditions where the material is inelastic, which is typically observed from asphalt materials' behavior at intermediate temperatures or higher, the size of the fracture process zone is not small; therefore, the $K$-dominant LEFM approach cannot provide a good approximation of the complete stress field. For viscoelastic materials including asphalt concrete, the generalized $J$-integral has been employed by researchers to characterize crack propagation accompanied by large-scale yielding (35-38).

The second modeling approach based on fracture mechanics involves the development of analytical (or closed-form) expressions that describe the behavior of a pavement system with relatively simple geometry and loading conditions as presented in several studies (39-46). The advantages of the analytical approach are as follows: $(a)$ the expressions can be used to obtain instantaneous results (in a spreadsheet, for instance), and thus, rapid sensitivity analyses can be performed over ranges of model inputs or parameters and $(b)$ the solutions are exact, or have known accuracy over their entire stated validity range, and therefore can provide reliable benchmarks for more complex numerical models. The main disadvantage of this modeling approach is that the development of solutions becomes exceedingly complicated or mostly impossible with increasing complexity of model geometry, material complexity, and other complex model inputs (load conditions, interfaces between layers, temperature gradients, etc.). Therefore, realistic fracture problems that roadway engineers face cannot be solved through analytical approaches. For complex problems, approximate numerical models or simulations are required.

Due to the clear limitations to the analytical approaches, numerical models have mostly been attempted by researchers for more complex (but realistic) problems. The numerical method typically involves the use of the finite element modeling (FEM) or discrete element modeling (DEM) technique to provide a numerical estimation of the structural response and/or distress. The main advantage of this approach is the ability to handle complex model geometry, complex material properties, and complex boundary conditions (frictional sliding, complex tire loads, temperature gradients that change with time, and existing and/or developing cracks and discontinuities). While this approach clearly provides a means for developing realistic models that can lead to insights about cracking mechanisms and key factors, the disadvantages of this approach are as follows: $(a)$ development and proper interpretation of the model require a highly trained analyst, and/or considerable work is needed to develop a non-proprietary user-friendly model for general use; $(b)$ model convergence is not always guaranteed due to some numerical instability; and $(c)$ the computational time may be excessive for complex problems, thereby limiting the number of cases that can be routinely considered. However, considering the steady growth of computing power and technologies in the future, the issue related to the computational efficiency may not be a significant obstacle. 
One of approaches that benefited from computational technology is the cohesive zone (CZ) modeling approach. The CZ modeling approach has received increasing attention from the asphalt mechanics community. This is because this approach is useful and powerful for modeling both brittle failure and ductile failure, which are frequently observed in asphalt mixtures due to the wide range of service temperatures and loading rates to which asphalt is subjected. The CZ modeling approach in asphalt materials and flexible pavements was first employed by Jeng and his colleagues $(47,48)$ to model crack resistance and propagation in asphalt pavement overlays. As mentioned earlier, traditional LEFM approaches based on stress intensity factors or strain energy release rates are not valid when the crack tip is subjected to certain levels of plastic yielding, which are frequently observed from asphalt mixtures. Furthermore, most of the traditional LEFM approaches assume the existence of infinitely sharp crack tips leading to stress singularities preceding the crack tips. However, in actual materials (rather than in the conceptual situations), neither the sharpness of the crack nor the stress singularity of the crack tip is often observed; therefore, an alternative approach is necessary for a more appropriate fracture characterization. As an alternative, CZ modeling is a well-established way to model crack development in monolithic and composite materials not only because this modeling approach removes the stress singularity at the crack tip, but also because this approach provides a powerful and efficient tool that can be easily implemented in various computational methods such as FEM and DEM. Moreover, the $\mathrm{CZ}$ approach can model cracks along bimaterial interfaces (such as aggregate-binder interfaces or interfaces between layers in pavements) that are often considered weak zones susceptible to cracking. Typical elastic fracture mechanics theories are limited to modeling damage evolution due to crack growth along bimaterial interfaces.

CZ models regard fracture as a gradual phenomenon in which separation takes place across an extended crack tip, or a cohesive zone (fracture process zone) where fracture is resisted by cohesive tractions. The $\mathrm{CZ}$ model effectively describes the material resistance when material elements are being displaced. In other words, the cohesive zone model describes the relationship at any material point between its capacity to transfer load (traction, $T$ ) and potential opening (displacement jump, $\Delta$ ) due to damage or cracking. Figure 4 illustrates the process zone, defined herein as the distance between a cohesive crack tip where the traction is maximum $\left(\sigma_{\max }\right)$ and a physical crack tip where a traction-free region develops. Therefore, the process zone describes the region between the point of no damage (full load-carrying capacity) and the point of complete failure (no load-bearing capacity). Along this zone, crack nucleation, initiation, and propagation behavior such as microcracking, crack bridging, crack branching, and other complex non-linear damage effects occur. Figure 4 shows a schematic illustration of the relation between displacement jump and the traction along the process zone. The cohesive surfaces are joined together by a cohesive traction, which varies depending upon the displacement jump across the crack faces. As the displacement jump increases, the traction first increases, reaches a maximum, and finally decays to zero. This softening relationship can be developed due to fundamental fracture properties of asphalt mixtures such as the material strength, a critical displacement $(\delta)$, and cohesive fracture energy.

Recently, the $\mathrm{CZ}$ modeling concept has been actively implemented in the modeling of asphalt concrete particularly to simulate fracture with the consideration of the bulk material viscoelasticity. Examples of research efforts that consider the viscoelasticity of the bulk material in asphalt mixtures are presented in various studies (49-56). More particularly, researchers at the University of Nebraska-Lincoln have incorporated the cohesive zone models into a microstructure computational modeling framework that considers mixture heterogeneity 


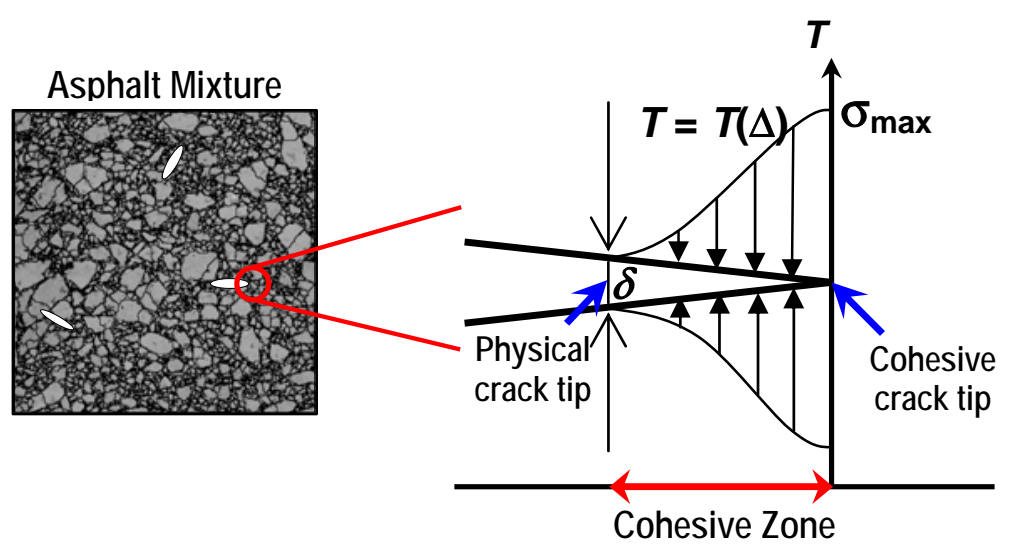

FIGURE 4 Cohesive zone and its schematic traction $(T)-$ displacement $(\Delta)$ relation.

$(51,52,55,56)$. The approach is based on the finite element modeling of mixture microstructure. Individual mixture components (i.e., asphalt binder or matrix phase subject to cracking and coarse aggregates) are separately modeled with their material properties measured from laboratory tests. The computational modeling approach incorporated with the mixture microstructure and the $\mathrm{CZ}$ fracture produces great benefits in the sense that this approach requires only fundamental properties of mixture constituents for the simulation, which results in considerable savings in both time and cost because the model can significantly reduce timeconsuming and expensive laboratory performance tests of mixture samples. A successfully developed model can be an efficient analysis-design tool in that performance of any macroscopic mixture can be predicted if the properties of the mixture constituents are known.

The CZ model can also be applied to fracture simulations of pavement structures. Baek and Al-Qadi (57) used the three-dimensional finite element method and the cohesive zone model to investigate the reflective cracking mechanisms in HMA overlays and the ability of the steel reinforcement netting interlayer to retard reflective cracking. The study found that steel reinforcement netting placed between the HMA overlay and existing cement concrete pavement significantly delays reflective crack initiation. Another recent study was performed by Kim and Buttlar (58), who employed the CZ model implemented in the FEM to investigate the lowtemperature fracture behavior of airport pavements. The authors demonstrated that the finite element pavement fracture models could successfully predict the progressive crack behavior of asphalt pavements under critical temperature and heavy aircraft gear loading conditions.

As clearly indicated from the numerous efforts introduced herein, the $\mathrm{CZ}$ approach can be used to model various fracture-related events in many different asphaltic materials, mixtures, and structures due to its excellent flexibility and compatibility with the commonly used numerical techniques: FEM and DEM.

\section{CONCLUDING REMARKS: CHALLENGES AND FUTURE DIRECTIONS}

In the past several decades, pavement researchers have performed extensive studies to better understand the mechanism of various forms of cracking and to develop new test procedures and 
prediction models to improve asphalt pavement performance. One of the most notable trends is that more and more researchers rely on fundamental-based fracture tests to evaluate cracking resistance in a more accurate manner. Clearly, significant advances have been made over the past decade in the development of asphalt material fracture tests, such as the DC(T) (22) and the SCB test (31). These tests have been found to be vastly superior to distinguish between mixtures with different mixture ingredients.

Along with the use of fundamental fracture tests, the community has been interested in the use or development of better cracking models. Empirical models, typically developed through regression analyses of field data, are useful in identifying parameters that affect cracking; however, they are limited to the data set on which they were based, and they do not fully explain the cracking phenomenon at a fundamental level. Any extrapolation outside this data set may result in unreasonable predictions. Conversely, mechanics-based models rely on advanced mechanistic theories in describing the cracking process. Although the mechanistic cracking models are computationally more complex, they are based upon fundamental materials characteristics and properties; these models can provide more accurate predictions and are not limited to specific cases. New fracture models, such as the cohesive zone model, are now available for asphalt concrete and can be incorporated with powerful numerical techniques to capture the combined effects of traffic and climate on crack initiation and propagation in asphalt pavements. These models directly utilize laboratory fracture test data. These tools represent the cutting edge and, if deemed useful, could be feasibly implemented as a replacement for the fracture engine in the pavement design guide.

In fact, two recent NCHRP projects, the 1-41 related to reflective cracks and the 1-42A on top-down cracking in asphalt pavements, exactly intend to reinforce the MEPDG. The primary objectives of both research efforts are to better account for the effects of those cracking distresses on pavement performance and, more importantly, to identify or develop mechanisticbased models for use in mechanistic-empirical procedures for the analysis and design of HMA pavements. A transportation pooled-fund study (59) that has recently been completed by researchers in northern U.S. states (Minnesota, Illinois, Wisconsin, and Iowa) is another good example of the research effort on the development of advanced fracture test methods and crack models. Researchers studied low-temperature cracking in asphaltic pavements through a comprehensive investigation that included experimental tests (both traditional and new protocols), test data analyses (laboratory-prepared specimens and field samples from pavements), and mechanistic fracture modeling for both mixture level and pavement scale.

Another recent significant effort is the asphalt research consortium, which is composed of several research groups (i.e., the Western Research Institute, Texas A\&M University, the University of Wisconsin-Madison, the University of Nevada-Reno, and Advanced Asphalt Technologies). A number of sub-tasks in the consortium effort are closely related to the development of new testing protocols and prediction models that can be implemented in practice. Researchers have not only targeted to meet scientific aspects by considering materials fundamentals and mechanics but also intended to deliver practical tools that can be readily employed by engineers and practitioners. Particular focuses related to fracture include the cracking characterization of asphaltic materials considering adhesive-cohesive bond strengths of mixture components, inelasticity of materials, effects of moisture, chemical aging, and damage recovery due to crack healing and performance prediction models such as the $\mathrm{CZ}$ fracture model $(55,56,60,61)$ and the multiscale model $(62,63)$. 
In spite of the great promise and potential of the mechanistic approaches based on fracture mechanics, a number of challenges need to be overcome in order to move the outcomes of the research efforts into practice. There is little understanding of the relationships between the conventional material properties and the fracture mechanics properties. There is no test method that can comprehensively define fracture properties of asphalt materials that are subjected to various environmental conditions (temperatures and moisture) and loading conditions. At the current stage, no fracture model has been fully validated yet.

The model for the next generation should appropriately address the current modeling challenges such as material inelasticity, nonlinear damage evolution, mixture heterogeneity, microstructure characteristics, and the multiscale-multiphysics phenomenon. In these endeavors, the numerical solutions (and models) will serve as useful tools given the steady growth expected in computational efficiency for the next decades. The success of the next-generation performance prediction depends on the availability and quality of the models and test methods that provide model inputs.

\section{REFERENCES}

1. NCHRP. Guide for Mechanistic-Empirical Design of New and Rehabilitated Pavement Structures. Project 1-37A. National Cooperative Highway Research Program, Transportation Research Board of the National Academies, Washington, D.C., 2004.

2. Paris, P. C., and E. Erdogan. A Critical Analysis of Crack Propagation Laws. Journal of Basic Engineering, Series D, Vol. 85, 1963, pp. 528-883.

3. Majidzadeh, K., E. M. Kaufmann, and D. V. Ramsamooj. Application of Fracture Mechanics in the Analysis of Pavement Fatigue. Proc., Association of Asphalt Pavement Technologists, Vol. 40, 1971, pp. 227-246.

4. ASTM E399-90. Plane-Strain Fracture Toughness for Metallic Materials. Annual Book of ASTM Standards, Vol. 03.01, 2002.

5. Lee, N. K., and S. A. M. Hesp. Low Temperature Fracture Toughness of Polyethylene-Modified Asphalt Binders. In Transportation Research Record 1436,TRB, National Research Council, Washington, D.C., 1994, pp. 54-59.

6. Lee, N. K., G. R. Morrison, and S. A. M. Hesp. Low Temperature Fracture of Poluethylene-Modified Asphalt Binders and Asphalt Concrete Mixes. Journal of the Association of Asphalt Paving Technologists, Vol. 64, 1995, pp. 534-574.

7. Dongre, R., M. G. Sharma, and D. A. Anderson. Development of Fracture Criterion for Asphalt Mixtures at Low Temperatures. In Transportation Research Record 1228, TRB, National Research Council, Washington, D.C., 1989, pp. 94-105.

8. Anderson, D. A., L. Champion-Lapalu, M. O. Marasteanu, Y. M. LeHir, J. P. Planche, and D. Martin. Low-Temperature Thermal Cracking of Asphalt Binders as Ranked by Strength and Fracture Properties. In Transportation Research Record: Journal of the Transportation Research Board, No. 1766, Transportation Research Board of the National Academies, Washington, D.C., 2001, pp. 1-6.

9. Olard, F., and H. Di Benedetto. Fracture Toughness and Fracture Energy of Bituminous Binders at Low Temperatures. Proc., 5th RILEM International Conference on Cracking in Pavements, 2004, Limoges, France.

10. Li, X., and M. O. Marasteanu. Evaluation of the Low Temperature Fracture Resistance of Asphalt Mixtures Using the Semi-Circular Bend Test. Journal of the Association of Asphalt Paving Technologists, Vol. 73, 2004, pp. 401-426.

11. Andriescu, A., S. A. M. Hesp, and J. S. Youtcheff. On the Essential and Plastic Works of Ductile 
Fracture in Asphalt Binders. Presented at 83rd Annual Meeting of the Transportation Research Board, Washington, D.C., 2004.

12. Cotterell, B., and J. K. Reddel. The Essential Work of Plane Stress Ductile Fracture. International Journal of Fracture, Vol. 13, No. 3, 1977, pp. 267-277.

13. Roy, S. D., and S. A. M. Hesp. Low-Temperature Binder Specification Development: Thermal Stress Restrained Specimen Testing of Asphalt Binders and Mixtures. Presented at 80th Annual Meeting of the Transportation Research Board, Washington, D.C., 2001.

14. Zofka, A., and M. Marasteanu. Development of Double Edge Notched Tension (DENT) Test for Asphalt Binders. Journal of Testing and Evaluation, Vol. 35, No. 3, 2007, pp. 259-265.

15. Gauthier, G. G., and D. A. Anderson. Fracture Mechanics and Asphalt Binders. International Journal of Road Materials and Pavement Design, Vol. 7, 2006, pp. 9-35.

16. Ramsamooj, D. Prediction of Fatigue Life of Asphalt Concrete Beams for Fracture Tests. Journal of Testing and Evaluation, Vol. 19, No. 3, 1991, pp. 231-239.

17. Mobasher, B., M. S. Mamlouk, and H.-M. Lin. Evaluation of Crack Propagation Properties of Asphalt Mixtures. Journal of Transportation Engineering, Vol. 123, No. 5, 1997, pp. 405-413.

18. Hossain, M., S. Swartz, and E. Hoque. Fracture and Tensile Characteristics of Asphalt-Rubber Concrete. Journal of Materials in Civil Engineering, Vol. 11, No. 4, 1999, pp. 287-294.

19. Wagoner, M. P., W. G. Buttlar, and G. H. Paulino. Development of a Single-Edge Notched Beam Test for Asphalt Concrete Mixtures. Journal of Testing and Evaluation, Vol. 33, No. 6, 2005, pp. 452-460.

20. Wagoner, M. P., W. G. Buttlar, and G. H. Paulino. Disk-Shaped Compact Tension Test for Asphalt Concrete Fracture. Society for Experimental Mechanics, Vol. 45, No. 3, 2005, pp. 270-277.

21. Wagoner, M. P., W. G. Buttlar, G. H. Paulino, and P. Blankenship. Investigation of the Fracture Resistance of Hot-Mix Asphalt Concrete Using a Disk-Shaped Compact Tension Test. In Transportation Research Record: Journal of the Transportation Research Board, No. 1929, Transportation Research Board of the National Academies, Washington, D.C., 2005, pp. 183192.

22. ASTM D7313-07a. Standard Test Method for Determining Fracture Energy of Asphalt-Aggregate Mixtures Using the Disk-Shaped Compact Tension Geometry. Annual Book of ASTM Standards, Vol. 04.03, American Society for Testing and Materials, Philadelphia, Pa., 2007.

23. Basham, K. D., K. P. Chong, and A. P. Boseri. A New Development in Devising Tension-Softening Curves for Brittle Materials. Proc., 9th International Conference on Experimental Mechanics, Copenhagen, Denmark, 1990, pp. 1423-1432.

24. Khalid, H. A., and I. Artamendi. Measurement and Effective Evaluation of Crack Growth in Asphalt Mixtures. Proc., 6th RILEM International Conference on Cracking in Pavements, Chicago, Ill., 2008, pp. 417-425.

25. Mohammad, L. N., and M. D. Kabir. Evaluation of Fracture Properties of Hot Mix Asphalt. Proc., 6th RILEM International Conference on Cracking in Pavements, Chicago, Ill., 2008, pp. 427-436.

26. van Rooijen, R. C., and A. H. de Bondt. Crack Propagation Performance Evaluation of Asphaltic Mixes Using a New Procedure Based on Cyclic Semi-Circular Bending Tests. Proc., 6th RILEM International Conference on Cracking in Pavements, Chicago, Ill., 2008, pp. 437-446.

27. Molenaar, J. M. M., and A. A. A. Molenaar. Fracture Toughness of Asphalt in the Semi-Circular Bend Test. Proc., 2nd Eurasphalt and Eurobitume Congress, Barcelona, Spain, 2000.

28. Li, X., M. O. Marasteanu, S. Dai, and E. Lukanen. Prediction of Low Temperature Crack Spacing in Asphalt Pavements. Proc., 7th International Conference on the Bearing Capacity of Roads, Railways, and Airfields, Trondheim, Norway, 2005.

29. Li, X. Investigation of the Fracture Resistance of Asphalt Mixtures at Low Temperature with a Semi Circular Bend (SCB) Test. Ph.D. dissertation. University of Minnesota, Minneapolis, 2005.

30. Chong, K. P., and M. D. Kuruppu. New Specimens for Mixed Mode Fracture Investigations of Geomaterials. Engineering Fracture Mechanics, Vol. 30, No. 5, 1988, pp. 701-712.

31. Standard Method of Test for Determining the Fracture Energy of Asphalt Mixtures Using the Semi 
Circular Bend Geometry. AASHTO, in press.

32. Roque, R., Z. Zhang, and B. Sankar. Determination of Crack Growth Rate Parameters of Asphalt Mixtures Using the Superpave IDT. Journal of the Association of Asphalt Paving Technologists, Vol. 68, 1999, pp. 404-433.

33. Roque, R., B. Birgisson, B. Sangpetngam, and A. Zhang. Hot Mix Asphalt Fracture Mechanics: A Fundamental Crack Growth Law for Asphalt Mixtures. Journal of the Association of Asphalt Paving Technologists, Vol. 70, 2001, pp. 816-827.

34. Koh, C., G. Lopp, and R. Roque. Development of a Dog-Bone Direct Tension Test (DBDT) for Asphalt Concrete. Proc., 7th International RILEM Symposium ATCBM09 on Advanced Testing and Characterization of Bituminous Materials, 2009, pp. 585-596.

35. Schapery, R. A. A Theory of Crack Initiation and Growth in Viscoelastic Media: Theoretical Development. International Journal of Fracture, Vol. 11, 1975, pp. 141-159.

36. Schapery, R. A. Correspondence Principles and a Generalized J Integral for Large Deformation and Fracture Analysis of Viscoelastic Media. International Journal of Fracture, Vol. 25, 1984, pp. 195223.

37. Lytton, R. L., J. Uzan, E. G. Fernando, R. Roque, D. Hiltunen, and S. M. Stoffels. Development and Validation of Performance Prediction Models and Specifications for Asphalt Binders and Paving Mixes. Research Report SHRP-A-357, TRB, National Research Council, Washington, D.C., 1993.

38. K. Haidong, H. J. Lee, G. Zi, and S. Mun. Application of Generalized J Integral to Crack Propagation Modeling of Asphalt Concrete under Repeated Loading. In Transportation Research Record: Journal of the Transportation Research Board, No. 2127, Transportation Research Board of the National Academies, Washington, D.C., 2009, pp. 72-81.

39. Timm, D. H., B. B. Guzina, and V. R. Voller. Prediction of Thermal Crack Spacing. International Journal of Solids and Structures, Vol. 40, 2003, pp. 125-142.

40. Shen, W., and D. J. Kirkner. Distributed Thermal Cracking of AC Pavement with Frictional Constraint. Journal of Engineering Mechanics, Vol. 125, No. 5, 1999, pp. 554-560.

41. Chen, G., and G. Baker. Analytical Model for Predication of Crack Spacing Due to Shrinkage in Concrete Pavements. Journal of Structural Engineering, Vol. 130, 2004, pp. 1529-1533.

42. Beuth, J. L. Cracking of Thin Bonded Films in Residual Tension. International Journal of Solids and Structures, Vol. 29, 1992, pp. 1657-1675.

43. Hong, A. P., Y. N. Li, and Z. P. Bažant. Theory of Crack Spacing in Concrete Pavements. Journal of Engineering Mechanics, Vol. 123, 1997, pp. 267-275.

44. Xia, Z. C., and J. W. Hutchinson. Crack Patterns in Thin Films. Journal of Mechanics and Physics of Solids, Vol. 48, 2000, pp. 1107-1131.

45. Shenoy, V. B., A. F. Schwartzman, and L. B. Freund. Crack Patterns in Brittle Thin Films. International Journal of Fracture, Vol. 109, 2001, pp. 29-45.

46. Yin, H. M., W. G. Buttlar, and G. H. Paulino. Low Temperature Cracking in Asphalt Overlays Bonded to Rigid Pavements. Proc., 6th RILEM International Conference on Cracking in Pavements, Chicago, Ill., 2008, pp. 683-692.

47. Jeng, Y. S., and J. D. Perng. Analysis of Crack Propagation in Asphalt Concrete Using Cohesive Crack Model. In Transportation Research Record 1317, TRB, National Research Council, Washington, D.C., 1991, pp. 90-99.

48. Jeng, Y. S., C. Liaw, and P. Liu. Analysis of Crack Resistance of Asphalt Concrete Overlays: A Fracture Mechanics Approach. In Transportation Research Record 1388,TRB, National Research Council, Washington, D.C., 1993, pp. 160-166.

49. Souza, F. V., J. B. Soares, D. H. Allen, and F. Evangelista. Model for Predicting Damage Evolution in Heterogeneous Viscoelastic Asphaltic Mixtures. In Transportation Research Record: Journal of the Transportation Research Board, No. 1891, Transportation Research Board of the National Academies, Washington, D.C., 2004, pp. 131-139.

50. Kim, Y. R., D. H. Allen, and D. N. Little. Damage-Induced Modeling of Asphalt Mixtures through Computational Micromechanics and Cohesive Zone Fracture. Journal of Materials in Civil 
Engineering, Vol. 17, No. 5, 2005, pp. 477-484.

51. Kim, Y. R., D. H. Allen, and D. N. Little. Computational Model to Predict Fatigue Damage Behavior of Asphalt Mixtures under Cyclic Loading. In Transportation Research Record: Journal of the Transportation Research Board, No. 1970, Transportation Research Board of the National Academies, Washington, D.C., 2006, pp. 196-206.

52. Kim, Y. R., D. H. Allen, and D. N. Little. Computational Constitutive Model for Predicting Nonlinear Viscoelastic Damage and Fracture Failure of Asphalt Concrete Mixtures. International Journal of Geomechanics, Vol. 7, No. 2, 2007, pp. 102-110.

53. Song, S. H., G. H. Paulino, and W. G. Buttlar. A Bilinear Cohesive Zone Model Tailored for Fracture of Asphalt Concrete Considering Viscoelastic Bulk Material. Engineering Fracture Mechanics, Vol. 73, No. 18, 2006, pp. 2829-2847.

54. Song, S. H., M. P. Wagoner, and G. H. Paulino. $\delta 25$ Crack Opening Displacement Parameter in Cohesive Zone Models: Experiments and Simulations in Asphalt Concrete. Fatigue and Fracture of Engineering Materials and Structures, Vol. 31, 2008, pp. 850-856.

55. Aragão, F. T., Y. R. Kim, J. Lee, and D. H. Allen. A Micromechanical Model for Heterogeneous Asphalt Concrete Mixtures Subjected to Fracture Failure. Journal of Materials in Civil Engineering, 2010.

56. Kim, Y., F. T. Aragão, D. H. Allen, and D. N. Little. Damage Modeling of Bituminous Mixtures Considering Mixture Microstructure, Viscoelasticity, and Cohesive Zone Fracture. Canadian Journal of Civil Engineering, 2010.

57. Baek, J., and I. L. Al-Qadi. Mechanism of Overlay Reinforcement to Retard Reflective Cracking under Moving Vehicular Loading. Proc., 6th RILEM International Conference on Cracking in Pavements, Chicago, Ill., 2008, pp. 563-573.

58. Kim, H., and W. G. Buttlar. Finite Element Cohesive Fracture Modeling of Airport Pavements at Low Temperatures. Cold Regions Science and Technology, Vol. 57, 2009, pp. 123-130.

59. Marasteanu, M., A. Zofka, M. Turos, X. Li, R. Velasquez, X. Li, W. Buttlar, G. Paulino, A. Braham, E. Dave, J. Ojo, H. Bahia, C. Williams, J. Bausano, A. Kvasnak, A. Gallistel, and J. McGraw. Investigation of Low Temperature Cracking in Asphalt Pavements-A Transportation Pooled Fund Study. Research Report MN/RC 2007-43. Minnesota Department of Transportation, 2007.

60. Caro, S., E. Masad, A. Bhasin, and D. Little. Micromechanical Modeling of the Influence of Material Properties on Moisture-Induced Damage in Asphalt Mixtures. Construction and Building Materials, Vol. 24, No. 7, 2010, pp. 1184-1192.

61. Caro, S., E. Masad, A. Bhasin, and D. Little. Coupled Micromechanical Model of Moisture-Induced Damage in Asphalt Mixtures. Journal of Materials in Civil Engineering, Vol. 22, No. 4, 2010, pp. 380-388.

62. Soares, R. F., Y. Kim, and D. H. Allen. Multiscale Computational Modeling for Predicting Evolution of Damage in Asphaltic Pavements. Proc., 6th RILEM International Conference on Cracking in Pavements, Chicago, Ill., 2008, pp. 599-608.

63. Lutif, J. E. S., F. V. Souza, Y. Kim, J. B. Soares, and D. H. Allen. Multiscale Modeling to Predict the Mechanical Behavior of Asphalt Mixtures. In Transportation Research Record: Journal of the Transportation Research Board, No. 2181, Transportation Research Board of the National Academies, 2010, pp. 28-35. 


\title{
Viscoelastic Continuum Damage Model
}

\author{
Y. RICHARD KIM \\ North Carolina State University
}

$\mathrm{T}$

his section presents a constitutive model that can describe the deformation behavior of asphalt-aggregate mixtures in tension under complex loading conditions. The modeling strategy adopted is based on $(a)$ the elastic and viscoelastic behavior of asphalt concrete using the elastic-viscoelastic correspondence principle based on pseudostrain; $(b)$ the effect of microcracking on the constitutive behavior using continuum damage mechanics; $(c)$ the plastic and viscoplastic behavior using a time- and stress-dependent viscoplastic model; and $(d)$ the effect of temperature on the constitutive behavior using the time-temperature superposition (TTS) principle with growing damage. The resulting models are integrated by the strain decomposition approach to form the viscoelastoplastic continuum damage (VEPCD) model. The VEPCD model has been validated under various loading and temperature conditions. Finally, the viscoelastic continuum damage (VECD) model is implemented into the finite element program (VECD-FEP++) to model the cracking behavior of asphalt pavements. Effects of microdamage healing, aging, viscoplastic strain, and climate on the fatigue performance of asphalt pavements are incorporated into the current version of the VECD-FEP++. Implementation of the full VEPCD model into the finite element program is currently ongoing at North Carolina State University.

One of the major findings that form the basis of the VEPCD model is that the timetemperature superposition principle holds true even when asphalt concrete is significantly damaged. This principle was proven valid both in tension $(1,2)$ and in compression $(3-5)$ for unmodified and modified asphalt mixtures. In other words, the response of a mixture with growing damage at one temperature can be predicted by shifting its response at another temperature using the time-temperature shift factor determined from the linear viscoelastic dynamic modulus tests.

Another significant finding in the VEPCD model is that a single damage characteristic curve exists regardless of loading rate or loading frequency and load type (monotonic versus cyclic) when the testing conditions are such that only elastic and viscoelastic behaviors are present (e.g., low temperatures or fast loading rates at intermediate temperatures). By combining the findings of the damage characteristic curve and TTS, it has been demonstrated $(\sigma)$ that the damage characteristic curve obtained from a simple monotonic constant crosshead rate test (i.e., a strength test) at a single temperature can be used to predict the cyclic behavior of the same mixture in the fatigue tests at different temperatures. This prediction algorithm has been proven to be successful using various WesTrack mixtures. Later, Underwood et al. (7) developed a simplified VECD modeling technique based on the analysis of cyclic data. This technique allows the prediction of the fatigue lives of asphalt concrete at various strain-stress amplitudes under different temperatures using the dynamic modulus master curve and the cyclic fatigue data from a single temperature and single stress or strain amplitude.

The major contribution of the TTS principle and the damage characteristic curve is the significant reduction in testing requirements. The model allows the prediction of the material's behavior at any temperature from a test result obtained from a single temperature and the timetemperature shift factors obtained from temperature sweep complex modulus tests as long as the 
viscoplastic response is minimal in the stress-strain behavior in each cycle. That is, one can perform a simple strength test or a cyclic test at a single temperature and dynamic modulus tests at multiple temperatures and predict the cyclic fatigue life of the mix under different testing conditions (i.e., loading frequencies, stress-strain amplitudes, and temperatures).

As the temperature increases or the rate of loading decreases, the viscoplastic and plastic components become significant in modeling the stress-strain behavior of hot-mix asphalt (HMA). The first step in modeling the viscoplastic behavior is to separate the viscoplastic response from the viscoelastic response, a task achieved when the loading and unloading are applied as a step function (i.e., the creep and recovery test). The creep and recovery test is relatively easy to conduct in compression; however, in tension maintaining the zero load on the specimen becomes challenging because the specimen is glued to the end plates, which are rigidly connected to the ram and the load cell. In tension, the viscoplastic strain is determined by subtracting the viscoelastic strain from the total strain measured from the monotonic constant crosshead rate test. The strain hardening theory is then used to model the viscoplastic strains, which are expressed as a function of loading time and stress.

The strain decomposition principle suggests that the total strain is expressed as the sum of the viscoelastic and viscoplastic strains. Using this principle, the VECD model and the viscoplastic model are combined to form the VEPCD model. The VEPCD model in tension developed by Chehab et al. ( 8 ) is shown in the following equation:

$\varepsilon=\varepsilon_{v e}+\varepsilon_{v p}=E_{R} \int_{0}^{\xi} D\left(\xi-\xi^{\prime}\right) \frac{d\left(\frac{\sigma}{c\left(\xi^{*}\right)}\right)}{d \xi^{\prime}} d \xi^{\prime}+\left(\frac{p+1}{Z}\right)^{1 / p+1}\left(\int_{0}^{\xi} \sigma^{q} d \xi\right)^{1 / p+1}$

where

$$
\begin{aligned}
\varepsilon_{\mathrm{ve}} & =\text { viscoelastic strain; } \\
\varepsilon_{\mathrm{vp}} & =\text { viscoplastic strain; } \\
E_{R} & =\text { reference modulus; } \\
D(t) & =\text { creep compliance; } \\
t & =\text { physical time; } \\
\xi & =\text { reduced time; } \\
\xi^{\prime} & =\text { integration variable; } \\
C\left(S^{*}\right) & =\text { normalized pseudostiffness; } \\
S^{*} & =\text { damage parameter; and } \\
p, q, Z & =\text { material constants. }
\end{aligned}
$$

\section{MODELING APPROACH}

The VEPCD model adopts a stepwise approach, in which the experiment necessary for the model characterization is designed such that these strain components can be systematically evaluated from the simplest state to the state that includes more complex mechanisms. More specifically, the material's behavior in the simplest state [i.e., linear viscoelasticity (LVE) behavior without any cracking or permanent strain] is first modeled by the elastic-viscoelastic correspondence 
principle. Then, the effect of microcracking damage is modeled by applying continuum damage mechanics to the experimental data from low temperatures and high strain rates where the viscoplastic strain is minimal. The strain hardening viscoplastic model is applied to the experimental data at high temperatures and slow strain rates to develop the viscoplastic model. Finally, these models are combined with the TTS principle with growing damage to allow the prediction of the material's behavior at any temperature.

In the VEPCD model, the viscoelastic strain covers both LVEand the damage due to microcracking. The VECD model forms the basis for the viscoelastic strain. This model is based on two principles: the elastic-viscoelastic correspondence principle based on pseudostrain and the continuum damage mechanics-based work potential theory.

\section{Elastic-Viscoelastic Correspondence Principle}

The elastic-viscoelastic correspondence principle states that the stress-strain relationships of viscoelastic materials can be represented by elastic-like equations through the use of a simple conversion procedure. A well-known conversion procedure for linear viscoelastic materials is the Laplace transform. A more general correspondence principle was developed by Schapery (9), which introduces so-called pseudo variables.

Consider a stress-strain equation for linear viscoelastic materials,

$\sigma_{i j}=\int_{0}^{\xi} E_{i j k l}(\xi-\tau) \frac{\partial \varepsilon_{k l}}{\partial \tau} d \tau$

where

$\sigma_{i j}, \varepsilon_{k}=$ stress and strain tensors,

$E_{i j k l}(t)=$ the relaxation modulus matrix, $\xi=t / a_{T}=$ reduced time,

$t=$ physical time,

$a_{T}=$ the time-temperature shift factor, and

$\tau=$ the integration variable.

Equation 2 can be written as

$\sigma_{i j}=E_{R} \varepsilon_{k l}^{R} \quad$ or $\quad \varepsilon_{k l}^{R}=\frac{\sigma_{i j}}{E_{R}}$

if Equation 4 is defined as

$\varepsilon_{k l}^{R}=\frac{1}{E_{R}} \int_{0}^{\xi} E_{i j k l}(\xi-\tau) \frac{\partial \varepsilon_{k l}}{\partial \tau} d \tau$

where $E_{R}$ is termed the reference modulus, which is a constant and has the same dimension as the relaxation modulus, $E_{i j k l}(t)$. The usefulness of Equation 3 is that a correspondence can be found between Equation 3 and the linear elastic stress-strain relationship. That is, the equations in 
Equation 3 take the form of elastic stress-strain equations even though they are actually viscoelastic stress-strain equations. The $\varepsilon_{k l}^{R}$ is called the pseudostrain. The pseudostrain accounts for all the hereditary effects of the material through the convolution integral. If we take $E_{R}=1$ in Equation 4, pseudo strains are simply the linear viscoelastic stress response to a particular strain input. For the remainder of this section, $E_{R}$ is set to 1 .

These observations suggest that if the hysteretic behavior of asphalt concrete is due to LVEonly, the presentation of the hysteretic data in terms of stress and pseudostrain (instead of physical strain) would make the hysteretic behavior appear to be the same as linear elastic behavior. This observation is illustrated using the experimental data in Figure 1. Figure 1a shows the stress-strain behavior for controlled-stress cyclic loading within the material's LVE range (such as for a complex modulus test). Because the material is being tested in its LVE range, no damage is induced and the hysteretic behavior and accumulating strain are due to viscoelasticity only. Figure $1 b$ shows the same stress data plotted against the pseudostrains calculated from Equation 6 with $E_{R}=1$. As can be seen from Figure $1 b$, hysteretic behavior due to both loadingunloading and repetitive loading has disappeared using the pseudo strains. It is also noted that the stress-pseudostrain behavior in Figure $1 b$ is linear with a slope of 1 (i.e., following the line of equality).

This example demonstrates the benefit of using pseudostrain; that is, pseudostrain essentially accounts for the viscoelasticity of the material and reduces the viscoelastic problem into a corresponding elastic problem, making the modeling of the complex hysteretic behavior of asphalt concrete much easier. The results from experimental verification of the correspondence principle have been documented by Kim and Little (10), Kim et al. (11), and Lee and Kim (12, 13) using uniaxial monotonic and cyclic data of asphaltic materials under a wide range of test

Because the complex modulus tests are performed on a separate set of representative specimens for the mixture in question, the relaxation modulus determined from the complex modulus tests may not be the same as the one for specimens used in damage testing due to sample-to-sample variability. In that case, the initial pseudostiffness in Figure $1 b$ may not follow the line of equality (LOE). In order to minimize the effect of the sample-to-sample variability, the initial secant pseudostiffness, $I$, is introduced. Thus, the governing constitutive equation in uniaxial mode becomes

$$
\sigma=I \varepsilon^{R}
$$

where

$\varepsilon^{R}=\frac{1}{E_{R}} \int_{0}^{\xi} E(\xi-\tau) \frac{\partial \varepsilon}{\partial \tau} d \tau$

In most cases, the $I$ value remains between 0.9 and 1.1 . When the $I$ value is significantly out of this range, a re-examination of the data (both the relaxation modulus and test results) is necessary. 

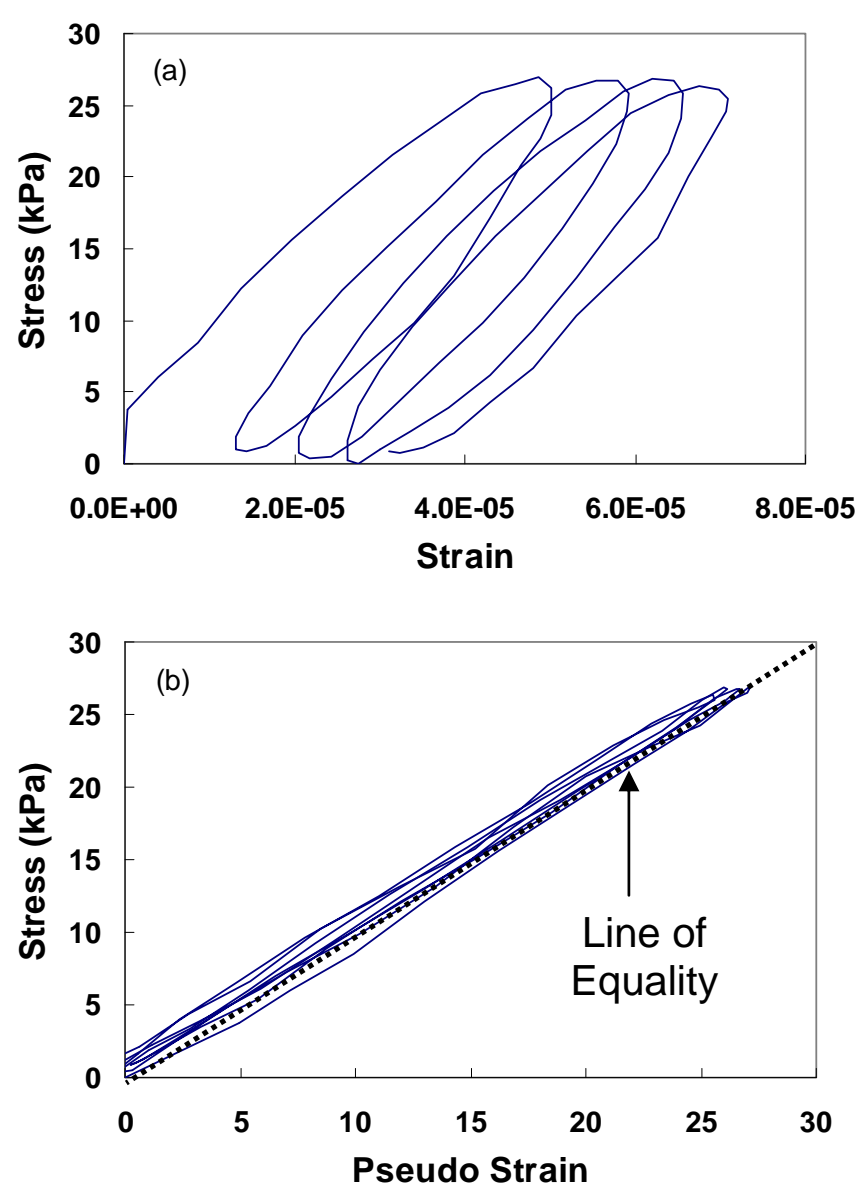

\section{FIGURE 1 (a) Stress-strain behavior for mixture under LVE cyclic loading and $(b)$ stress-pseudostrain behavior for the same data in $a$.}

\section{Work Potential Theory}

Figure $2 a$ shows typical stress-pseudostrain hysteresis loops at different numbers of cycles in the controlled-stress cyclic test. Relatively high stress amplitude is used to induce significant damage in the specimen. Unlike the negligible damage case seen in Figure $2 b$, change in the slope of each $\sigma-\varepsilon^{R}$ cycle (i.e., reduction in the pseudostiffness of the material) can be observed from this figure due to the damage incurred in the specimens.

The effect of damage on pseudostiffness can also be seen in the monotonic data shown in Figure $2 b$. In this figure, the stress-pseudostrain curves deviate from the LOE as damage grows. Also, the onset of this deviation occurs at different times as the rate of loading changes, indicating the presence of the rate-dependent damage mechanism.

Based on these observations, the following uniaxial versions of constitutive equations are presented for linear elastic and linear viscoelastic bodies with and without damage. They also show how models of different complexity may evolve from simpler ones. 
Elastic Body Without Damage

$\sigma=E \varepsilon$

Elastic Body With Damage

$\sigma=C\left(S_{m}\right) E \varepsilon$

Viscoelastic Body Without Damage

$\sigma=E_{R} \varepsilon^{R}$

Viscoelastic Body With Damage

$\sigma=C\left(S_{m}\right) E_{R} \varepsilon^{R}$

where $C\left(S_{m}\right)$ indicates that $C$ is a function of damage parameters, $S_{m}$. The function, $C\left(S_{m}\right)$, represents the changing stiffness of the material due to growing damage. Equation 10 results from Equations 7, 8, and 9. The form of Equation 10 is also supported by the observations made in Figure 2; i.e., the pseudostiffness changes as the damage grows. To determine an analytical representation of the damage function, $C$, the work potential theory, the continuum damage mechanics principle developed by Schapery (14), is adopted.

In studying the constitutive behavior of a material with damage, two general approaches are usually considered: a micromechanical approach and a continuum approach. In continuum damage mechanics, the damaged body can be viewed as a homogeneous continuum on a macroscopic scale, and the influence of damage is typically reflected in terms of reduction in stiffness or strength of the material. The state of damage can be quantified by a set of parameters often referred to as internal state variables or damage parameters in the context of thermodynamics of irreversible processes. The growth of damage is governed by an appropriate damage (or internal state) evolution law. The stiffness of the material, which varies with the extent of damage, is determined as a function of the internal state variables by fitting the theoretical model to available experimental data.

Finally, the work potential theory applied to viscoelastic media with the rate type damage evolution law is represented by the following three components for the uniaxial loading condition:

Pseudostrain Energy Density Function

$W^{R}=W^{R}\left(\varepsilon^{R}, S\right)$

Stress-Strain Relationship

$\sigma=\frac{\partial W^{R}}{\partial \varepsilon^{R}}$ 

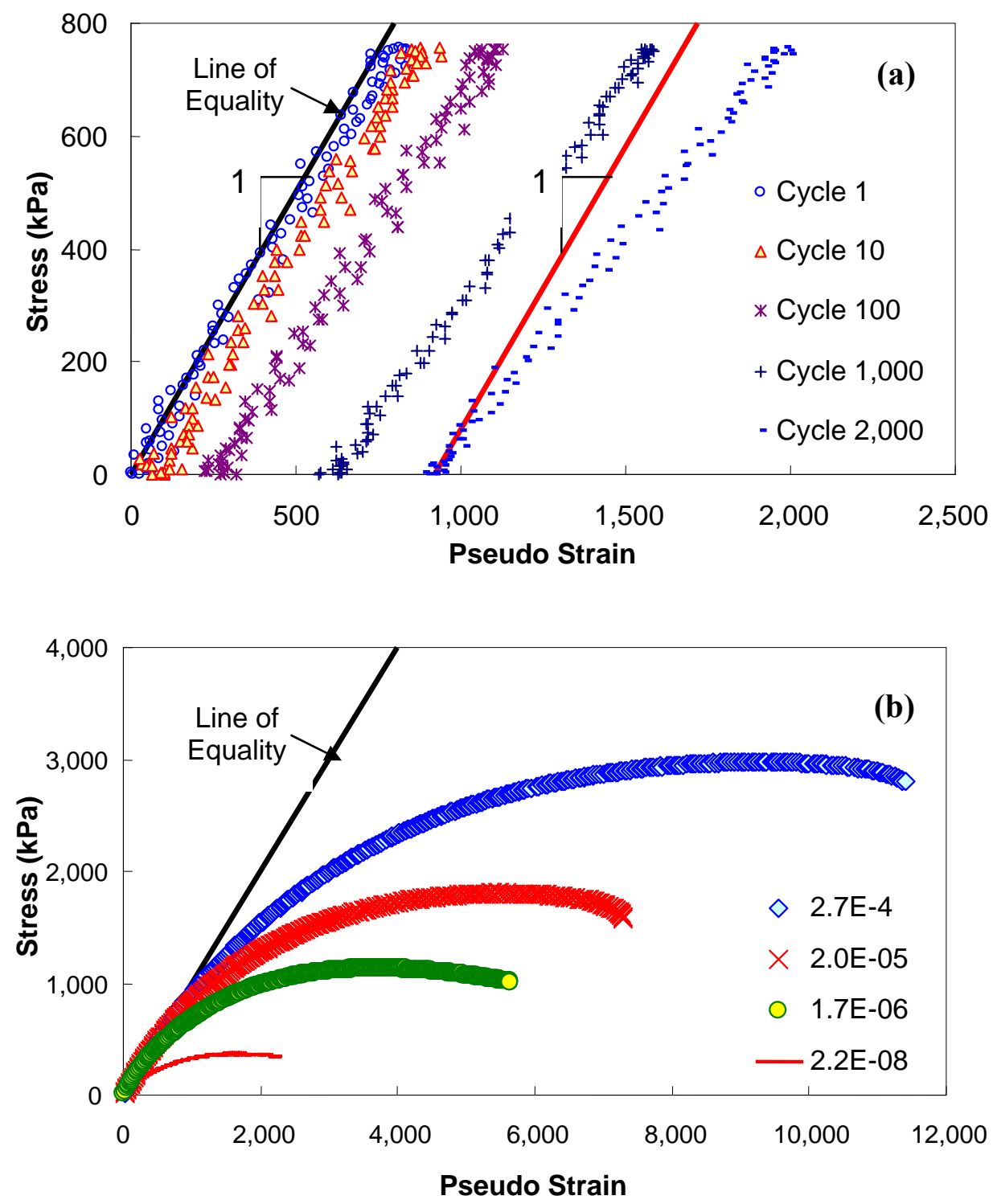

FIGURE 2 Stress-pseudostrain behavior of asphalt concrete in (a) controlled-stress cyclic test and $(b)$ constant-strain-rate monotonic test.

Damage Evolution Law

$\dot{S_{m}}=\left(-\frac{\partial W^{R}}{\partial S}\right)^{\alpha_{m}}$

Daniel and Kim (15) studied the relationship between damage parameter $(S)$ and the normalized pseudosecant modulus $(C)$ under varying loading conditions. The most significant finding from their study is that a unique damage characteristic relationship exists between $C$ and $S$, regardless of loading type (monotonic versus cyclic), loading rate, and stress-strain amplitude. In addition, the application of the TTS principle with growing damage to the $C$ versus $S$ relationships at varying temperatures yields the same damage characteristic curve in the reduced 
time scale. The only condition that must be met in order to produce the damage characteristic relationship is that the test temperature and loading rate combination must be such that only the elastic and viscoelastic behaviors prevail with negligible, if any, viscoplasticity. When the test temperature is too high or the loading rate is too slow, it was found that the $C$ versus $S$ curve deviates from the characteristic curve.

To ensure that the test temperature is low enough and the loading rate is fast enough not to induce any significant viscoplastic strains, the tests are performed at a low temperature (typically $5^{\circ} \mathrm{C}$ ) with varying loading rates. If the $C$ versus $S$ curves at different rates overlap to form a unique relationship, the combinations of the temperature and loading rate are sufficiently satisfactory to develop the damage characteristic relationship.

Finally, the VECD model is

$\sigma=C(S) \varepsilon^{R}$

or

$\varepsilon_{v e}=E_{R} \int_{0}^{\xi} D(\xi-\tau) \frac{d\left(\frac{\sigma}{C(S)}\right)}{d \tau} d \tau$

by converting Equation 14 to predict the viscoelastic strain. Note that $E_{R}$ in Equation 15 is set to one and that the initial secant pseudostiffness, $I$, is not used in Equation 14. $I$ is only necessary in calibrating the model using the experimental data from several replicate specimens.

The major advantage of the damage characteristic relationship is that it allows a reduction in testing requirements. Since the same relationship exists in monotonic and cyclic tests, the material behavior under cyclic loading can be predicted from the damage characteristic curve characterized from the much simpler monotonic tests. Daniel and Kim (15) have verified that this approach can predict the fatigue life of asphalt concrete within the sample-to-sample variation.

\section{MODEL VERIFICATION}

Underwood et al. (2) characterized the control and three modified mixtures [crumb rubber modified, Terpolymer modified, and styrene-butadiene-styrene (SBS) modified] from the FHWA Accelerated Loading Facility (ALF) experiments using the VEPCD technique. They used the random input loading history shown in Figure 3 to validate the VEPCD model. Note that the same loading input is used for each of the mixtures and that the test temperature is $25^{\circ} \mathrm{C}$. Figure 4 shows the measured and predicted responses, separated by component viscoplastic and viscoelastic damage, for the four FHWA ALF mixtures. An examination of these two figures shows that the measured and predicted behaviors closely agree. As the specimen approaches localization, the model tends to underpredict the measured data. 


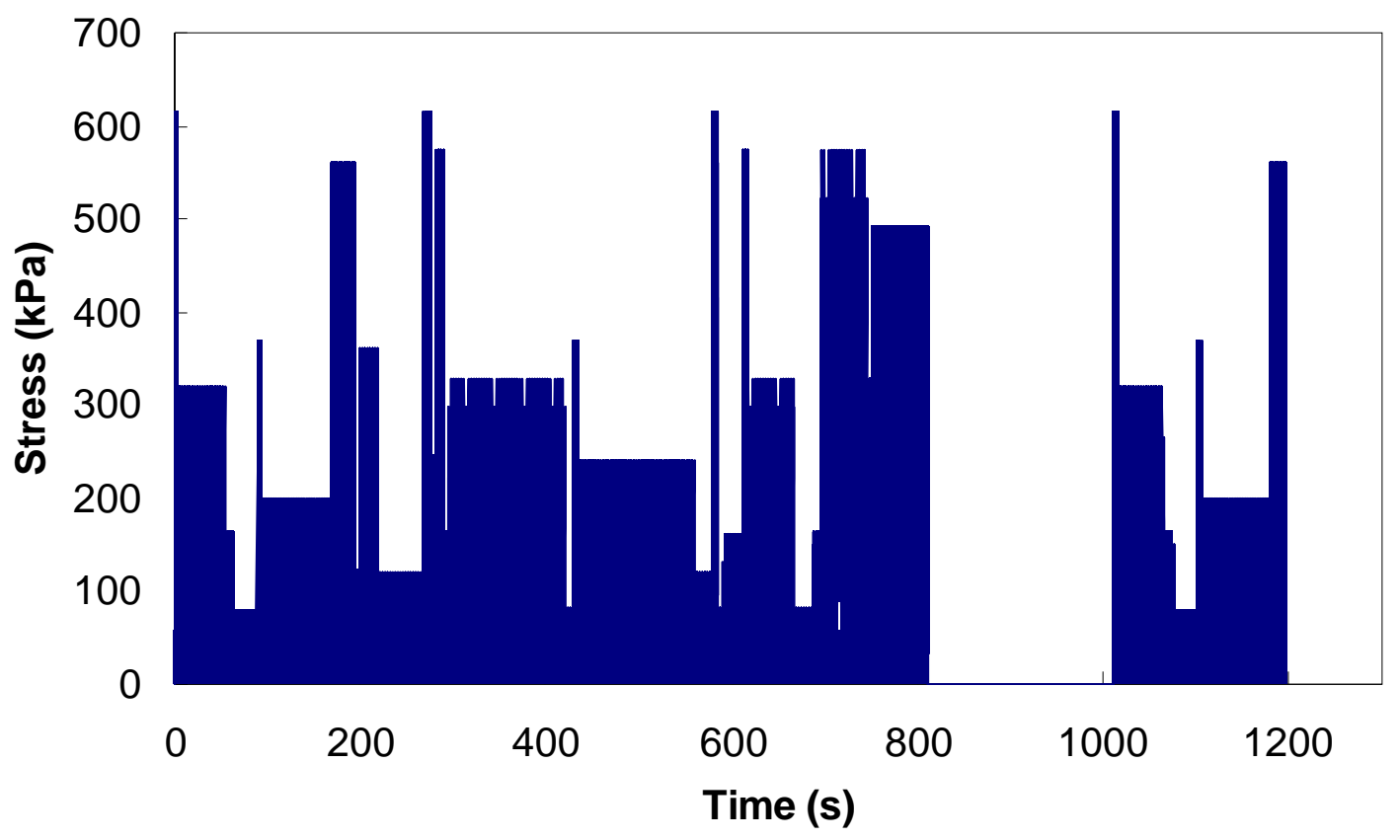

FIGURE 3 Input loading history for random loading tests.
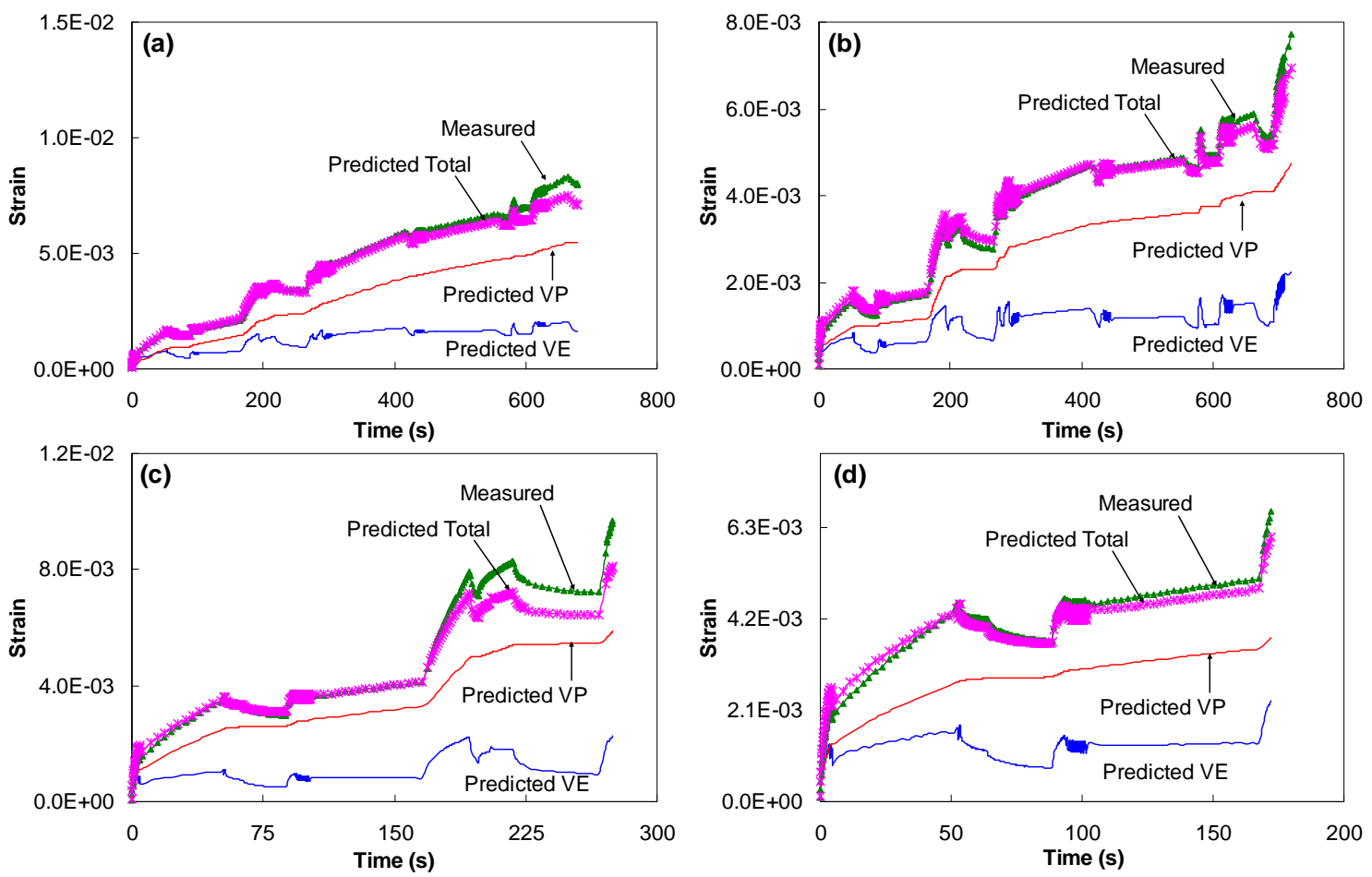

FIGURE 4 Random load prediction results for ALF mixtures:

(a) control, (b) CRTB, (c) SBS, and (d) terpolymer. 
As part of the NCHRP Project 9-19 efforts, the UVEPCD model has been applied to predict the response of HMA to temperature stress restrained specimen test (TSRST) testing. TSRST tests measure a material's resistance to thermal damage by cooling a restrained prism at a consistent rate. Theoretical aspects of this testing can be found elsewhere (10).

For this verification, testing was conducted at the FHWA Turner-Fairbanks Highway Research Center. The TSRST verification is particularly important because these tests were not used in the model development. Moreover, the stresses used in the TSRST tests are thermally induced, whereas mechanically induced stresses are used in the characterization process. Using specimen dimensions as well as the initial temperature and load in addition to cooling rates, predictions were made for the stress-time history, stress-temperature history, and stress, time, and temperature at failure. These responses were modeled according to three levels of complexity: ( $a$ ) LVE, $(b)$ VECD, and $(c)$ VEPCD. The predicted responses were compared against the measured values to determine the accuracy of each model. In the following, these comparisons are presented. For notational brevity, the thermal stress and strain are identified by $\sigma$ and $\varepsilon$, respectively.

Figure 5 shows the plots for the stresses predicted for the three cooling rates using the three models as a function of time. Also shown are the plots for the average measured stresses from all replicates tested at each rate. As apparent by visual inspection, the stresses predicted using the linear viscoelastic model are greater than the measured stresses, with the difference increasing as time increases and the cooling rate decreases. This discrepancy occurs because the linear viscoelastic model does not account for stress relaxation due to microcracking. For all cases, the degree of error between the VECD-predicted stresses and the measured stresses is much smaller than that for the linear viscoelastic case. Moreover, the error decreases with an increase in time and decrease in cooling rate. The VEPCD-predicted stresses match the measured stresses very well, with discrepancies being the greatest at the slowest cooling rate. From the comparison of the predicted stresses across conditions, it is evident that the VEPCD model yields the most accurate predictions.

The significant effect of the viscoplasticity on the thermal stress prediction at low temperatures, where the thermal cracking is of concern, should not be surprising, because the constitutive behavior of asphalt concrete is dependent not only on temperature but also on the rate of loading. Further, the typical cooling rates to which asphalt pavements are subjected in the northern United States range from $0.5^{\circ} \mathrm{C} / \mathrm{h}$ to $1^{\circ} \mathrm{C} / \mathrm{h}$, with a maximum of $2.7^{\circ} \mathrm{C} / \mathrm{h}$ in Canada (17). These rates are much slower than those used in this study, and therefore the inclusion of the viscoplastic model is expected to be as significant as, or more significant than, what is shown in this section.

Using strength mastercurves generated as part of the NCHRP Project 9-19 efforts, predictions are also made for the failure conditions of these tests. Once failure stress is determined, the corresponding time and temperature can be determined from the cooling rate. Figure 6 presents the comparison of the TSRST parameters. In general, the predicted values are in good agreement with the measured ones. 


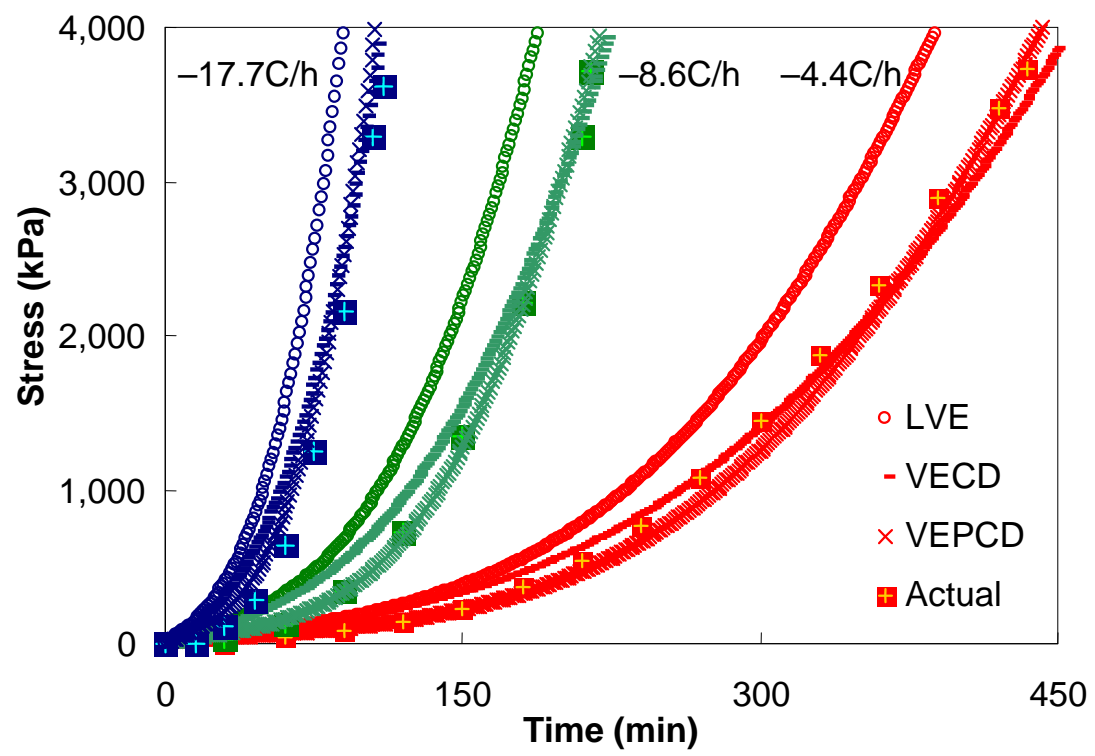

FIGURE 5 Average measured and predicted stress histories for different material models and cooling rates.
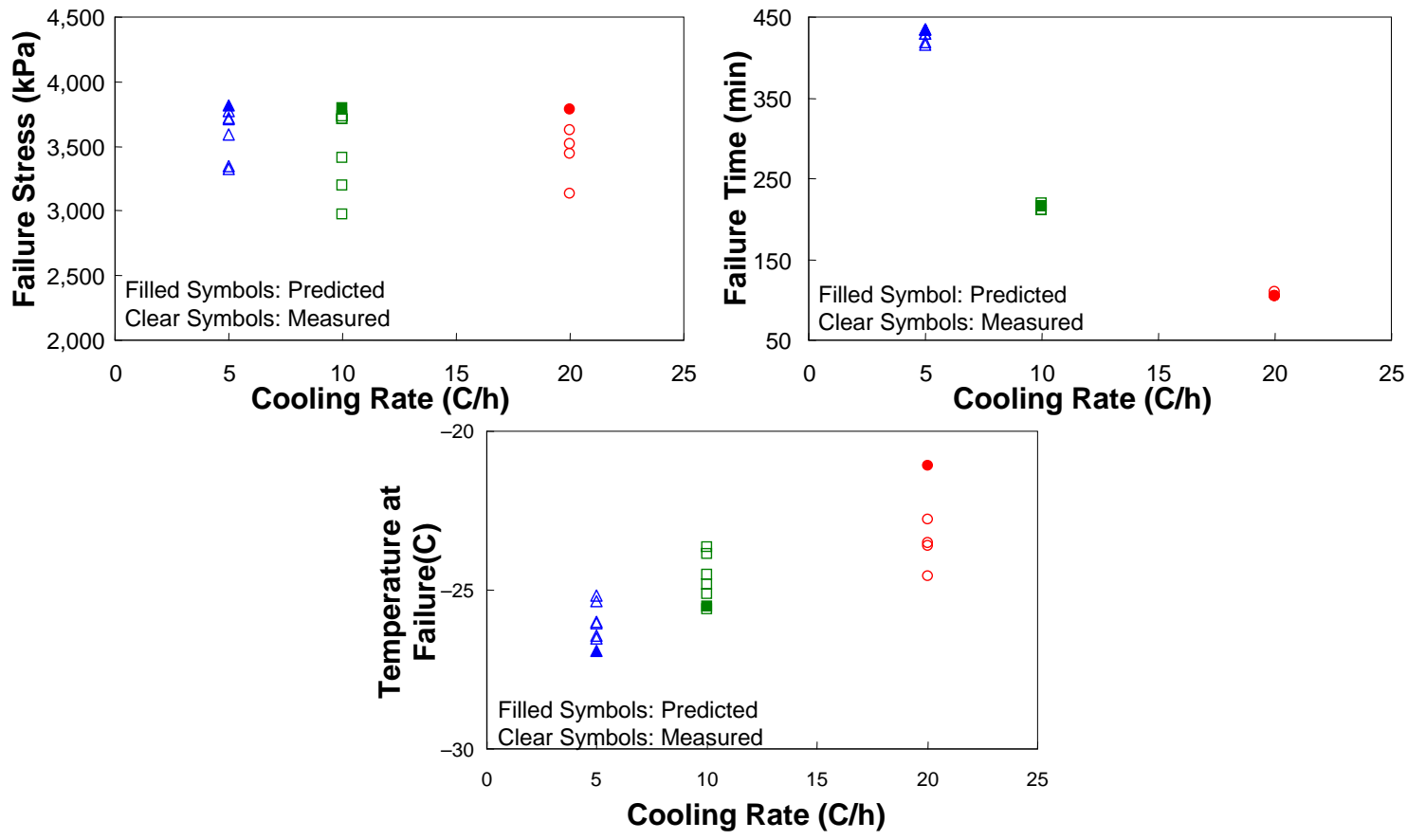

FIGURE 6 Comparison of the TSRST parameters predicted from the VEPCD model using the measured values. 
In very recent work, the North Carolina State University research team has devised a method by which the continuum model can be easily characterized using results from cyclic fatigue tests. This finding has major potential implications because the model can be characterized quickly using results from tests performed with the asphalt mixture performance tester (AMPT). The analysis that proves this concept is shown in Figure 7, which illustrates the measured and predicted fatigue life for tests performed on five different mixtures. Each point in this graph represents a different test performed at $5^{\circ}, 19^{\circ}$, or $27^{\circ} \mathrm{C}$ and at varying strain amplitudes. To predict the fatigue life, a single test for each mixture determines the damage characteristic relationship for that mixture. This function is then used to predict the failure of all the other tests performed using that same mixture. Overall, it is found that the approach yields good predictions with high $R^{2}$ and low Se/Sy.

Figure 8 presents another way to examine the predictive capabilities of the simplified VECD model. Here, the traditional fatigue relationship $\left(\varepsilon_{0}\right.$ versus $\left.N_{f}\right)$ is shown for a single mixture. The graph illustrates both the measured and the predicted fatigue life obtained from tests performed at three temperatures and multiple strain levels. This figure also shows that the model predictions match quite well with the measured fatigue life. There is a slight tendency to overestimate the fatigue life of the $27^{\circ} \mathrm{C}$ data, but with the exception of the lowest loading magnitude tests, these expected maximum errors are approximately $30 \%$. This percentage is in line with that reported elsewhere (15) and is considered adequate for fatigue life predictions. It is also important to note that the VECD model, under actual test conditions, can explain what would be construed as experimental variability when analyzing these tests using the traditional fatigue model (i.e., the power law model).

\section{Damage Evolution Law}

$\dot{S}_{m}=\left(-\frac{\partial W^{R}}{\partial S}\right)^{\alpha_{m}}$

\section{MODEL APPLICATIONS}

\section{Pavement Performance Modeling Through Finite Element Implementation}

The major advantage of the VECD model over the conventional fatigue performance prediction models is that the VECD model is the constitutive model that describes the relationship between stresses and strains. Therefore, it can be implemented into the structural model in a rigorous manner. In this study, the VECD model is implemented into the finite element program (hereinafter called VECD-FEP++ model) and is used to evaluate the effect of lime modification on fatigue damage of HMA pavements with moisture conditioning. Experimental evaluations were performed to characterize the linear viscoelastic properties $\left(\left|E^{*}\right|\right)$ and the damage characteristic curves ( $C$ versus $S$ ) for both of the unmodified and lime-modified mixtures with and without moisture conditioning. The material properties were then input to the VECD-FEP++ program to predict the performance of a standard pavement structure constructed with these materials. 

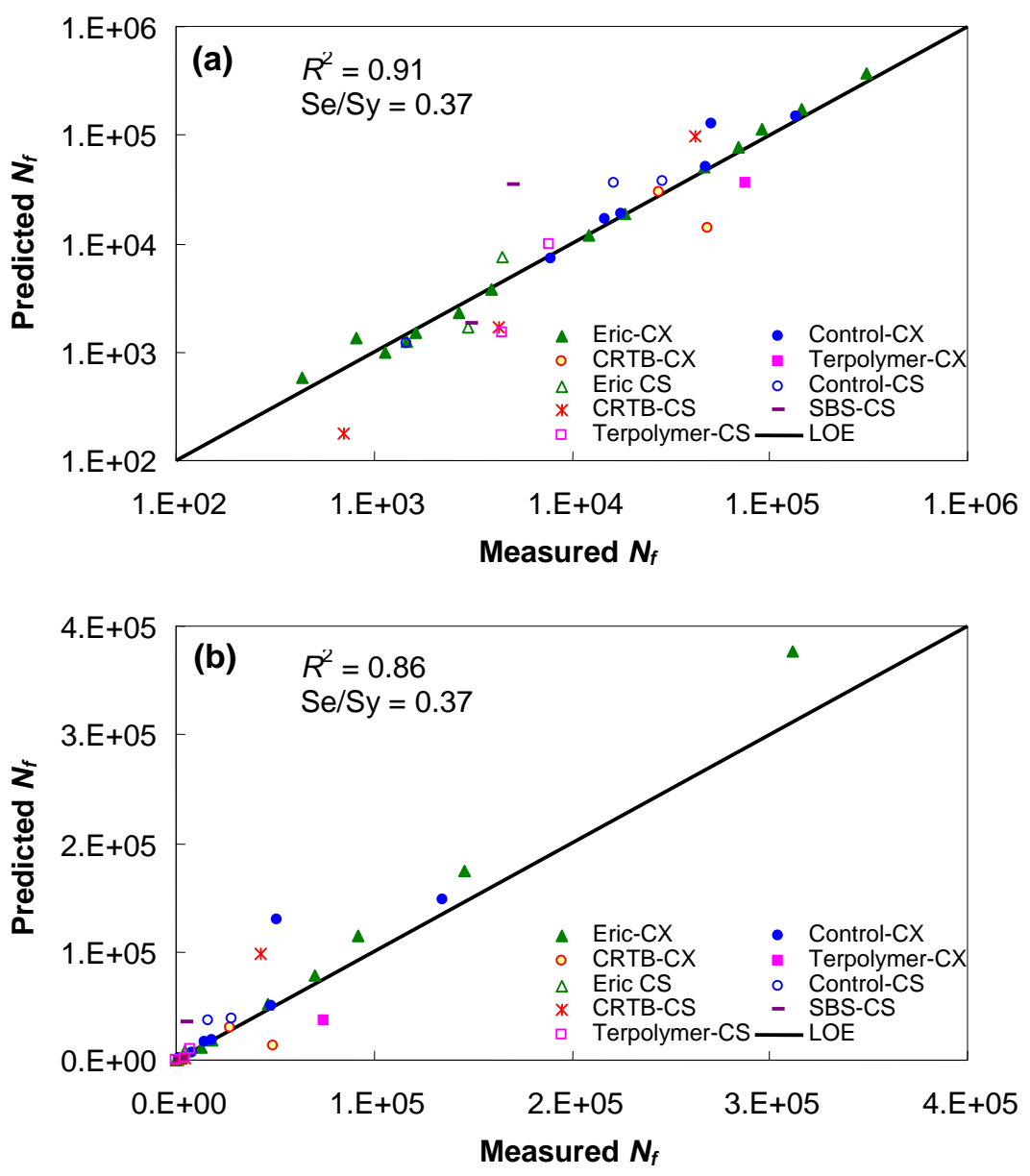

FIGURE 7 Comparison of measured and VECD predicted fatigue life of various mixtures in (a) logarithmic space and (b) arithmetic space.

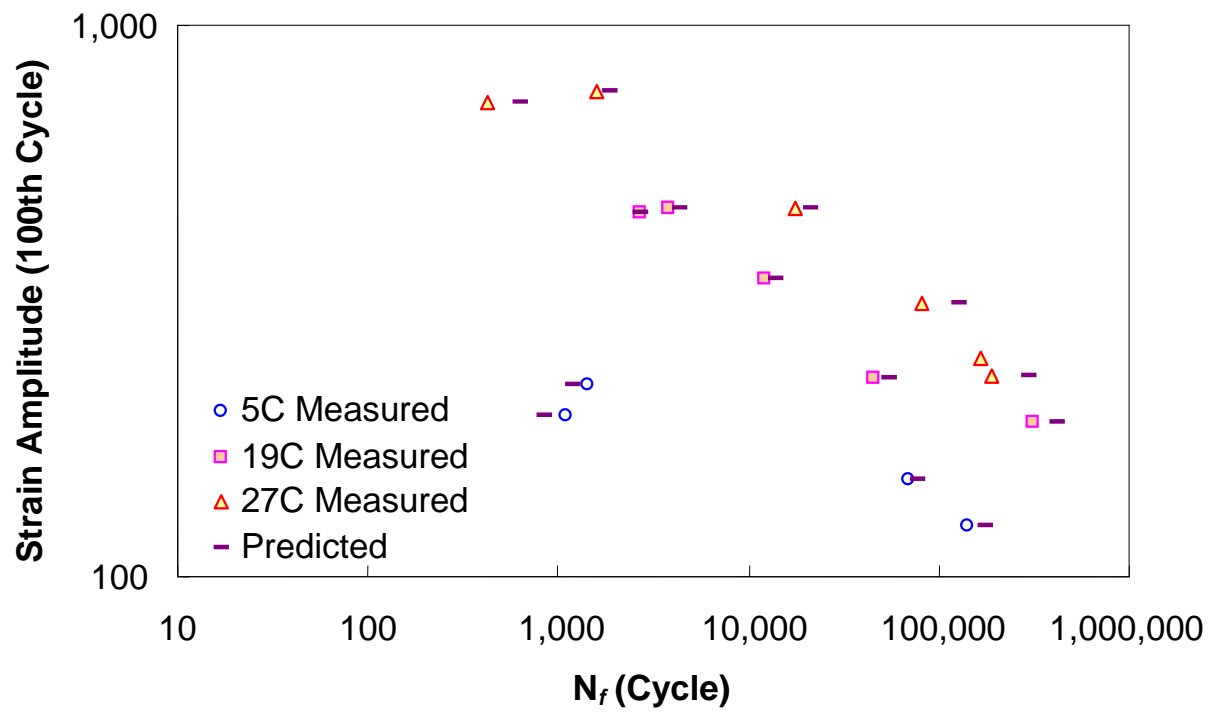

FIGURE 8 Predictive capabilities of VECD model in traditional fatigue test graph space. 
Figure 9 illustrates the typical output from the VECD-FEP++ runs, where contours of the VECD material integrity parameter, $C$, are shown for different number of loading cycles and mixtures. The layer shown in this figure is a 4-in. thick HMA layer. With regard to these contour plots, it should be noted that if the $C$ value decreases below 0.25 , the area where the material has reduced in integrity, i.e., the localization of the damage, starts to spread over the pavement section that is indicated in red in Figure 9. It is clearly observed that as the number of cycles increases, damage grows throughout the pavement. Another interesting observation is that the damage tends to concentrate at the bottom of the layer and the right edge of the upper layer at the center of the shear. The benefit of lime modification in reducing the moisture-induced damage is clearly shown in Figure 9. The increase in the amount of damage after moisture conditioning is much less with the lime-modified mixture than that with the unmodified mixture.

To verify the VECD model for field conditions requires the coupling of the VECD model and an acceptable structural model. The effort can be completely consistent, e.g., the VECD model parameters affect the structural response, or simplified, e.g., the structural model is used to determine the pavement response that is input to the VECD model. This latter approach is similar in principle to the analysis being performed with the Project NCHRP 1-37A, Mechanistic-Empirical Pavement Design Guide. An example of the first, completely consistent approach is shown for the 2D case in Figures 10 and 11.

For these figures a single structural parameter, asphalt concrete layer thickness, is being considered and the contours represent the VECD damage parameter for both a thin and thick pavement at different load cycles. As the contour color moves from blue to red it is an indication that more damage is accumulating. It is observed by comparing Figures 10 and 11 that the thick pavement is prone to more top-down damage (cracking) than the thin pavement.

\section{Simplified Performance Prediction Model}

The application of the VECD modeling principles is not constrained to fully consistent, computationally intensive structural modeling. Although this type of approach is the most fundamentally accurate technique available, simplified modeling schemes offer the key advantage of reduced analysis time. A recently reformulated version of the VECD model allows for easier characterization via cyclic fatigue tests and easier predictions using strain kernel histories, such as those given by pavement response models (18). When coupled with an appropriate strain response model, such as layered elastic or viscoelastic analysis or linear finite element analysis, the resulting modeling scheme can provide rational predictions of the fatigue performance.

This type of approach has been applied to the FHWA ALF pavements using laboratorymeasured experimental data and backcalculated unbound layer moduli. Response modeling is performed using a three-dimensional finite element code that considers the asphalt concrete layers to be linear viscoelastic and the unbound layers to be linear elastic. This level of complexity is believed to provide a more accurate representation of asphalt concrete pavements while using the same inputs currently required for the NCHRP 1-37A Mechanistic-Empirical Pavement Design Guide. The 3-D finite element analysis is used because of its convenience for the research team; however, when available, a layered viscoelastic model will be used instead to reduce computational time. The predicted strain from this response model, as shown in Figure 12 , is presented as a repeating input to the VECD model, which produces a predicted number of cycles to failure. 


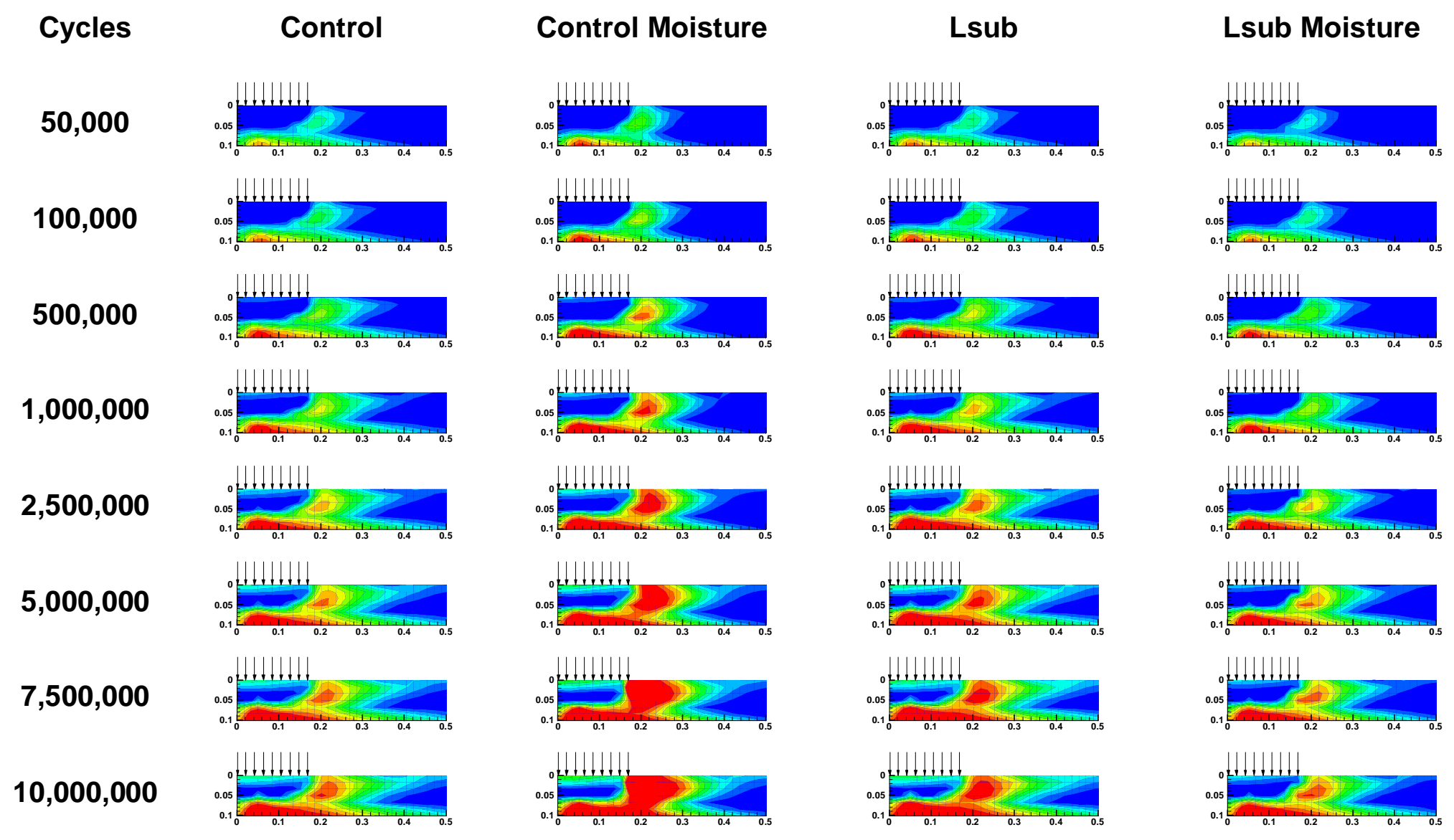

FIGURE 9 Effect of moisture conditioning on fatigue damage of unmodified and lime-modified mixtures. 


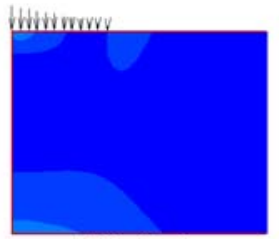

- 10th Cycle -

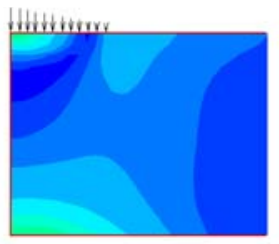

- 1000th Cycle -

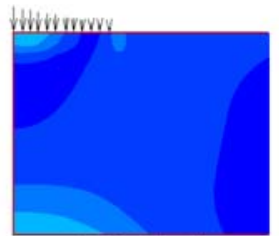

- 100th Cycle -

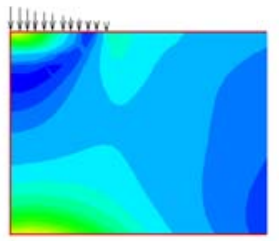

- 5000th Cycle -

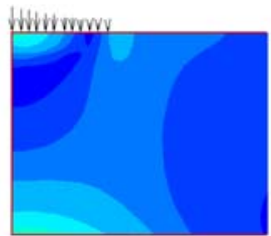

- 500th Cycle -

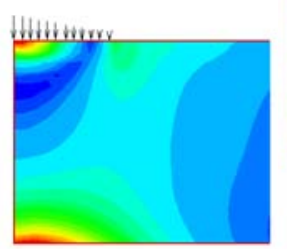

- 10000th Cycle -

Damage Parameter

(Thick AC Thickness)

1270.0

1230.0

1140.0

970.0
8700

870.0
790.0

790.0
700.0

750.0
5150.0

520.0
450.0
350.0

350.0
260.0

170.0

40.0
10.0

FIGURE 10 VECD-FEP++ damage contours for thick asphalt concrete pavement at different load cycles.

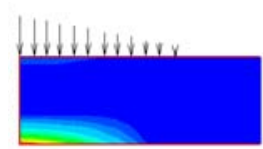

- 10th Cycle -

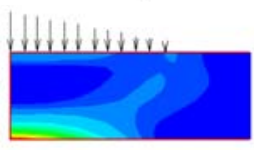

- 1000th Cycle -

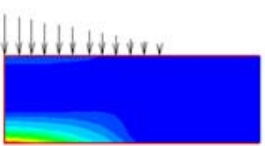

- 100th Cycle -

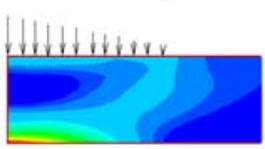

- 5000th Cycle -

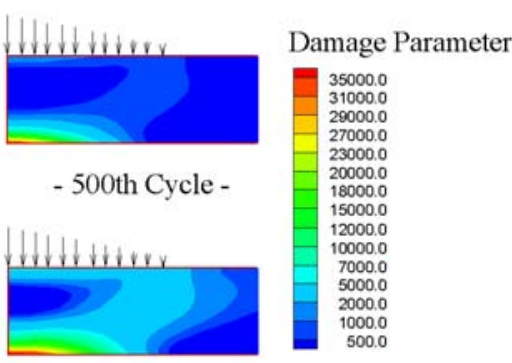

-10000 th Cycle -

FIGURE 11 VECD-FEP++ damage contours for thin asphalt concrete pavement at different load cycles.

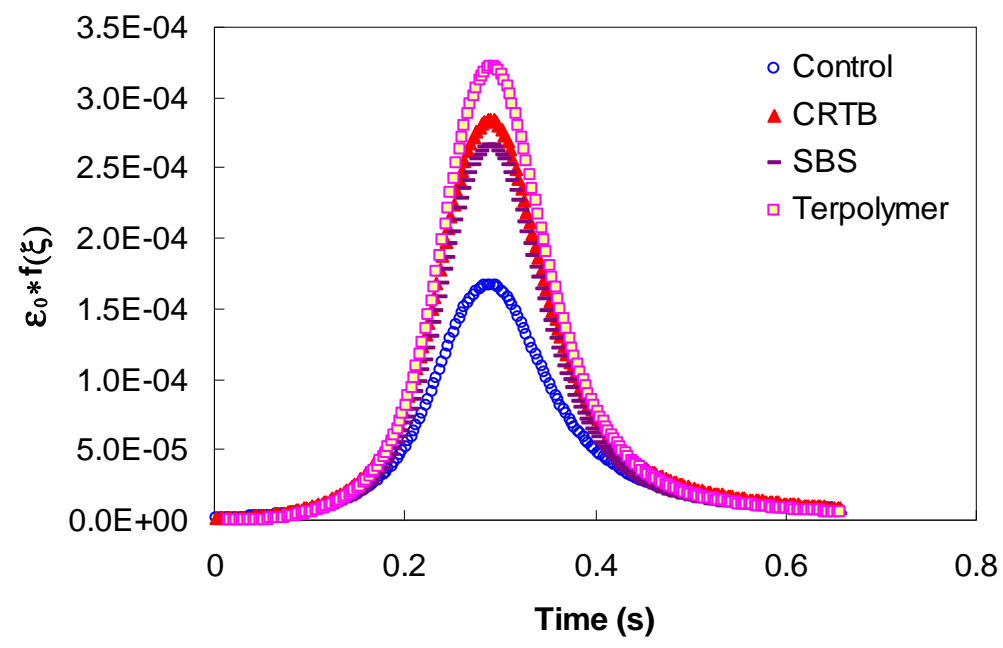

FIGURE 12 Loading function for each pavement structure. 
The results of the test simulations are shown for the available ALF pavements in Figure 13. Based on the results of Kutay et al. (18), failure in the ALF pavements is defined as the cycle when $20 \%$ of the lane has cracked. Note that two scenarios are shown, one that includes Terpolymer and one that does not include terpolymer. It has been noted by other researchers that certain problems relating to the distribution of hydrated lime throughout the Terpolymer test lane may have affected the ALF test results. Both scenarios are shown here in light of the fact that it cannot be stated with absolute certainty that the distribution errors do in fact have a significant effect on the test results. For the analysis shown in Figure 13, the function is clearly more consistent if terpolymer is not included; this seems to indicate that a problem did indeed exist in this lane, but such an assumption is not definitive.

The findings from Figure 13 are quite encouraging and provide some interesting insight. Comparisons are drawn between the continuum damage model failure point and surface crack density. These observed surface cracks are the result of initiated microcracks that have propagated and coalesced into some dominant macrocracks, which have then propagated to the surface. Note that strain gauge measurements taken at the ALF confirm that failure occurred due to bottom-up fatigue cracking (19). Material in the continuum damage model fails due to coalescence of the microcracks into macrocracks. The point at which this failure occurs is referred to as localization in the literature relating to the VECD model. However, the fact that the continuum model, which does not account for macrocrack propagation, shows a good relationship with the measured surface cracking further suggests that the microcrack and macrocrack propagation behaviors are related. It is felt that extending the VECD model to fracture (i.e., continuum damage to fracture) is a natural evolution of the model. In fact, the VECD model was originally derived based on fracture mechanics generalizations; thus, clear similarities exist in the formulations, as is shown in Table 1. This work is the subject of ongoing investigation by the NCSU research team under the ARC funding.

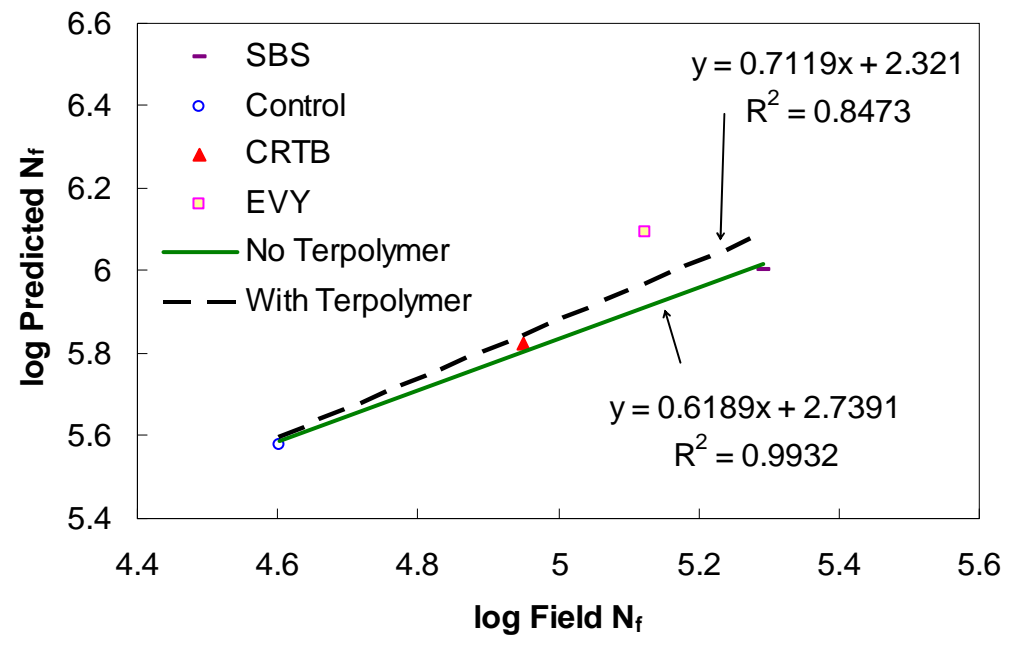

FIGURE 13 Comparison of measured and predicted cycles to failure in ALF experiment using best fit function. 


\section{TABLE 1 Comparison of Fracture Mechanics and Continuum Damage Mechanics Principles}

\begin{tabular}{|l|l|l|}
\hline \multicolumn{1}{|c|}{ Types of Approaches } & \multicolumn{1}{c|}{ Fracture Mechanics } & Continuum Damage Mechanics \\
\hline Crack/damage driving force & $\begin{array}{l}G \equiv-\frac{\partial W}{\partial a}= \\
\text { Energy Release Rate }\end{array}$ & $\begin{array}{l}f \equiv-\frac{\partial W}{\partial S}= \\
\text { Thermodynamic Force }\end{array}$ \\
\hline Crack/damage resistance & $G_{c} \equiv-\frac{\partial W_{c}}{\partial a}$ & $f_{s} \equiv-\frac{\partial W_{s}}{\partial S}$ \\
\hline $\begin{array}{l}\text { Damage evolution law for elastic } \\
\text { body }\end{array}$ & $\begin{array}{l}G=G_{c} \\
\text { Damage evolution law for } \\
\text { viscoelastic body }\end{array}$ & $\begin{array}{l}\dot{a}=C(G)^{n} \\
\dot{a}=A\left(J_{v}\right)^{k}\end{array}$ \\
\hline
\end{tabular}

NOTE: $a=$ crack length; $W=$ strain energy; $W_{c}=$ dissipated energy; $n, k=$ damage evolution rate; $S=$ internal state variable; $\alpha=$ damage evolution rate.

\section{SUMMARY AND FUTURE DIRECTIONS}

The VECD model developed at NCSU considers asphalt concrete to be an initially isotropic, homogeneous, and stress state-dependent linear viscoelastic material. As a result, the extended elastic-viscoelastic correspondence principle is chosen to describe the material behavior. The material behavior transforms from this initial state to one of transverse isotropy due to microdamage growth. The negative effects of aging and moisture damage and the beneficial effects of microdamage healing are accounted for in the current formulation. Further, the effects of the stress state on the damage processes are taken into account in the multiaxial form of the VECD model. Permanent deformation effects are modeled using either a simple strain hardening formulation in tension, or a HISS-Krempl model that accounts for the experimentally observed strain hardening and softening behaviors in compression.

To date, the VECD model has been implemented into an in-house, stand-alone finite element package for analyzing asphalt concrete pavements. This package includes analysis tools that consider temperature-related damage, temperature gradients across the pavement crosssection, support and loading conditions, aging, and healing. The VECD-FEP++ code has been used in solving actual engineering problems.

Future efforts in this modeling approach will focus on $(a)$ extending continuum damage mechanics to the post-peak, or fracture, domain for fatigue analysis and $(b)$ linking the HMA VEPCD model to smaller scales (i.e., mastic and binder) in asphalt mixture. To consider other distresses, such as permanent deformation, efforts will be extended for implementing the viscoplasticity models into the FEP++. Experimental observations at North Carolina State University suggest that such efforts should include considerations for strain-induced anisotropy, an issue that has also been shown experimentally to have little effect on the fatigue process. 


\section{REFERENCES}

1. Chehab, G., Y. R. Kim, R. A. Schapery, M. Witczack, and R. Bonaquist. Time-Temperature Superposition Principle for Asphalt Concrete Mixtures with Growing Damage in Tension State. Asphalt Paving Technology, Vol. 71, 2002, pp. 559-593.

2. Underwood, B. S., Y. R. Kim, and M. N. Guddati. Characterization and Performance Prediction of ALF Mixtures Using a Viscoelastoplastic Continuum Damage Model. Asphalt Paving Technology, Vol. 75, 2006, pp. 577-636.

3. Zhao, Y., and Y. R. Kim. Time-Temperature Superposition for Asphalt Mixtures with Growing Damage and Permanent Deformation in Compression. In Transportation Research Record: Journal of the Transportation Research Board, No. 1832, Transportation Research Board of the National Academies, Washington, D.C., 2003, pp. 161-172.

4. Gibson, N. H., C. W. Schwartz, R. A. Schapery, and M. W. Witczak. Viscoelastic, Viscoplastic, and Damage Modeling of Asphalt Concrete in Unconfined Compression. In Transportation Research Record: Journal of the Transportation Research Board, No. 1860, Transportation Research Board of the National Academies, Washington, D.C., 2003, pp. 3-15.

5. Yun, T. Y, B. S. Underwood, and Y. R. Kim. Time-Temperature Superposition for HMA with Growing Damage and Permanent Strain in Confined Tension and Compression. ASCE Journal of Materials in Civil Engineering, Vol. 22, No. 5, 2009, pp. 415-422.

6. Daniel, J. S., and Y. R. Kim. Laboratory Evaluation of Fatigue Damage Growth and Healing of Asphalt Concrete Mixtures Using the Impact Resonance Method. ASCE Journal of Materials in Civil Engineering, Vol. 13, No.6, 2001, pp. 434-440.

7. Underwood, B. S., Y. R. Kim, and M. N. Guddati. Improved Calculation Method of Damage Parameter in Viscoelastic Continuum Damage Model. International Journal of Pavement Engineering, 2010.

8. Chehab, G. R., Y. R. Kim, R. A. Schapery, M. W. Witczak, and R. Bonaquist. Characterization of Asphalt Concrete in Uniaxial Tension Using a Viscoelastoplastic Continuum Damage Model. Asphalt Paving Technology, Vol. 72, 2003, pp. 315-355.

9. Schapery, R. A. Correspondence Principles and a Generalized J-integral for Large Deformation and Fracture Analysis of Viscoelastic Media. International Journal of Fracture, Vol. 25, 1984, pp. 195223.

10. Kim, Y. R. and D. N. Little. One-Dimensional Constitutive Modeling of Asphalt Concrete. ASCE Journal of Engineering Mechanics, Vol. 116, No. 4, 1990, pp. 751-772.

11. Kim, Y. R., Y. Lee, and H. J. Lee. Correspondence Principle for Characterization of Asphalt Concrete. ASCE Journal of Materials in Civil Engineering, Vol. 7, No. 1, 1995, pp. 59-68.

12. Lee, H. J., and Y. R. Kim. A Uniaxial Viscoelastic Constitutive Model for Asphalt Concrete under Cyclic Loading. ASCE Journal of Engineering Mechanics, Vol. 124, No. 1, 1998, pp. 32-40.

13. Lee, H. J., and Y. R. Kim. A Viscoelastic Continuum Damage Model of Asphalt Concrete with Healing. ASCE Journal of Engineering Mechanics, Vol. 124, No. 11, 1998, pp. 1224-1232.

14. Schapery, R. A. A Theory of Mechanical Behavior of Elastic Media with Growing Damage and Other Changes in Structure. Journal of Mechanics of Physical Solids, Vol. 38, 1990, pp. 215-253.

15. Daniel, J. S., and Y. R. Kim. Development of a Simplified Fatigue Test and Analysis Procedure Using a Viscoelastic Continuum Damage Model. Asphalt Paving Technology, Vol. 71, 2002, pp. 619-650.

16. Kim, Y. R., and G. Chehab. Development of Viscoelastoplastic Continuum Damage Model for Asphalt-Aggregate Mixtures. Final Report to the Arizona State University, NCHRP, 2004. NCHRP 9-19 Final Report CD.

17. Jung, D. H., and T. S. Vinson. Prediction of Low Temperature Cracking: Test Selection. Report SHRP-A-400. Strategic Highway Research Program, National Research Council, Washington, D.C., 1994. 
18. Underwood. B. S., Y. R. Kim, S. Savadatti, S. Thirunavukkarasu, and M. N. Guddati. Response and Fatigue Performance Modeling of ALF Pavements Using 3-D Finite Element Analysis and a Simplified Viscoelastic Continuum Damage Model. Asphalt Paving Technology, 2009.

19. Kutay, M. E., N. Gibson, and J. Youtcheff. Conventional and Viscoelastic Continuum Damage (VECD) - Based Fatigue Analysis of Polymer Modified Asphalt Pavements. Asphalt Paving Technology, 2008.

20. Qi, X., N. Gibson, and J. Youtcheff. Strain Responses and Fatigue Performances from the FHWA ALF Modified Binder Pavements. Advanced Characterisation of Pavement and Soil Engineering Materials: Proceedings of the International Conference on Advanced Characterisation of Pavement and Soil Engineering, Athens, Greece, 2007.

\section{Additional Resources}

Schapery, R. A. Deformation and Fracture Characterization of Inelastic Composite Materials using Potentials. Polymer Engineering and Science, Vol. 27, No. 1, 1987, pp. 63-76.

Schapery, R. A. Nonlinear Viscoelastic and Viscoplastic Constitutive Equations with Growing Damage. International Journal of Fracture, Vol. 97, 1999, pp. 33-66. 


\title{
Viscoplastic Modeling of Bituminous Mixtures
}

\author{
ChaRLes W. SCHWARTZ \\ Regis L. CARVALHO \\ University of Maryland
}

\begin{abstract}
A key feature of bituminous mixtures is the accumulation of permanent deformations as a function of load magnitude, rate, and duration. Viscoplastic constitutive models that treat the heterogeneous bituminous composite as an equivalent homogeneous continuum are one approach for predicting this material behavior. The main components of all viscoplastic models are a yield criterion to govern the onset and magnitude of yielding and a flow rule to dictate the directions of the ensuing viscoplastic strains. Most models also include some type of hardening or softening law to reflect the evolution of material strength with accumulated strain. Material behavior prior to yield and during unloading is typically modeled using conventional elastic or viscoelastic models, often with the inclusion of microstructural damage effects.

This section briefly outlines the conceptual underpinnings of viscoplasticity theory. This description is followed by examples of the application of the theory to various pavement engineering questions and scenarios, with an emphasis on predictions of real-world pavement behavior and performance.
\end{abstract}

\section{THEORETICAL CONCEPTS}

\section{One-Dimensional Formulations}

The objective of any constitutive model is to relate strains to stresses (or vice versa) for a material. For a linearly elastic constitutive model, strains are directly proportional to stresses and are fully recoverable upon unloading. For a viscoplastic constitutive model, however, the strains are a nonlinear function of stresses, are rate dependent, and are non-recoverable upon unloading.

The distinctive components of a viscoplastic constitutive model are: $(a)$ a yield function that controls the magnitude of viscoplastic flow; $(b)$ a hardening law, which describes change in strength of the material accompanying accumulated viscoplastic straining; and (c) a potential function, which controls the direction of the viscoplastic strain increments These components can be described conceptually in terms of the simple rheological model for elastic-viscoplastic behavior shown in Figure 1. The deformation of the spring (characterized by the elastic modulus $E)$ represents the instantaneous elastic response while the deformation of the dashpot (controlled by the viscosity $\eta$ ) represents the rate-dependent viscoplastic response once the yield strength $\sigma_{Y}$ of the parallel slider element has been exceeded. ${ }^{1}$ The total strain is then just the sum of the elastic and viscoplastic components:

$\varepsilon=\varepsilon_{e}+\varepsilon_{v p}$ 


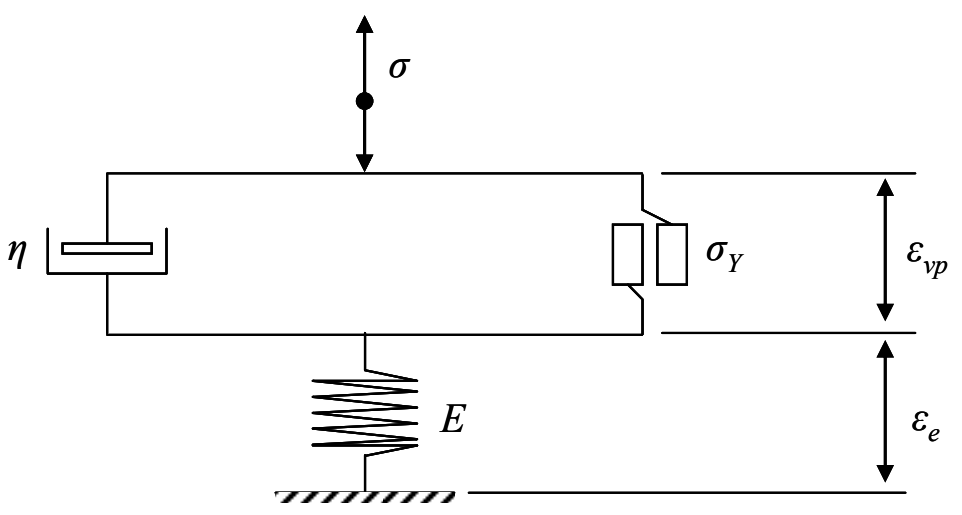

FIGURE 1 One-dimensional elasto-viscoplastic rheological model.

For viscoplastic strain to occur, the applied stress $\sigma$ must be larger than the yield stress, $\sigma_{Y}:$

$f(\sigma)=|\sigma|-\sigma_{Y}>0$

in which $f(\sigma)$ is the yield function controlling the magnitude of viscoplastic flow. Typically, some type of hardening rule (or softening rule) complements the yield function to reflect the tendency of real materials to become stronger (or weaker) as plastic strains accumulate For example, a simple linear hardening rule for one-dimensional loading can expressed as:

$\sigma_{Y}=\sigma_{Y o}+H \varepsilon_{v p}$

in which $\sigma_{Y o}$ is the initial yield and $H$ is a hardening modulus.

Once flow commences (i.e., once Equation 2 is satisfied), the viscoplastic strain rate $\dot{\varepsilon}_{v p}$ $\dot{\varepsilon}_{v p}$ is governed by the viscous dashpot:

$\dot{\varepsilon}_{v p}=\frac{\sigma}{\eta}$

Equations 2 and 4 can be written in shorthand notation as

$\dot{\varepsilon}_{v p}=\frac{\langle f(\sigma)\rangle}{\eta} \frac{\partial g(\sigma)}{\partial \sigma}=\Gamma\langle f(\sigma)\rangle \frac{\partial g(\sigma)}{\partial \sigma}$

in which $\Gamma=\frac{1}{\eta}$ is a fluidity material parameter and the notation $\langle f(\sigma)\rangle$ is interpreted as

$\langle f(\sigma)\rangle=f(\sigma)$ for $f(\sigma)>0$

$\langle f(\sigma)\rangle=0 \quad$ for $f(\sigma) \leq 0$ 
The $g(\sigma)$ term in Equation 5 is the viscoplastic potential function controlling the direction of plastic flow. For the simple uniaxial loading considered here, there are only two possible directions: tensile (positive direction) or compressive (negative direction). In the simplest formulation, the plastic potential $g(\sigma)$ is set equal to the yield function $f(\sigma)$; this is termed associated flow viscoplasticity. In this case, for $f(\sigma)$ given by Equation 2:

$$
\begin{aligned}
& \frac{\partial g(\sigma)}{\partial \sigma}=\frac{\partial f(\sigma)}{\partial \sigma}=+1 \text { for } \sigma>\sigma_{Y} \text { (tensile viscoplastic flow) } \\
& \frac{\partial g(\sigma)}{\partial \sigma}=\frac{\partial f(\sigma)}{\partial \sigma}=-1 \text { for }-\sigma>\sigma_{Y} \text { (compressive viscoplastic flow) }
\end{aligned}
$$

For associated flow viscoplasticity, Equation 5 becomes

$$
\dot{\varepsilon}_{v p}=\Gamma\langle f(\sigma)\rangle \frac{\partial f(\sigma)}{\partial \sigma}
$$

Equation 8 can be integrated in time to predict the viscoplastic strains generated by a given loading history.

\section{Multidimensional Perzyna Viscoplasticity}

Equation 5 is the simple uniaxial form of Perzyna's viscoplastic constitutive theory (1). Perzyna's general theory is fully multidimensional and broad enough to accommodate a wide variety of yield functions, plastic potentials, and hardening rules. Temperature effects, which are critical for asphalt concrete, can be incorporated into Perzyna's theory using time-temperature superposition. Time-temperature superposition implies that loading time and temperature are interchangeable and that their combined effects can be incorporated via a single reduced time variable. Schwartz et al. (2), Chehab et al. (3), Zhao and Kim (4), and others have demonstrated that time-temperature supervision for asphalt concrete remains valid at strain levels approaching peak strength and beyond.

The multidimensional form of Perzyna's viscoplasticity theory can be expressed as

$$
\dot{\varepsilon}_{i j}^{v p}=\frac{d \varepsilon_{i j}^{v p}}{d t_{R}}=\Gamma\langle f(\mathbf{s})\rangle \frac{\partial g(\mathbf{s})}{\partial \sigma_{i j}}
$$

in which $\sigma_{i j}$ and $\dot{\varepsilon}_{i j}^{v p}$ are specific components of stress and viscoplastic strain rate; $t_{R}$ is reduced time; $f(s)$ is the yield function in the multidimensional stress space $\mathbf{s}$; and $g(\mathbf{s})$ is the viscoplastic potential function. For associated flow viscoplasticity, $g(s)=f(s)$. The yield and potential functions can both be interpreted as surfaces in multidimensional stress space.

Equation 9 states that viscoplastic strains develop when the applied stress state lies outside the flow surface-i.e., when $f(\mathbf{s})>0$. The magnitude of the viscoplastic strain rate is proportional to the distance between the applied stress state and the flow surface in multidimensional stress space. 
As before, the derivative of the viscoplastic potential function $\frac{\partial g(\mathbf{s})}{\partial \sigma_{i j}}$ governs the direction of the viscoplastic strain increments. For the case of associated viscoplasticity, the direction of the incremental viscoplastic strain vector is always normal to the yield surface.

As before, the key components of the multidimensional Perzyna viscoplastic constitutive model in Equation 9 are the yield function, the hardening law, and the viscoplastic potential function. Most of the differences among the various viscoplastic models in the literature for asphalt concrete center on specific choices for these three components. For example, frictional materials like asphalt concrete, aggregates, and soils are best characterized by yield functions that include the strengthening effects of confining stress. Examples of such yield functions are the standard Drucker-Prager generalization of Mohr-Coulomb frictional yield. Extensions to Drucker-Prager theory like the hierarchical single surface (HiSS) model (5) add other refinements such as a nonlinear yield surface and a cap on viscoplastic flow under hydrostatic compression loading. A variety of hardening types (e.g., isotropic versus kinematic) and various specific hardening laws have been employed in models in the literature. Although most implementations employ an associated plasticity assumption for the viscoplastic potential function, this is known to overestimate dilatancy for many geomaterials and as a consequence a variety of nonassociated flow schemes have been proposed. Recent representative examples of viscoplastic constitutive models for asphalt concrete applications can be found in Schwartz et al. (6), Gibson et al. (7), Chehab et al. (8), Chehab and Kim (9), Huang et al. (10, 11), Masad et al. $(12,13)$, Tashman et al. $(14,15)$, Uzan $(16,17)$, Saadeh et al. (18), Panneerselvam and Panoskaltsis (19), Collop et al. (20), Oeser and Moller (21), and Lu and Wright (22).

\section{LABORATORY CALIBRATION AND VALIDATION}

All constitutive models contain sets of material parameters that must be determined through laboratory testing. For the simple one-dimensional associated viscoplasticity model, these include the fluidity parameter $\Gamma$ in Equation 8 and the initial yield stress $\sigma_{Y o}$ and hardening modulus $H$ in Equation 3. The multidimensional form in Equation 9 will generally contain substantially more material parameters. For viscoplasticity models, these parameters are typically calibrated using cyclic creep and recovery tests, repeated load permanent deformation tests (sometimes termed "flow number" tests), and other similar loadings. Ideally, the calibration tests include unconfined and confined loading in both compression and tension under a range of stress magnitudes and temperatures. The cyclic loading tests are usually designed with a rest period of sufficient duration for full recovery of all viscoelastic strains so that the permanent viscoplastic strains can be measured directly.

The calibrated model is then sometimes validated via predictions of the original calibration test results. This of course is a necessary but not sufficient exercise to establish true validity of the model. Any good model must be able to reproduce the test results used to calibrate its parameters. The true strength of a model, though, is its ability to predict material response under conditions substantially different from those in the calibration tests. For example, Gibson and colleagues calibrated their viscoplasticity model using low-cycle creep and recovery tests at $25^{\circ} \mathrm{C}$ and $35^{\circ} \mathrm{C}$ and then validated the model through predictions of independent constant strain rate to failure tests at $25^{\circ} \mathrm{C}$ and $40^{\circ} \mathrm{C}$ (Figure 2) and repeated load permanent deformation tests (23). 

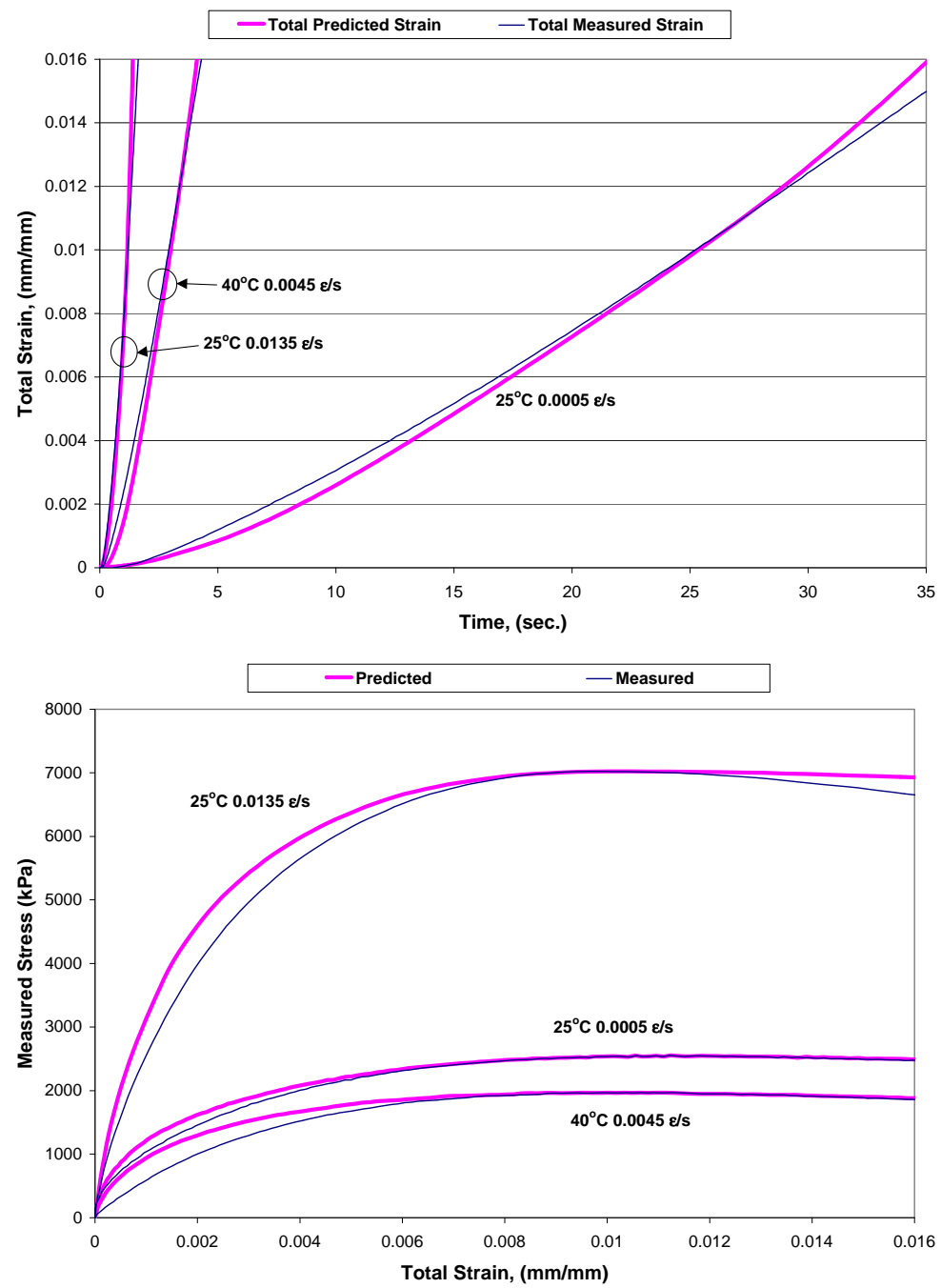

FIGURE 2 Viscoplastic, viscoelastic, and damage model validation for $25^{\circ} \mathrm{C}$ and $40^{\circ} \mathrm{C}(a)$ measured total strain versus predicted strain and (b) stress versus measured and predicted strain (7).

\section{MODEL STRENGTHS AND LIMITATIONS}

The Perzyna viscoplasticity formulation is a well-established theory that provides great flexibility in choice of yield functions, hardening laws, and plastic flow rules. It can therefore be formulated to model a wide range of material behavior. Most formulations for asphalt concrete differ only in the specific details of the yield, hardening, and other characteristics.

Complications arise can arise when complex yield or flow surfaces are employed. It can be computationally challenging to find an unconditionally stable numerical algorithm for computing normal trajectories for all possible stress state conditions. Identification of the most appropriate hardening-softening formulations for cyclic behavior is also an open issue at this point.

Another potential issue is the lack of a viscoplastic damage function in most current models. Typically, damage due to the formation of microcracks is included only in the 
recoverable viscoelastic strain components $(8,13)$. However, damage can be incorporated in the viscoplastic model through the fluidity parameter and updated using a stress-based evolution formulation (20) or the ratio of deformed to undeformed area (19). The inclusion of damage in the viscoplastic fluidity parameter may improve predictions for the tertiary large-strain region of the permanent deformation curve.

Arguably the most significant limitation in current viscoplasticity (and other) models for asphalt concrete is the lack of integration of compressive and tensile response. The behavior of asphalt concrete, especially at large strain levels of interest for simulating pavement distresses, is significantly different for pure compression versus pure tension versus mixed stress states. Most modeling approaches to date have focused primarily on one of the extremes-e.g., primarily compressive (7) or primarily tensile (8) loading. This limitation in the underlying model formulations is exacerbated by the constraints on laboratory calibration testing. Most calibration testing is performed under very simple stress states, typically either unconfined tension or unconfined-confined compression. It is very difficult to simulate in the laboratory the complex stress states experienced in real pavement structures.

\section{APPLICATIONS}

Viscoplasticity theory provides the basic models for describing the stress versus strain response of the material. These models must be implemented in a computational framework before they can be used to predict response and performance for real-world scenarios. The standard tool for this is the finite element (FE) method, which provides a powerful and robust framework for analyzing complex structural geometries, material behavior, and loading conditions.

There are many examples in the literature of viscoplastic model implementation in FE programs. Specific applications to asphalt concrete include simulations of laboratory tests for model validation purposes $(6,15,24)$. However, the main focus in this section is practical applications in which viscoplastic models implemented in FE applications are used to simulate real-world pavement problems.

\section{Permanent Deformation}

Prediction of permanent deformation is the most common application of viscoplasticity modeling in pavement engineering. The simplest case is viscoplastic creep in which the material is subjected to a constant load and the permanent deformations over time are predicted. Collop et al. (20), for example, developed and implemented a three-dimensional isotropic elastoviscoplastic model and illustrated its capabilities using an example of a container loading on an industrial port pavement. The predictions demonstrated the importance of stress dependency and confinement on permanent deformations, especially near the load points.

A key feature of permanent deformations in real pavement systems is that they develop under repeated traffic loading. Repeated traffic loading can be simulated in its most simple form by applying and removing the tire contact pressure distribution at a certain frequency related to traffic speed. This might be termed a "bouncing wheel" simulation. The problem can be further simplified by assuming a circular tire footprint and taking advantage of axial symmetry to reduce the problem to two dimensions $(19,25-27)$. 
Saleeb and Al-Qablan $(26,28)$ successfully applied the axisymmetric bouncing wheel loading scheme with a viscoplastic constitutive model to simulate the asphalt pavement analyzer (APA). Performance verification or torture tests like the APA and the hamburg wheel tracker are commonly used to assess the rutting potential of asphalt concrete mixtures. These tests are widely used and accepted by various departments of transportation as verification of mixture design and quality acceptance. Saleeb and Al-Qablan simulated 8,000 cycles of APA loading using a two-dimensional viscoplastic model implemented in ABAQUS. Different mixtures at different loading rates and temperature were simulated. The results from the numerical analysis summarized in Figure 3 showed very good agreement with measured permanent deformations.

Computational time and data storage requirements become critical limitations when simulating real pavement structures for large numbers of load cycles. A short cut employed by several researchers is to use an equivalent load time approach. Rather than cycle the loading, the tire pressure distribution is a applied as a static loading having a duration equal to the accumulated duration of all of the load cycles in the loading history (29-31). Treating the traffic history as a constant load permits larger time step increments during the computations, thereby reducing the memory required and processing time (26).

Huang et al. (29) modeled the Louisiana accelerated loading facility (ALF) using an elasto-viscoplastic model and the equivalent load time approach to simulate a large number of load applications. As depicted in Figure 4, the predicted permanent deformation results agreed reasonably well with measured values over the full 700,000 load cycles in the test. Hua and White (30) and Park et al. (31) used an elasto-viscoplastic model and the equivalent load time approach to investigate the effects of nonuniform tire pressure on flexible pavement response and rutting. Figure 5 compares the predicted and measured profiles from the Westrack after 93,000 cycles (31).

Although the equivalent load time approach successfully reduces computational burden and appears to produce reasonable predictions of rutting, one can question whether this is a truly valid substitute for repeated traffic loading. There have been no direct comparisons between the results from the equivalent load time approach and bouncing wheel analyses or a more realistic rolling wheel analysis for viscoplastic conditions.
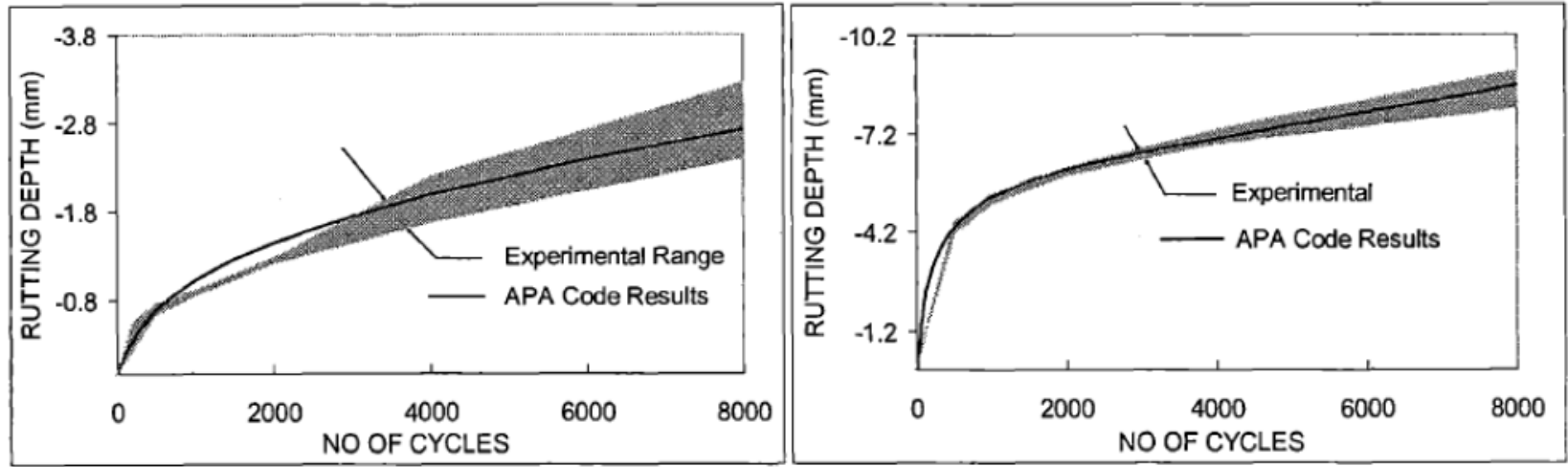

FIGURE 3 Comparison of APA simulation predictions versus measured values at $25^{\circ} \mathrm{C}$ and $40^{\circ} \mathrm{C}(28)$. 


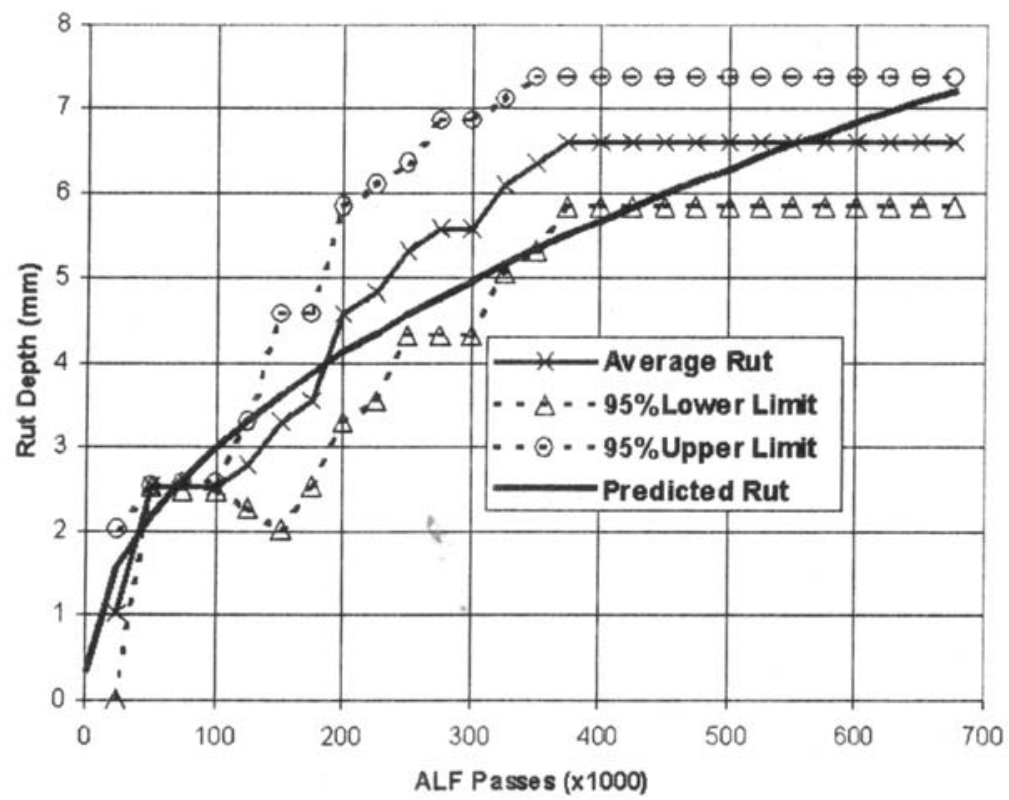

FIGURE 4 Comparison of predicted versus measured permanent deformation at the Louisiana ALF (Huang et al., 2001).

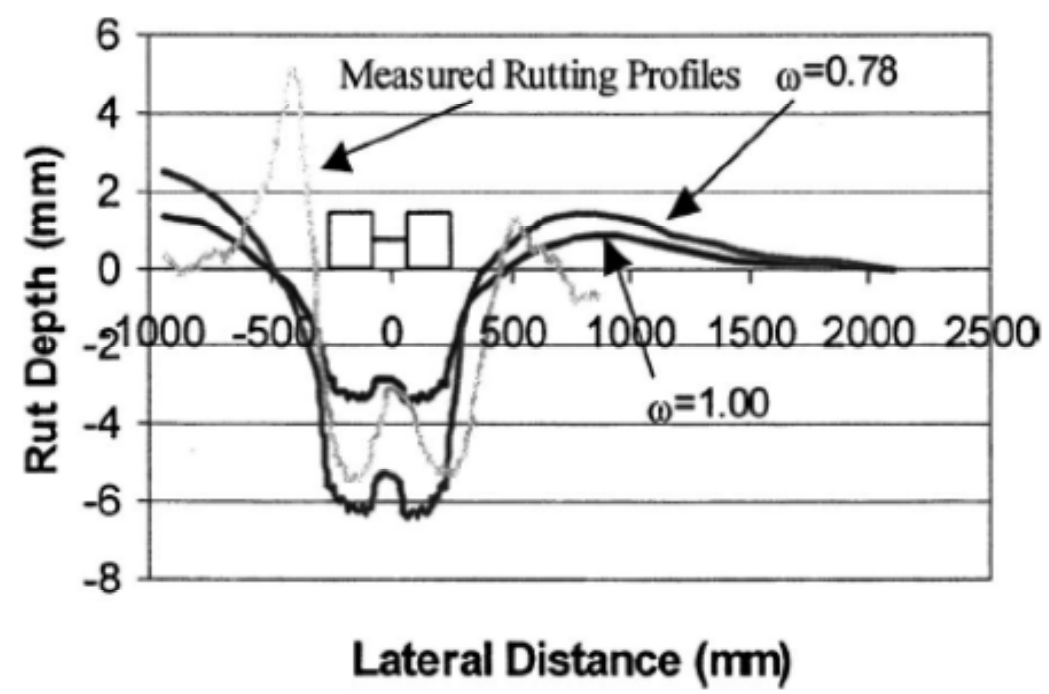

FIGURE 5 Comparison of predicted versus measured rutting profiles (Park et al., 2005).

Viscoplasticity theory can also provide insights that can be used to improve simpler mechanistic-empirical pavement performance models. Schwartz and Carvalho $(27,32)$ performed a bouncing wheel viscoplastic analysis in an effort to provide a mechanistic explanation for the empirical depth correction function in the MEPDG HMA rutting model.

The empirical depth correction function in the MEPDG adjusts the predicted permanent strain distributions to match the rutting concentrations in the upper portion of the HMA layer observed in the field (e.g., at WesTrack and MnRoad). Examination of the vertical residual compressive strains after load removal in the nonlinear viscoplastic analysis found an increase 


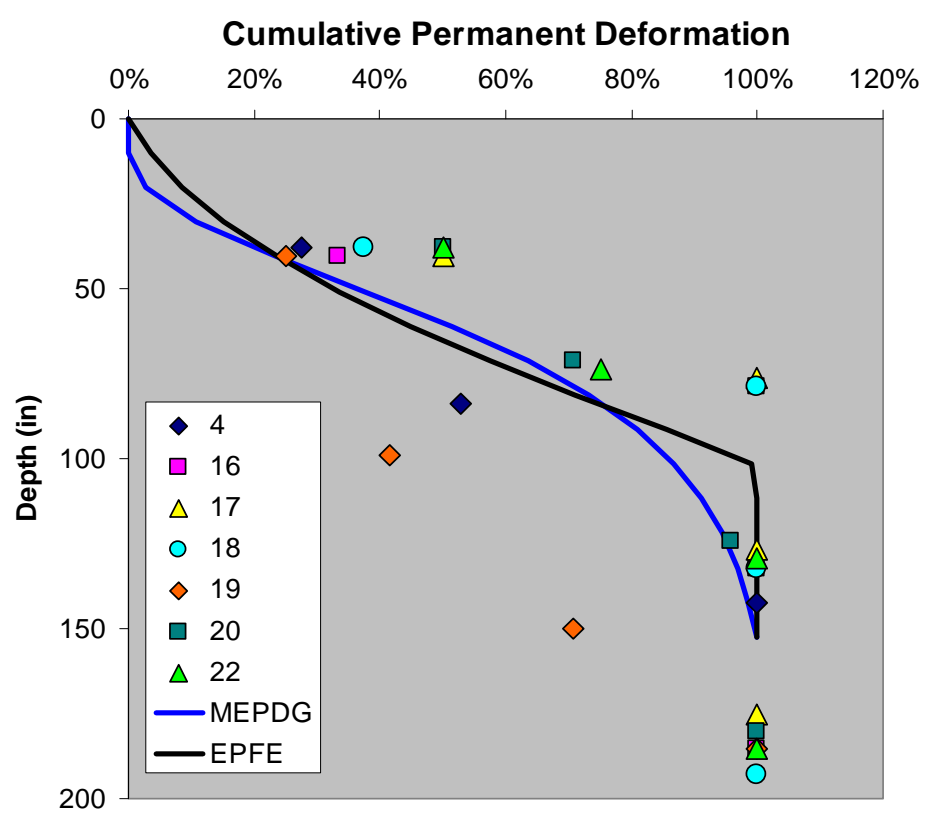

\section{FIGURE 6 Cumulative permanent deformation distribution as measured at MnRoad and as predicted by the empirical (MEPDG) and viscoplastic (EPFE) models. Numbers in legend refer to MnRoad test cells (32).}

with depth in the upper portion of the HMA layer and then a decrease at greater depths, consistent with field observations. Figure 6 illustrates the agreement between accumulated permanent deformations predicted by the analyses and the actual distributions measured in the MnRoad test cells. The mechanistic predictions match the measured data as well as the purely empirical MEPDG depth correction function. (Note that the MEPDG depth correction factor was calibrated using the MnRoad data, so that it is good trend through the data in Figure 6 should come as no surprise.)

Of course, a moving wheel simulation is required to realistically capture all of the influence of loading rate, stress rotations, and other complex and potentially important effects. This requires a fully three-dimensional analysis. Advanced FE modeling is capable of this type of simulation but at extremely high computational cost. Some attempts have been made to predict permanent deformations under a moving wheel $(26,29)$, but these were ultimately simplified to bouncing wheel or equivalent load time approximations because of computational constraints. Better success has been achieved using viscoelastic models focused primarily on reflective cracking and damage (33). However, viscoplasticity is computationally more intense than elasticity and viscoelasticity, and as a consequence moving wheel simulations have not been attempted for large numbers of load applications, especially for field performance prediction. 


\section{Other Applications in Pavements and Geomechanics}

An important advantage of FE modeling is the opportunity to examine problems via relatively inexpensive computational simulations instead of more expensive and time-consuming largescale laboratory models or full-scale field experiments. The effect of compaction on asphalt concrete mixtures is a good example of this. Wang et al. (34) implemented a rate-dependent porous plasticity model to evaluate the effects of various compaction variables on asphalt concrete mixtures. Compaction efficiency can be evaluated through the element volume change in the FE simulation for different compaction pressures and numbers of passes at different locations in the HMA layer, as shown in Figure 7. The ultimate goal is to use these types of FE simulations optimize the number of passes, compaction pressure, and/or lift thickness.

Beyond pavement engineering, viscoplasticity has been applied widely in various geotechnical applications. For example, it has been used to model the nonlinear behavior of soft clayey soils (35-38). Rowe and Hinchberger (39) studied the behavior of geotextile-reinforced embankments over soft clay using a viscoplastic FE model. Ohta et al. (40) employed a viscoplasticity model to predict consolidation settlement and lateral movement of a clay highway embankment.

Dynamic effects in soil are important when designing structures in earthquake hazard areas (41). The damping characteristics of soft soils can be modeled using viscoplastic constitutive equations. Tanaka (42) used an elasto-viscoplastic model based on a MohrCoulomb yield function to simulate the dynamic behavior of embankment dams. The good agreement between predicted cyclic permanent deformations of the crest of the dam and measured values from a laboratory scale model on a shake table supported the applicability of the predictive model to full-scale dams under earthquake loading.

\section{CONCLUDING REMARKS}

Viscoplasticity theory has proven to be a very successful approach for simulating the behavior of bituminous mixtures at moderate to high temperatures. It has been most commonly employed for predicting the accumulation of permanent deformations in these materials as a function of load magnitude, rate, and duration. When coupled with other components such as elasticity,

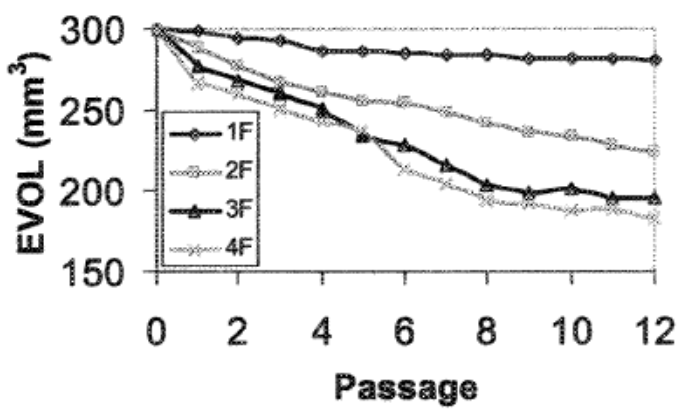

(a)

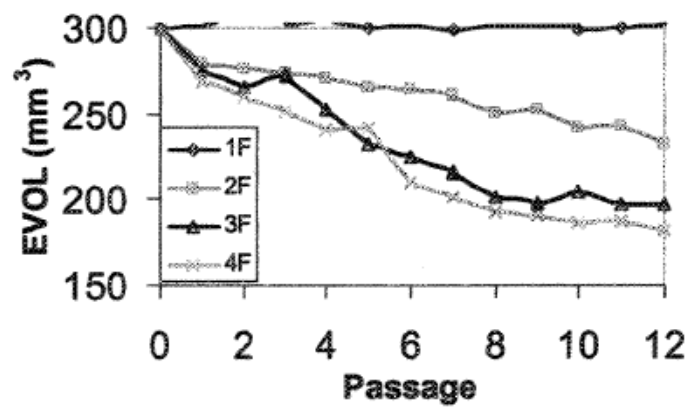

(b)

FIGURE 7 Element volume change due to compaction for different roller forces at (a) bottom and (b) mid-height of HMA layer (34). 
viscoelasticity, and continuum damage and implemented in a finite element analysis framework, the result is a comprehensive and powerful modeling tool for simulating the behavior of bituminous mixtures over the full range of conditions encountered in real pavement systems.

A wide variety of viscoplastic constitutive formulations can be found in the literature. However, these all share the same basic components of a yield function, a hardening rule, and a viscoplastic potential function. The differences among the various formulations lie principally in the detailed choices for each of these components. The inherent flexibility of the viscoplastic model formulation makes it possible to incorporate a wide range of second-order effects by tweaking the basic components. In terms of underlying concepts, though, the many models in the literature are more alike than different.

Although most applications of viscoplastic models to date have focused on simulation of laboratory tests for the purposes of model validation, there have been some limited but successful attempts at predicting permanent deformations observed in large-scale accelerated pavement tests and field sections. Initial applications of viscoplasticity theory to asphalt concrete compaction also appear promising. Simulation of real-world scenarios is, of course, the ultimate objective of any modeling effort. The major challenges in modeling pavement performance today are less in the fine-tuning of the constitutive models for the pavement materials and more in the realistic simulation of the complex loading and varying environmental conditions for the pavement system built with these materials. The important issues of tension versus compression versus mixed stress state behavior, three-dimensional rolling wheel effects, and analysis of highcycle loading for full-scale pavement structures remain at or beyond the forefront of the current state of the art.

\section{NOTE}

1. Note that the linearly elastic spring could be replaced by a viscoelastic spring and dashpot combination for the more general case of a viscoelastic-viscoplastic constitutive model.

\section{REFERENCES}

1. Perzyna, P. Fundamental Problems in Viscoplasticity. Advanced Applied Mechanics, Vol. 9, 1966, pp. 343-377.

2. Schwartz, C. W., N. Gibson, and R. A. Schapery. Time-Temperature Superposition for Asphalt Concrete at Large Compressive Strains. In Transportation Research Record: Journal of the Transportation Research Board, No. 1789, Transportation Research Board of the National Academies, Washington, D.C., 2002, pp. 101-112.

3. Chehab, G. R., Y. R. Kim, R. A. Schapery, M. W. Witczak, and R. Bonaquist. Time-Temperature Superposition Principle for Asphalt Concrete with Growing Damage in Tension State. Proc., Association of Asphalt Paving Technologists, Vol. 71, 2002, pp. 559-593.

4. Zhao, Y., and Y. R. Kim. Time-Temperature Superposition for Asphalt Mixtures with Growing Damage and Permanent Deformation in Compression. In Transportation Research Record: Journal of the Transportation Research Board, No. 1832, Transportation Research Board of the National Academies, Washington, D.C., 2003, pp. 161-172.

5. Desai, C. S., and D. Zhang. Viscoplastic Model for Geological Materials with Generalized Flow Rule. International Journal for Numerical and Analytical Methods in Geomechanics, Vol. 11, No. 6, 1987, pp. 603-620. 
6. Schwartz, C. W., N. H. Gibson, R. A. Schapery, and M. W. Witczak. Viscoplasticity Modeling of Aphalt Concrete Behavior. Geotechnical Special Publication No. 123: Recent Advances in Materials Characterization and Modeling of Pavement System, 2004, pp. 144-159.

7. Gibson, N. H., C. W. Schwartz, R. A. Schapery, and M. W. Witczak. Viscoelastic, Viscoplastic, and Damage Modeling of Asphalt Concrete in Unconfined Compression. In Transportation Research Record: Journal of the Transportation Research Board, No. 1860, Transportation Research Board of the National Academies, Washington, D.C., 2003, pp. 3-15.

8. Chehab, G. R., Y. R. Kim, R. A. Schapery, M. W. Witczak, and R. Bonaquist. Characterization of Asphalt Concrete in Uniaxial Tension Using a Viscoelastoplastic Continuum Damage Model. Proc., Association of Asphalt Paving Technologists, Vol. 72, 2003, pp. 315-335.

9. Chehab, G. R., and Y. R. Kim. Viscoelastoplastic Continuum Damage Model Application to Tthermal Cracking of Asphalt Concrete. Journal of Materials in Civil Engineering, Vol. 17, No. 4, 2005, pp. 384-392.

10. Huang, B., L. Mohammad, W. Wathugala, and H. Paul. Development of a Thermo-Viscoplastic Constitutive Model for HMA Mixtures. Proc., Association of Asphalt Paving Technologists, Vol. 71, 2002, pp. 594-618.

11. Huang, B., L. Mohammad, and W. Wathugala. Application of a Temperature Dependent Viscoplastic Hierarchical Single Surface Model for Asphalt Mixtures. Journal of Materials in Civil Engineering, Vol. 16, No. 2, 2004, pp. 147-154.

12. Masad, E., L. Tashman, D. Little, and H. Zbib. Viscoplastic Modeling of Asphalt Mixes with the Effects of Anisotropy, Damage and Aggregate Characteristics." Mechanics of Materials, Vol. 37, No. 12, 2005, pp. 1242-256.

13. Masad, E., S. Dessouky, and D. Little. Development of an Elastoviscoplastic Microstructural-Based Continuum Model to Predict Permanent Deformation in Hot Mix Asphalt. International Journal of Geomechanics, Vol. 7, No. 2, 2007, pp. 119-130.

14. Tashman, L., E. Masad, H. Zbib, D. Little, and K. Kaloush. Anisotropic Viscoplastic Continuum Damage Model for Asphalt Mixes. Geotechnical Special Publication, No. 123: Recent Advances in Materials Characterization and Modeling of Pavement Systems, 2004, pp. 111-125.

15. Tashman, L., E. Masad, H. Zbib, D. Little, and K. Kaloush. Microstructural Viscoplastic Continuum Model for Permanent Deformation in Asphalt Pavements. Journal of Engineering Mechanics, Vol.131, No. 1, 2005, pp. 48-57.

16. Uzan, J. Asphalt Concrete Characterization for Pavement Performance Prediction. Proc., Association of Asphalt Paving Technologists, Vol. 65, 1996, pp. 573-607.

17. Uzan, J. Viscoelastic-Viscoplastic Model with Damage for Asphalt Concrete. Journal of Materials in Civil Engineering, Vol. 17, No. 5, 2005, pp. 528-534.

18. Saadeh, S., E. Masad, and D. Little. Characterization of Asphalt Mix Response Under Repeated Loading Using Anisotropic Nonlinear Viscoelastic-Viscoplastic Model. Journal of Materials in Civil Engineering, Vol. 19, No. 10, 2007, pp. 912-924.

19. Panneerselvam, D. ,and V. P. Panoskaltsis. Numerical Implementation of a Hyperelastic-Viscoplastic Damage Model for Asphalt Concrete Materials and Pavements. ASCE Geotechnical Special Publication No. 146, 2006, pp. 61-72.

20. Collop, A. C., A. Scarpas, C. Kasbergen, and A. De Bondt. Development and Finite Element Implementation of Stress-Dependent Elastoviscoplastic Constitutive Model with Damage for Asphalt. In Transportation Research Record: Journal of the Transportation Research Board, No. 1832, Transportation Research Board of the National Academies, Washington, D.C., 2003, pp. 96-104.

21. Oeser, M., and B. Moller. 3D Constitutive Modeling for Asphalt Pavements. International Journal of Pavement Engineering, Vol. 3, No. 3, 2004, pp. 153-161.

22. Lu, Y., and P. J. Wright. Numerical Approach of Visco-Elastoplastic Analysis for Asphalt Mixtures. Computers and Structures, Vol. 69, No. 2, 1998, pp .139-147.

23. Gibson, N. H. A Comprehensive Model for the Compressive Behavior of Asphalt Concrete. Ph.D. dissertation. University of Maryland, College Park, 2006. 
24. Scarpas, A., J. Blaauwendraad, R. Al-Khoury, and C. van Gurp. Experimental Calibration of a Viscoplastic Fracturing Computational Model, Journal of Computational Methods and Experimental Measurements: Proceedings of 8th International Conference, Rhodes, Greece, 1997, pp. 643-652.

25. Lu, Y., L. Lu, and P. J. Wright. Visco-Elastoplastic Method for Pavement Performance Evaluation. Proc., Institution of Civil Engineers: Transport, Vol. 153, No. 4, 2002, pp. 227-234.

26. Saleeb, A., R. Y. Liang, H. Al-Qablan, and D. Powers. Numerical Simulation Techniques for HMA Rutting Under loaded Wheel Tester. International Journal of Pavement Engineering, Vol. 6, No. 1, 2005, pp. 57-66.

27. Schwartz, C. W., and R. L. Carvalho. The Complex Guiding the Simple: Enhancement of Mechanistic-Empirical Pavement Rutting Models Using Nonlinear Finite Element Analysis. Proc., Advanced Characterization of Pavement and Soil Engineering Materials Conference, Athens, Greece, Vol. 1, 2007, pp. 441-449.

28. Al-Qablan, H., A. Saleeb, and R. Y. Liang. Mechanistic Modeling of Rutting in Asphalt Pavement Analyzer (APA) Tests. ASCE Conference Proceedings: Pavement Mechanics and Performance, Shanghai, China, 2006.

29. Huang, B., L. Mohammad, and M. Rasoulian. Three-Dimensional Numerical Simulation of Asphalt Pavement at Louisiana Accelerated Loading Facility. In Transportation Research Record: Journal of the Transportation Research Board, No. 1764, TRB, National Research Council, Washington, D.C., 2001, pp. 44-58.

30. Hua, J., and T. White. A Study of Nonlinear Tire Contact Pressure Effects on HMA Rutting. International Journal of Geomechanics, Vol. 2, No. 3, 2002, pp. 353-376.

31. Park, D. W., A. E. Martin, and E. Masad. Effects on Nonuniform Tire Contact Stresses on Pavement Response. Journal of Transportation Engineering, Vol. 131, No. 11, 2005, pp. 873-879.

32. Schwartz, C. W., and R. L. Carvalho. Distribution of Permanent Deformations Within HMA Layers. Proc., ASCE 2008 Airfield and Highway Pavements Conference, Bellevue, Wash., 2008, pp. 86-98.

33. Baek, J., and I. L. Al-Qadi. Finite Element Modeling of Reflective Cracking Under Moving Vehicular Loading: Investigation of the Mechanism of Reflective Cracking in Hot-Mix Asphalt Overlays Reinforced with Interlayer Systems. Proc., 2008 Airfield and Highway Pavements Conference, Seattle, Wash, 2008, pp. 74-85.

34. Wang, L., B. Zhang, D. Wang, and Z. Yue. Fundamental Mechanics of Asphalt Compaction through FEM and DEM Modeling. Analysis of Asphalt Pavement Materials and Systems, Boulder, Colo., 2007.

35. Saliba, J. E. Elastic-Viscoplastic Finite-Element Program for Modeling Tire/Soil Interaction. Journal of Aircraft, Vol. 27, No. 4, 1990, pp. 350-357.

36. Oka, F., A. Yashima, and I. Kohara. Finite Element Analysis of Clay Foundation Based on Finite Elasto-Viscoplasticity. Proc., International Symposium on Numerical Models in Geomechanics, Vol. 2, 1992, pp. 915-922.

37. Zhu, G., and J. H. Yin. Finite Element Analysis of Consolidation of Layered Clay Soils Using an Elastic Visco-Pastic Model. International Journal for Numerical and Analytical Methods in Geomechanics, Vol. 23, No. 4, 1999, pp. 355-374.

38. Mimura, M., and W. Y. Jang. Description of Time-Dependent Behavior of Quasi-Overconsolidated Osaka Pleistocene Clays using Elasto-Viscoplastic Finite Element Analyses. Soils and Foundations, Vol. 44, No. 4, 2004, pp. 41-52.

39. Rowe, R. K., and S. D. Hinchberger. The Significance of Rate Effects in Modeling the Sackville Test Embankment. Canadian Geotechnical Journal, Vol. 35, No. 3, 1998, pp. 500-516.

40. Ohta, H., T. Takeyama, Y. Takeyama, M. Inagaki, T. Mizuta, M. Nabetani, and Y. Nishida. Performance of 5 Embankments on Soft Clay Foundation. Geotechnical Special Publication, No. 156:Geomechanics II: Testing, Modeling, and Simulation-Proceedings of the Second Japan-U.S. Workshop on Testing, Modeling, and Simulation in Geomechanics, 2006, pp. 440-453.

41. Yamada, K. Seismic Wave Propagation in Elastic-Viscoplastic Shear Layers. Journal of Geotechnical and Geoenvironmental Engineering, Vol. 126, No. 3, 2000, pp. 218-226. 
42. Tanaka, T. Numerical Methods for Plasticity and Viscoplasticity of Geomaterials, Geotechnical Special Publication, No. 156: Geomechanics II: Testing, Modeling, and Simulation-Proceedings of the Second Japan-U.S. Workshop on Testing, Modeling, and Simulation in Geomechanics, 2006, pp. 313-327. 



\section{THE NATIONAL ACADEMIES Advisers to the Nation on Science, Engineering, and Medicine}

The National Academy of Sciences is a private, nonprofit, self-perpetuating society of distinguished scholars engaged in scientific and engineering research, dedicated to the furtherance of science and technology and to their use for the general welfare. On the authority of the charter granted to it by the Congress in 1863, the Academy has a mandate that requires it to advise the federal government on scientific and technical matters. Dr. Ralph J. Cicerone is president of the National Academy of Sciences.

The National Academy of Engineering was established in 1964, under the charter of the National Academy of Sciences, as a parallel organization of outstanding engineers. It is autonomous in its administration and in the selection of its members, sharing with the National Academy of Sciences the responsibility for advising the federal government. The National Academy of Engineering also sponsors engineering programs aimed at meeting national needs, encourages education and research, and recognizes the superior achievements of engineers. Dr. Charles M. Vest is president of the National Academy of Engineering.

The Institute of Medicine was established in 1970 by the National Academy of Sciences to secure the services of eminent members of appropriate professions in the examination of policy matters pertaining to the health of the public. The Institute acts under the responsibility given to the National Academy of Sciences by its congressional charter to be an adviser to the federal government and, on its own initiative, to identify issues of medical care, research, and education. Dr. Harvey V. Fineberg is president of the Institute of Medicine.

The National Research Council was organized by the National Academy of Sciences in 1916 to associate the broad community of science and technology with the Academy's purposes of furthering knowledge and advising the federal government. Functioning in accordance with general policies determined by the Academy, the Council has become the principal operating agency of both the National Academy of Sciences and the National Academy of Engineering in providing services to the government, the public, and the scientific and engineering communities. The Council is administered jointly by both Academies and the Institute of Medicine. Dr. Ralph J. Cicerone and Dr. Charles M. Vest are chair and vice chair, respectively, of the National Research Council.

The Transportation Research Board is one of six major divisions of the National Research Council. The mission of the Transportation Research Board is to provide leadership in transportation innovation and progress through research and information exchange, conducted within a setting that is objective, interdisciplinary, and multimodal. The Board's varied activities annually engage about 7,000 engineers, scientists, and other transportation researchers and practitioners from the public and private sectors and academia, all of whom contribute their expertise in the public interest. The program is supported by state transportation departments, federal agencies including the component administrations of the U.S. Department of Transportation, and other organizations and individuals interested in the development of transportation. www.TRB.org 
TRANSPORTATION RESEARCH BOARD

500 Fifth Street, NW

Washington, DC 20001

\section{THE NATIONAL ACADEMIES}

Advisers to the Nation on Science, Engineering, and Medicine

The nation turns to the National Academies-National Academy of Sciences, National Academy of Engineering, Institute of Medicine, and National Research Councilfor independent, objective advice on issues that affect people's lives worldwide.

www.national-academies.org 